\title{
NEUTRON FLUX DISTRIBUTION MEASUREMENT IN THE FORT ST. VRAIN INITIAL CORE (RESULTS OF FORT ST. VRAIN START-UP TEST A-7)
}

by

A. C. Marshall and J. R. Brown

Work Supported in Part by

Contract AT(04-3)-633

for the

San Francisco Operations Office

U.S. Atomic Energy Commission

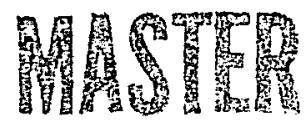

This report was prepared as

This report was prepared as an account of work sponsored by the United States Government. Neither the United States nor the United States Energy Research and Development Administration, nor any of their employees, nor any of their contractors, subcontractors, or their employees, makes any warranty, express or implied, or assumes any legal liability or responsibility for the accuracy, completeness or usefulness of any information, apparatus, product process disclosed, or represents that its use would or process disclosed, or represents that its use would not
infringe privately owned rights. 


\section{DISCLAIMER}

This report was prepared as an account of work sponsored by an agency of the United States Government. Neither the United States Government nor any agency Thereof, nor any of their employees, makes any warranty, express or implied, or assumes any legal liability or responsibility for the accuracy, completeness, or usefulness of any information, apparatus, product, or process disclosed, or represents that its use would not infringe privately owned rights. Reference herein to any specific commercial product, process, or service by trade name, trademark, manufacturer, or otherwise does not necessarily constitute or imply its endorsement, recommendation, or favoring by the United States Government or any agency thereof. The views and opinions of authors expressed herein do not necessarily state or reflect those of the United States Government or any agency thereof. 


\section{DISCLAIMER}

Portions of this document may be illegible in electronic image products. Images are produced from the best available original document. 
1. SUMMARY. . . . . . . . . . . . . . . . . . . 1-1

2. PURPOSE. . . . . . . . . . . . . . . . . . . . . $2-1$

3. EXPERIMENTAL EQUIPMENT ... . . . . . . . . . . . . . . 3-1

4. EXPERIMENTAL TECHNIQUES AND CONFIGURATIONS . . . . . . . . . 4-1

4. 1 Core Descriptión. . . . . . . . . . . . . . . 4-1

4.2 Configurations. . . . . . . . . . . . . . . . 4-4

4.3 Detector Locations. . . . . . . . . . . . . . . 4-4

4.4 Experimental Technique. . . . . . . . . . . . . . 4-8

5. ANALYSIS METHODS . . . . . . . . . . . . . . . . 5-1

5.1 Analysis of Measured Data . . . . . . . . . . . 5-1

5.2 Calculational Model . . . . . . . . . . . . 5-1

5.2 .1 Geometry . . . . . . . . . . . . . . 5-1

5.2.2 Macroscopic Cross Sections ........... 5-4

5.2.3 Control Rod Description. . . . . . . . . . 5-5

5.3 Evaluation of Calculated Data . . . . . . . . . 5-6

6. TEST RESUltS . . . . . . . . . . . . . . . . . . 6-1

7. COMPARISON WITH PREDICTIONS. . . . . . . . . . . . . . . 7-1

7.1 Initial Comparison. . . . . . . . . . . . . . 7-1

7.1 .1 General Shape. . . . . . . . . . . . . 7-1

7.1 .2 Evaluation of Peaks. . . . . . . . . . . 7-2

7.1.3 Response in Lower Block. ............. 7-4

7.2 Corrections . . . . . . . . . . . . . 7-6

7.3 Evaluation of Approximations. . . . . . . . . . 7-10

8. CONCLUSIONS. . . . . . . . . . . . . . 8-1

9. REFERENCES . . . . . . . . . . . . . . . . . . . 9-1

ACKNOWLEDGMENTS. • . . . . . . . . . . . . . . . . . . . . 10-1

APPENDIX I: PRELIMINARY COMPARISON OF CALCULATED AND MEASURED

AXIAL FLUX DISTRIBUTION . . . . . . . . . . . . . . I-1

APPENDIX II: FINAL COMPARISON OF CALCULATED AND MEASURED AXIAL
FLUX DISTRIBUTION . . . . . . . . . . . . . . II-1

APPENDIX III: SUMMARY OF STORED DATA FOR SUT A-7 ANALYSIS . . . . . III-1 


\section{FIGURES}

3-1. Flux plot nuclear instrumentation . . . . . . . . 3-2

3-2. Photograph inside PCRV showing detector drive mechanisms attached to several control rod drive assemblies. . . . . . 3-3

3-3. Source and detector drive control console . . . . . . . 3-5

4-1. Plan view of Fort St. Vrain reactor . . . . . . . . . . . 4-2

4-2. Critical rod configurations for axial flux distribution and regions measured. . . . . . . . . . . . . . 4-5

4-3. Control rod position correction . . . . . . . . . . 4-6

4-4. Detail of region showing location of control rod holes and reserve shutdown hole.............. 4-7

5-1. Core burnup region description (GATT-3D) for axial layer 9. . 5-2

5-2. Geometrical description for core assembly GATT Mode1 3D . . 5-3

7-1. GAMBLE RZ cell model. . . . . . . . . . . . . . . 7-3

7-2. Axial flux distribution (cell model) at several radial locations . . . . . . . . . . . . . . 7-5

7-3. Axial flux distribution (5 ppm in reflector), configuration 1 ,

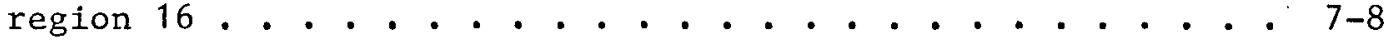

7-4. Axial flux distribution (5 ppm in reflector), configuration 1 , region 31 . . . . . . . . . . . . . . . . . 7-9

7-5. Axial flux distribution at edge of control element (cel1 model) with 7 groups and heterogeneities described, 4 groups and heterogeneities described, and 4 groups without heterogeneities... . . . . . . . . . 7-12

7-6. Full core GAMBLE RZ geometry model. . . . . . . . . . . 7-13

7-7. Axial flux distribution, 7 group thin buffer versus 4 group thick buffer at radial center (full core model) . . . . . 7-15

7-8. Axial flux distribution, 7 group thin buffer versus 4 group thick buffer near core edge (full core model) . . . . . . 7-16

I-1. Axial flux distribution, configuration 1, region 1...... I-1

I-2. Axial flux distribution, configuration 1, region 3. . . . . I-2

I-3. Axial flux distribution, configuration 1, region 6 , run A. . I-3

I-4. Axial flux distribution, configuration 1 , region 6 , run $B$. . I-4

I-5. Axial flux distribution, configuration 1, region 6 , run C.. I-5 
FIGURES (continued)

I-6. Axial flux distribution, configuration 1, region 10. . . . I-6

I-7. Axial flux distribution, configuration 1, region 16. . . . . I-7

I-8. Axial flux distribution, configuration 1, region 23, run A . I-8

I-9. Axial flux distribution, configuration 1, region 23, run B. I-9

I-10. Axial flux distribution, configuration 1, region 27. . . . I-10

I-11. Axial flux distribution, configuration 1, region 31. . . . I-11

I-12. Axial flux distribution, configuration 1, region 32 . . . . I-12

I-13. Axial flux distribution, configuration 1, region 37. . . . I-13

I-14. Axial flux distribution, configuration 2, region 6. . . . I-14

I-15. Axial flux distribution, configuration 2, region 16. . . . I-15

I-16. Axial flux distribution, configuration 2, region $31 . .$. . I-16

II-1. Axial flux distribution (5 ppm in reflector), configuration 1 ,

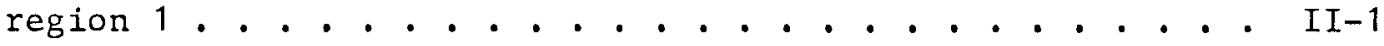

II-2. Axial flux distribution (5 ppm in reflector), configuration 1 ,

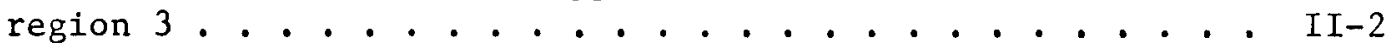

II-3. Axial flux distribution ( $5 \mathrm{ppm}$ in reflector), configuration 1 , region 6, run A. . . . . . . . . . . . . . . II-3

II-4. Axial flux distribution (5. ppm in reflector), configuration 1, region 6 , run B. . . . . . . . . . . . . . . II-4

II-5. Axial flux distribution (5 ppm in reflector), configuration 1 ,

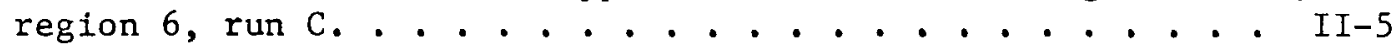

II-6. Axial flux distribution (5 ppm in reflector, configuration 1 ,

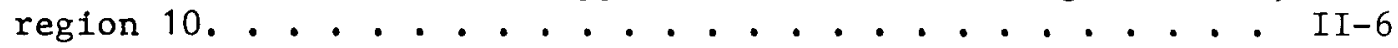

II-7. Axial flux distribution (5 ppm in reflector), configuration 1 , region 23, run A . . . . . . . . . . . . . . . . . II-7

II-8. Axial flux distribution ( $5 \mathrm{ppm}$ in reflector), configuration 1 , region 23, run $\mathrm{B} . .$. . . . . . . . . . . . . II-8

II-9. Axial flux distribution ( $5 \mathrm{ppm}$ in reflector), configuration 1 , region 27. . . . . . . . . . . . . . . . III-9

II-10. Axial flux distribution ( $5 \mathrm{ppm}$ in reflector), configuration 1 , region 32. . . . . . . . . . . . . . . . . I II-10

II-11. Axial flux distribution (5 ppm in reflector), configuration 1 , region 37. . . . . . . . . . . . . . . . . II-11

II-12. Axial flux distribution (5 ppm in reflector), configuration 1 , region 16 with 6 -in. shift . . . . . . . . . . . . II-12

II-13. Axial flux distrubution ( $5 \mathrm{ppm}$ in reflector), configuration 1 , region 31 with $6-i n$. shift . . . . . . . . . . . . . II-13 


\section{TABLES}

4-1. Control rod withdrawal sequence and predicted rod worth for the initial core... . . . . . . . . . . . . . 4-3

5-1. Energy group structure . . . . . . . . . . . . . 5-5

7-1. Percent deviation of calculated response in bottom control element from the measured value. . . . . . . . . . . 7-7 
1. SUMMARY

The axial flux distributions were measured within the reserve shutdown holes of selected regions. These measurements were made at zero power and in an air environment to permit use of in-core instrumentation. Special in-core nuclear detectors were used with drive units to permit remote positioning of the detectors at selected axial positions within the reserve shutdown holes. An in-core detector in a fixed core location was used to normalize the flux distribution measurements to compensate for any power level variations.

Two control rod configurations were examined. The first configuration was critical with control rods in regions 3, 5, and 7 partially withdrawn, and the second configuration was critical with the control rod in region 1 partially withdrawn. In each configuration the 12 control rods of groups $3 \mathrm{C}, 2 \mathrm{~A}, 4 \mathrm{~B}$, and $4 \mathrm{~F}$ were fully withdrawn.

Three-dimensional diffusion theory calculations were made with control rods in the critical configurations. From these calculations the axial detector response (boron reaction rate in the boron-10 lined proportional counter) was computed and compared to measurements. In general, the measured and calculated axial flux (detector response) distributions are in very good agreement. However, some discrepancies between the measured and calculated results were observed, particularly in the vicinity of the radial and axial reflectors.

Recent information has shown that the impurity level in the reflector regions is higher than that originally assumed. Also, there is a very strong indication that the detector position indication in two of the regions was in error by about 6 in. When these two corrections are made 
there is a significant improvement in the agreement between measured and calculated distributions.

The deviation between the calculated relative detector response in the lower fuel block and the measured value was determined. This comparison can be related to the technical specification limit LOC 4.1.3. When the two corrections described above are used, the agreement between the calculated and measured detector response in the lower control fuel element is within 10 percent for all regions examined. Hence, the measurements indicate that the calculational accuracy is within the technical specification limits.

An investigation was made of the effects of several approximations in the calculational model, i.e., the neutron energy group structure, the mesh interval size, the geometric description of the buffer region, and the treatment of heterogeneities. All of these approximations had a negligible effect on the calculated flux distribution. 
2. PURPOSE

The purpose of this test was to measure the axial flux distribution at several radial locations in the Fort St. Vrain core representing unrodded, rodded, and partially rodded regions. These measurements were intended to verify the calculational accuracy of the three-dimensional calculational model used to compute axial power distributions for the Fort St. Vrain core. 


\section{EXPERIMENTAL EQUIPMENT}

The experimental equipment for this test consisted of six in-core neutron detectors, six special detector drive mechanisms, a neutron source with a special drive mechanism, a control console for remote operation of the source and detector drive mechanisms, and an instrumentation console for obtaining count rate data from the in-core neutron detectors.

The in-core neutron detectors used were boron-10 lined proportional counters, 1-in. in diameter with a 12-in.-long active region. These detectors were Reuter Stokes Company model RSN-17A with a sensitivity of 4 counts per second per unit thermal flux. These detectors are the same as those used during initial fuel loading (Ref. 9).

A special instrumentation console in the control room was used to obtain count rate data from the in-core detectors. This console is described in Ref. 9. A block diagram of the instrumentation as used for this test is shown in Fig. 3-1.

To permit remote axial positioning of the in-core neutron detectors, a special cable-drive mechanism with a detector attached to the end of the cable was temporarily mounted on the control rod guide tubes just above the orifice valve inside the PCRV. The reserve shutdown tube of six control rod drives was temporarily removed, permitting the detector to be traversed vertically in the reserve shutdown hole of the core region where these special modified drives were located. The control rod operation was not affected by the modification. Figure 3-2 is a photograph of the plenum region above the core inside the PCRV and shows a part of the special detector-drive mechanisms attached to several control rod orifice assemblies. Any one of six detector-drive mechanisms could be operated remotely from a console in the control room. A position indicator was calibrated to 


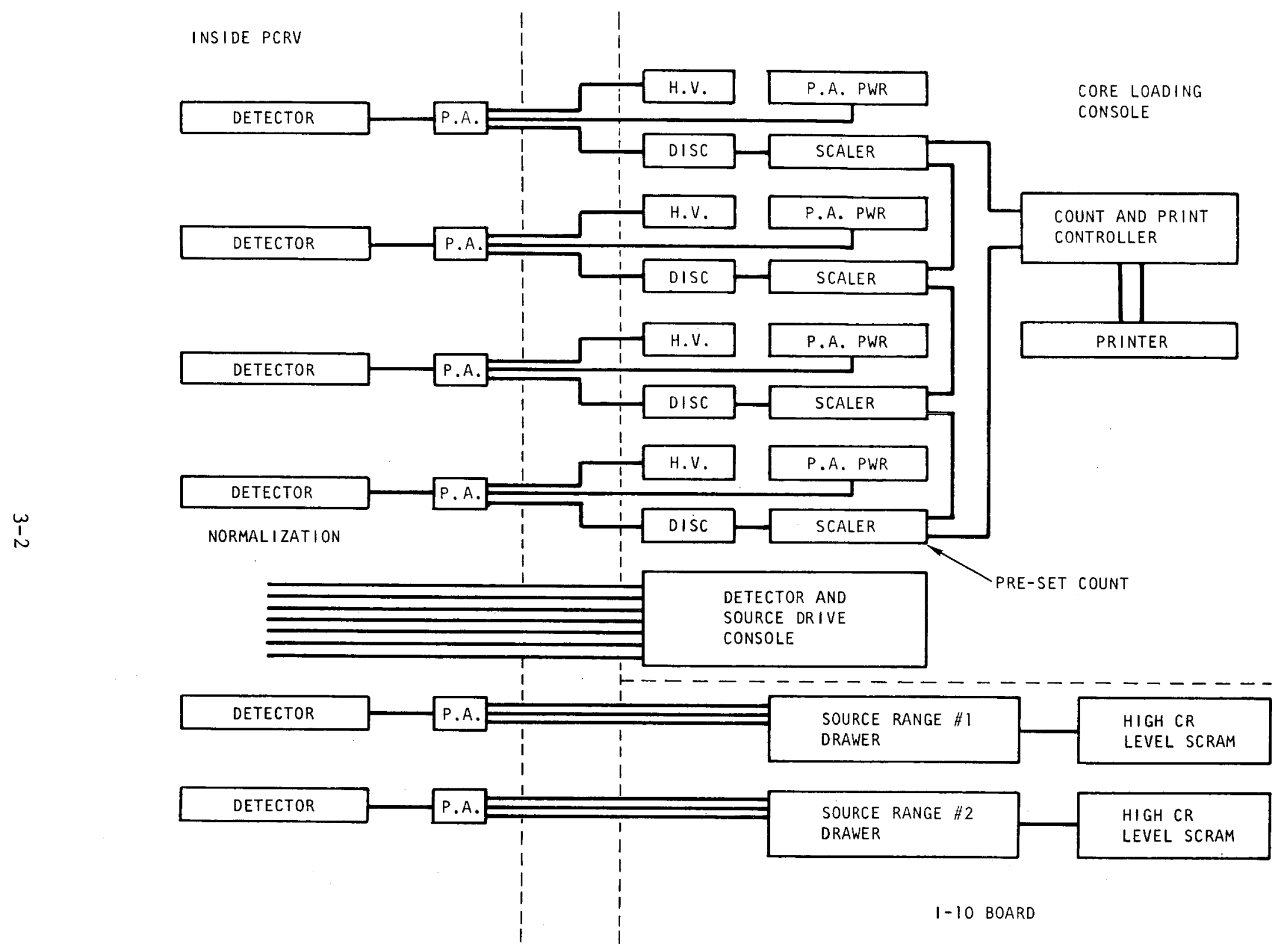

Fig. 3-1. Flux plot nuclear instrumentation 


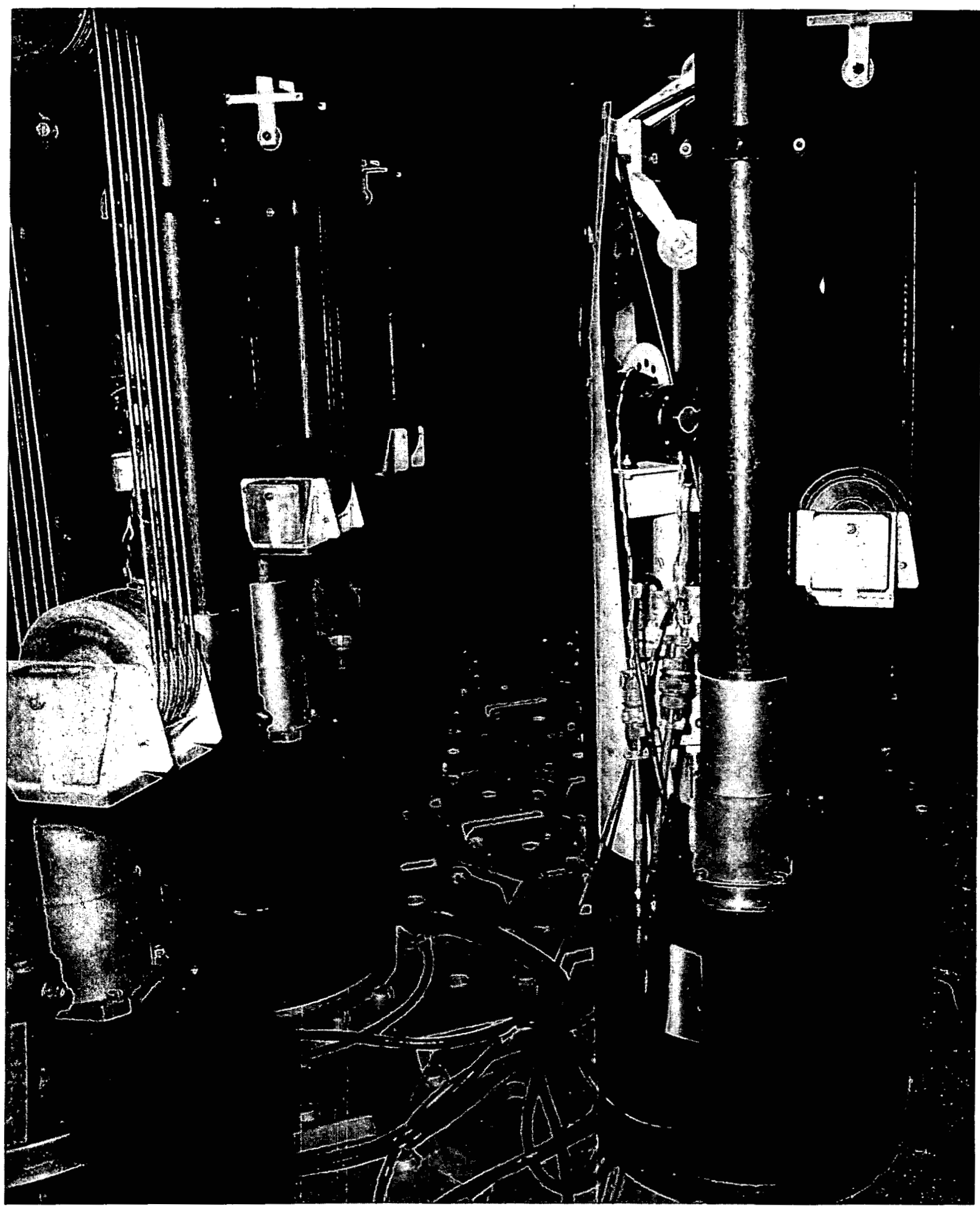

$74 \mathrm{HT} 3175$

Fig. 3-2. Photograph inside PCRV showing detector drive mechanisms attached to several control rod drive assemblies 
give the detector position above the bottom core-reflector interface. This console is shown in Fig. 3-3.

An additional control rod drive with the reserve shutdown tube removed had a similar temporarily mounted cable-drive for traversing a small 2curie plutonium-beryllium neutron source into or out of the core region. To achieve criticality at very low power (less than one watt) during this test it was desirable to have the neutron source removed from the core so there would be no source perturbation in the flux distribution. In its upper position, the source was retracted into a polyethylene shield just above the top borated reflector region. 


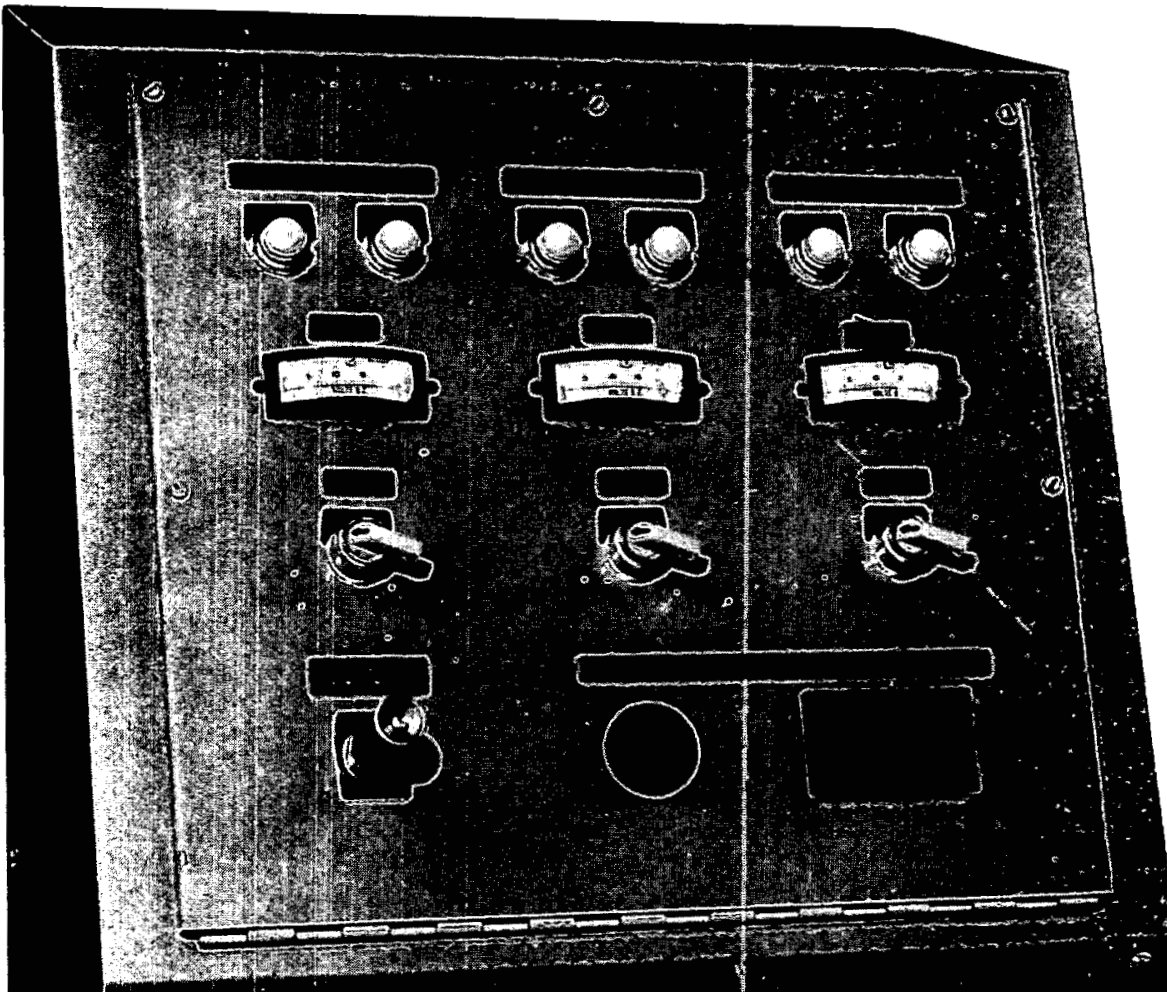

(e)

8

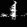




\section{EXPERIMENTAL TECHNIQUES AND CONFIGURATIONS}

\subsection{CORE DESCRIPTION}

Fort St. Vrain is a 330-MW High-Temperature Gas-Cooled Reactor (HTGR) designed by General Atomic (GA) for the Public Service Company of Colorado and is located about 35 miles north of Denver. The active core of the reactor consists of six layers of hexagonal fuel elements composed of graphite, thorium, and 93\% enriched uranium. Each layer has 247 fuel elements, for a total of 1482 in the core. The fuel is zoned both axially and radially. There is also a thin, axially uniform "buffer" zone at the core periphery. The active core is completely surrounded by graphite reflector elements, some hexagonal and others irregularly shaped. A plan view of the core and reflector is shown in Fig. 4-1.

The columns of fuel elements are grouped into 37 refueling regions, each containing seven columns, except for 6 five-column regions on the core periphery. The central fuel column in each region contains two vertical holes for a control rod pair and a hole for insertion of the reserve shutdown absorber. Since the two rods in this pair are physically coupled, the expression "control rod" will often be used in the remainder of this report instead of the more precise expression "control rod pair."

The control rods are operated in groups of three rod pairs. These groups with their predicted reactivity worths are listed in Table 4-1 in the normal withdrawal sequence. During start-up, the rod groups are with-

drawn in a prescribed sequence until criticality is achieved. Consequently, during normal operation only one group of rods and the central regulating rod are partially inserted. All other groups are either fully withdrawn or fully inserted. 


\section{NOTES :}

1. FUEL REGION BOUNDARIES

2. CONTROL ROD COLUMN (WITH FUEL REGION IDENTIFICATION NUMBER)

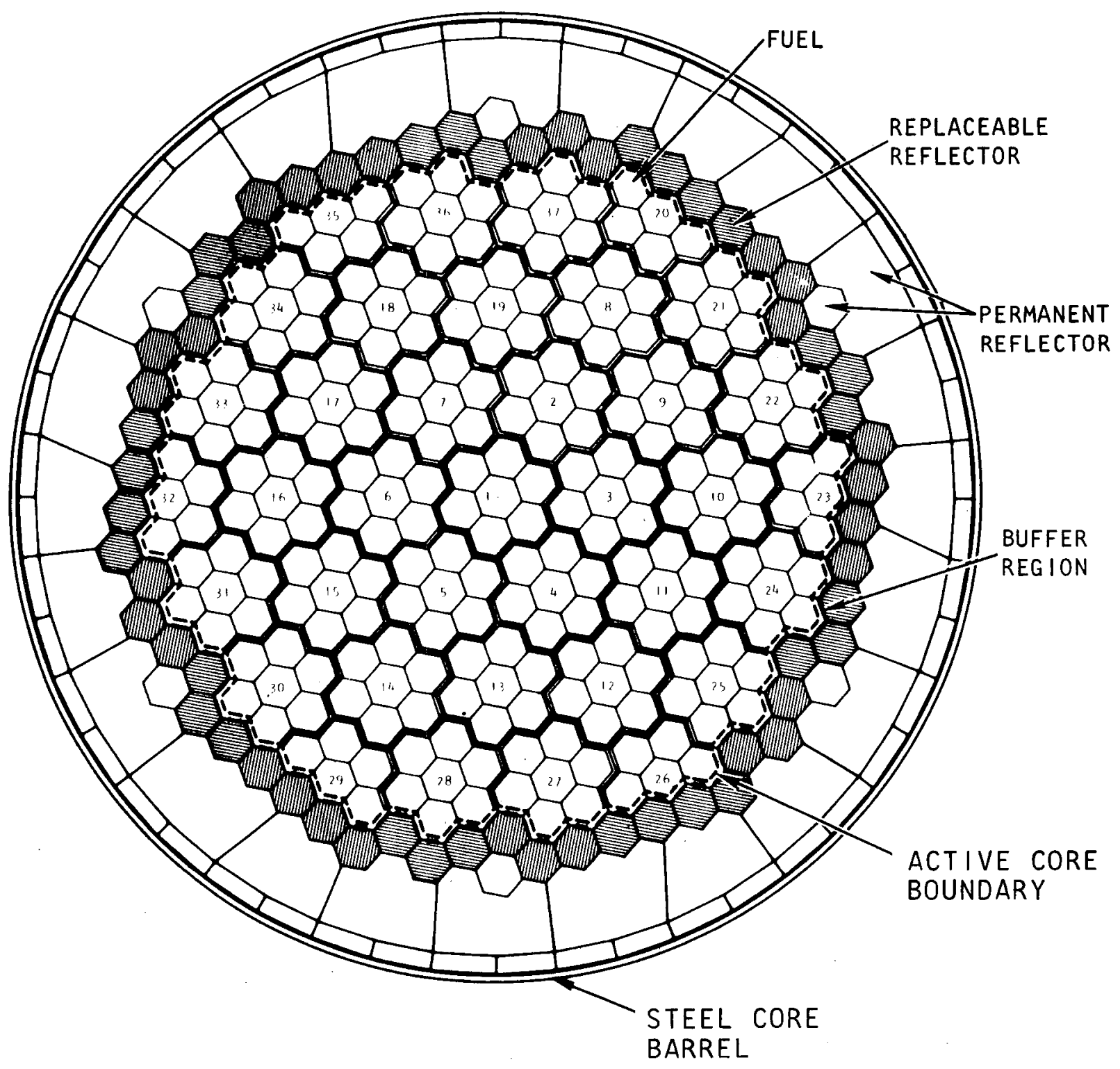

Fig. 4-1. P1an view of Fort St. Vrain reactor 
TABLE 4-1

CONTROL ROD WITHDRAWAL SEQUENCE AND PREDICTED ROD WORTH FOR THE INITIAL CORE

\begin{tabular}{|c|c|c|c|c|c|c|}
\hline \multirow[b]{2}{*}{ Sequence } & \multirow[b]{2}{*}{ Group Number } & \multicolumn{3}{|c|}{$\begin{array}{l}\text { Rod Pairs } \\
\text { Comprising } \\
\text { Group }\end{array}$} & \multirow{2}{*}{$\begin{array}{l}\text { Cumulative } \\
\text { When Pulled } \\
\text { in Sequence } \Delta \rho\end{array}$} & \multirow{2}{*}{$\begin{array}{l}\text { Cumulative } \\
\text { Group Worth } \\
\Delta \rho\end{array}$} \\
\hline & & $\mathrm{A}$ & $B$ & C & & \\
\hline 1 & $3 \mathrm{C}$ & 10 & 14 & 18 & $0.040^{(a)}$ & $0.040^{(a)}$ \\
\hline 2 & $2 \mathrm{~A}$ & 2 & 4 & 6 & $0.040^{(a)}$ & $0.080^{(a)}$ \\
\hline 3 & $4 B$ & 21 & 27 & 33 & $0.008^{(a)}$ & $0.088^{(a)}$ \\
\hline $3 \mathrm{~A}$ & 1 (half out) & & 1 & & $0.007^{(a)}$ & $0.095^{(a)}$ \\
\hline 4 & $4 \mathrm{~F}$ & 25 & 31 & 37 & $0.008^{(a)}$ & $0.103^{(a)}$ \\
\hline 5 & $2 \mathrm{~B}$ & 3 & 5 & 7 & 0.0416 & 0.145 \\
\hline 6 & $3 \mathrm{~A}$ & 8 & 12 & 16 & 0.0163 & 0.161 \\
\hline 7 & $4 \mathrm{D}$ & 23 & 29 & 35 & 0.0026 & 0.164 \\
\hline 8 & $3 \mathrm{~B}$ & 9 & 13 & 17 & 0.0232 & 0.187 \\
\hline 9 & $4 E$ & 24 & 30 & 36 & 0.0082 & 0.195 \\
\hline 10 & $4 \mathrm{~A}$ & 20 & 26 & 32 & 0.0083 & 0.203 \\
\hline 11 & $3 D^{(b)}$ & 11 & 15 & 19 & 0.0206 & 0.224 \\
\hline 12 & $4 C^{(b)}$ & 22 & 28 & 34 & 0.0071 & 0.231 \\
\hline 13 & 1 (last half) & & 1 & & 0.0024 & 0.233 \\
\hline
\end{tabular}

(a) These are measured values from SUT A-3 (Ref. 10).

(b) As of $10 / 15 / 74$ these groups were reversed in sequence such that $4 \mathrm{C}$ now corresponds to sequence number 11 and $3 \mathrm{D}$ corresponds to sequence number 12 . 


\subsection{CONFIGURATIONS}

Two control rod configurations were used for SUT-A7. These two configurations are shown in Fig. 4-2. For configuration 1 the reactor was critical with rod groups $3 \mathrm{C}, 2 \mathrm{~A}, 4 \mathrm{~B}$, and $4 \mathrm{~F}$ fully withdrawn and control rod group $2 \mathrm{~B}$ at $85-i n$. indicated position. A correction is required to the control rod position since there is a slight difference between the actual and indicated control rod position. The correction necessary to convert from indicated to actual control rod position is given in Fig. 4-3. (Henceforth, all rod positions will be indicated positions unless specifically noted as actual control rod positions.) From Fig. 4-3 the actual control rod position for group 2B, in configuration 1, is 79 in. (201 cm) withdrawn. For configuration 2, criticality was achieved with rod groups $3 \mathrm{C}, 2 \mathrm{~A}, 4 \mathrm{~B}$, and $4 \mathrm{~F}$ fully withdrawn and rod 1 at 127-in. indicated position. The actual position for rod 1 was 123 in. withdrawn.

\subsection{DETECTOR LOCATIONS}

The 12-in.-long boron-10 lined detectors were traversed in the reserve shutdown hole from the bottom core-reflector interface through the upper reflector. The location of the reserve shutdown hole is shown in Fig. 4-4. The core regions in which the traverses were made are shown in Fig. 4-2. It is seen that representative regions were chosen for a complete radial traverse and several additional regions adjacent to the radial reflector. This selection includes rodded, unrodded, and partially rodded regions. Two critical rod configurations were used to examine the effect of the partially inserted rods on other regions; i.e., a comparison of the flux profiles in the outer regions from configurations 1 and 2 will give an indication of the extent of the influence of the partially inserted control rods. For configuration 1 the reproducibility was checked by making three separate traverses in region 6 and two separate traverses in region 23. 

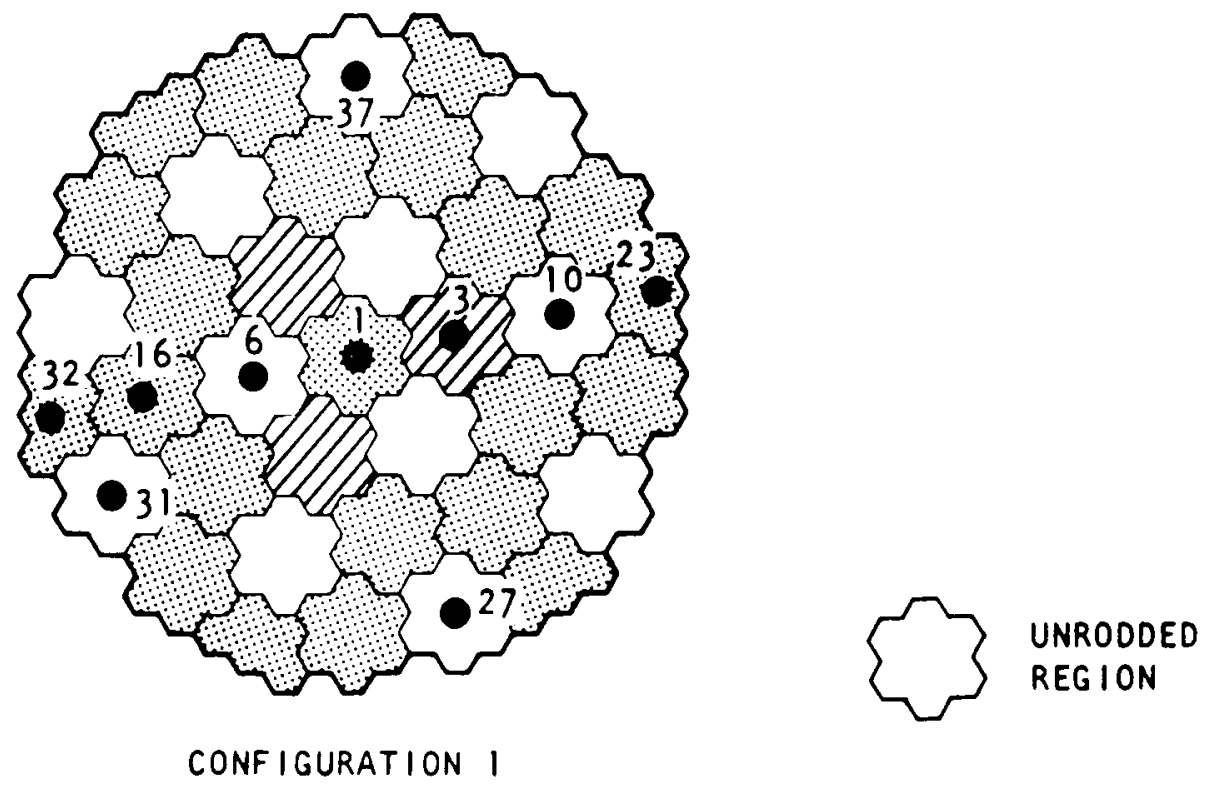

CRITICAL: ROD GROUP 2B AT 79.1 IN.

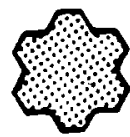

FULLY

RODOED

REGION
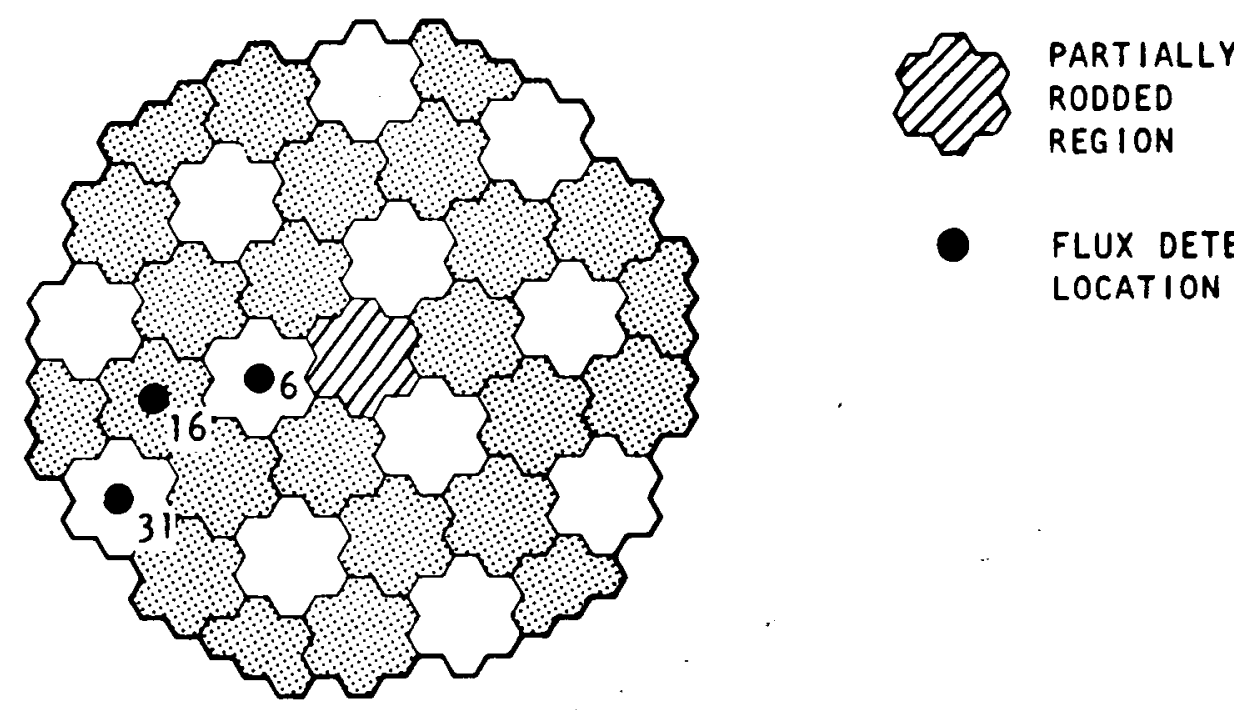

REGION

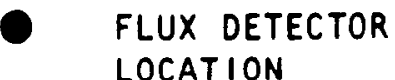

CONFIGURATION 2

CRITICAL: ROD GROUP I AT $122.8 \mathrm{IN}$.

Fig. 4-2. Critical rod configurations for axial flux distribution and regions measured 


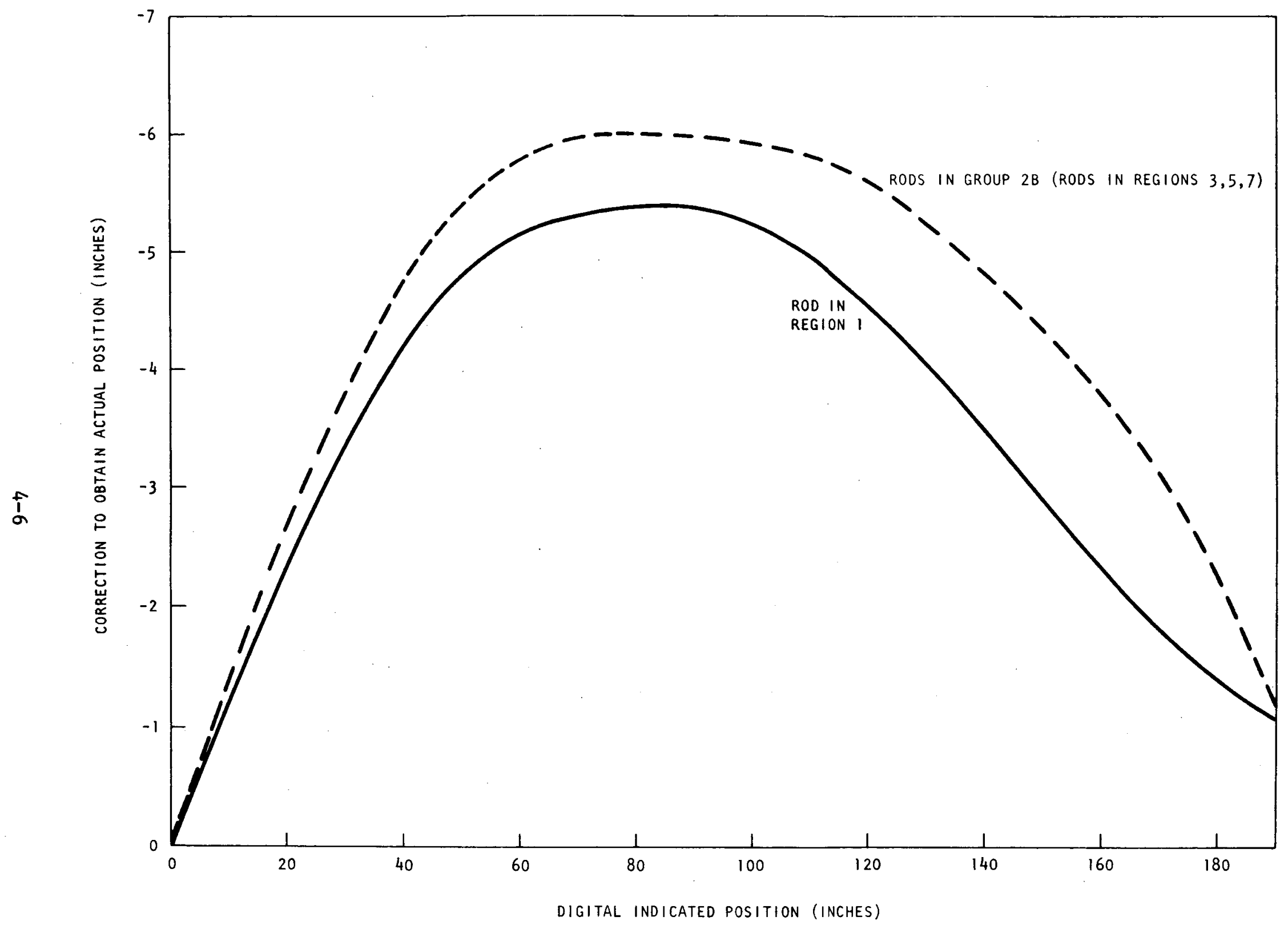

Fig. 4-3. Control rod position correction 


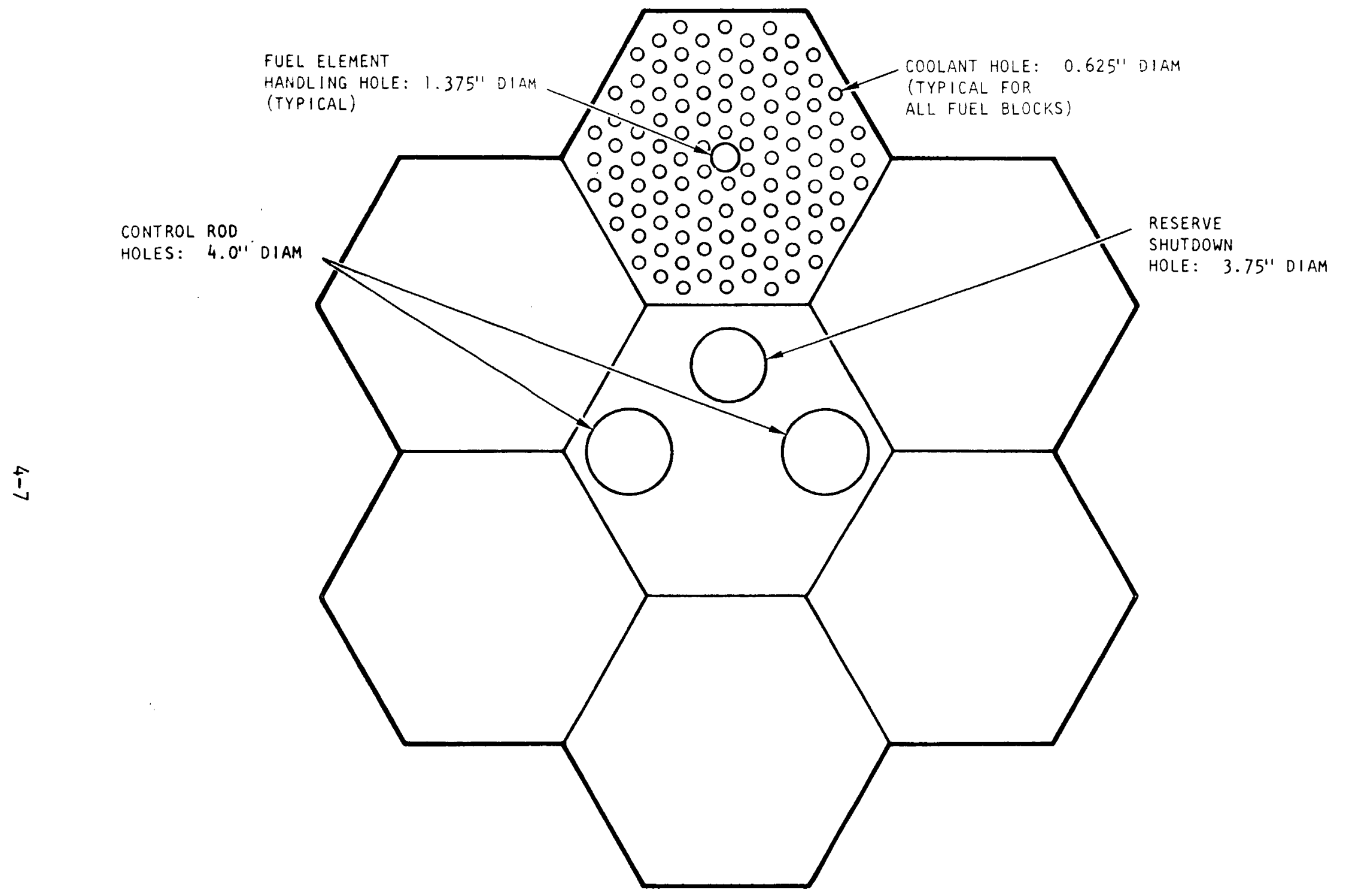

Fig. 4-4. Detail of region showing location of control rod holes and reserve shutdown hole 


\subsection{EXPERIMENTAL TECHNIQUE}

The experimental technique used in performing the axial flux distribution measurements is outlined as follows:

1. The six control rod drives with the special detector drives were installed in the refueling penetrations of six of the regions for which axial flux traverses were desired. All six detectors were positioned near the core midplane. The control rod drive with the special source drive was located in region 2 with the source initially near the core midplane.

2. Three of the detectors (flux data collection channels) were connected to the special instrumentation console in the control room such that scalar counts could be obtained from each detector.

3. One of the detectors (normalization channel) was connected to the special instrumentation console such that counts from this detector could be accumulated in a scalar with a pre-set count adjustment so that when this scalar reached the pre-set count level, the other three scalars (on the flux data collection detectors) would stop accumulating counts and a printout of the counts would be initiated.

4. Two of the detectors were connected to the start-up range channels of the plant protective system (PPS) to provide scram capability on high count rate.

5. Criticality was then established by withdrawing control rods in a specified sequence (with inverse count-rate extrapolations), removing the neutron source from the core and adjusting the reactor power to a value which gave approximately $5 \times 10^{3}$ counts per second on the normalization channel (less than 1 watt of thermal power). 
6. The three detectors connected to the flux data collection channels were remotely driven to the bottom of their respective reserve shutdown holes.

7. A scalar count was then obtained for each of the three flux data collection detectors for a length of time required to obtain a pre-set count of 10,000 counts (or in some cases 20,000 counts) on the normalization detector in a fixed core location. The use of the pre-set count on the normalization channel compensates for any power level changes during the traverse since the scalar counting time for the flux data collection channels is then inversely proportional to the power level. At the end of the counting time, the system automatically printed the data from all three of the flux data collection scalars, reset to zero, and waited for the next start signal.

8. All three detectors were then remotely moved one foot up and the count-rate data of step 7 was obtained. This stepwise process was repeated until the detectors were at (or above) the top corereflector boundary.

9. The three detectors were then traversed down the channel in 1-ft steps but with a 6-in. offset so that scalar counts were thus obtained for every $6 \mathrm{in.}$ of the height of the core. The entire up and down traverse was then repeated if desired. Several repeat traverses indicated reproducibility within a few percent.

10. The reactor was then taken slightly subcritical and detector connections changed such that the other three detectors (which had been the two PPS detectors and the normalization detector) became the flux data collection detectors. The reactor was again taken to critical and the flux traverse performed as in steps $6,7,8$, and 9. 


\section{ANALYSIS METHODS}

\subsection{ANALYSIS OF MEASURED DATA}

The detector positions for each measurement were obtained from the voltage readings using calibration curves (position versus voltage). These detector positions and the corresponding measured detector responses were then inserted in a small computer code called PROFIL (Ref. 1). The PROFIL code normalized the detector response to an average of 1.0 over the height of the fuel region of the control column and plotted the normalized detector response as a function of detector position above the bottom core-reflector interface.

\subsection{CALCULATIONAL MODEL}

5.2.1. Geometry

The three dimensional diffusion theory code GATT (Ref. 2) was used to predict the axial flux shape for configurations 1 and 2 . The geometric model used is illustrated in Figs. 5-1 and 5-2. Figure 5-1 is a plan view of the lowest axial fuel layer, core layer 9. Each hex block represents a fuel element. The $x-y$ mesh interval size is $20.9 \mathrm{~cm}$, the side length of a fuel element. The other axial layers will have the geometry shown in Fig. 5-1 except that the burnup region numbers will be different. A burnup region describes a homogeneous mixture of all the materials within the region. As can be seen, the smallest region which can be explicitly described in GATT is a fuel-element. Hence, the buffer region, control rods, lumped burnable poison, etc. are homogenized over the fuel elements which contain them.

The GATT model is limited to 8 slices axially, although each slice can be subdivided into two subslices having different macroscopic properties. 


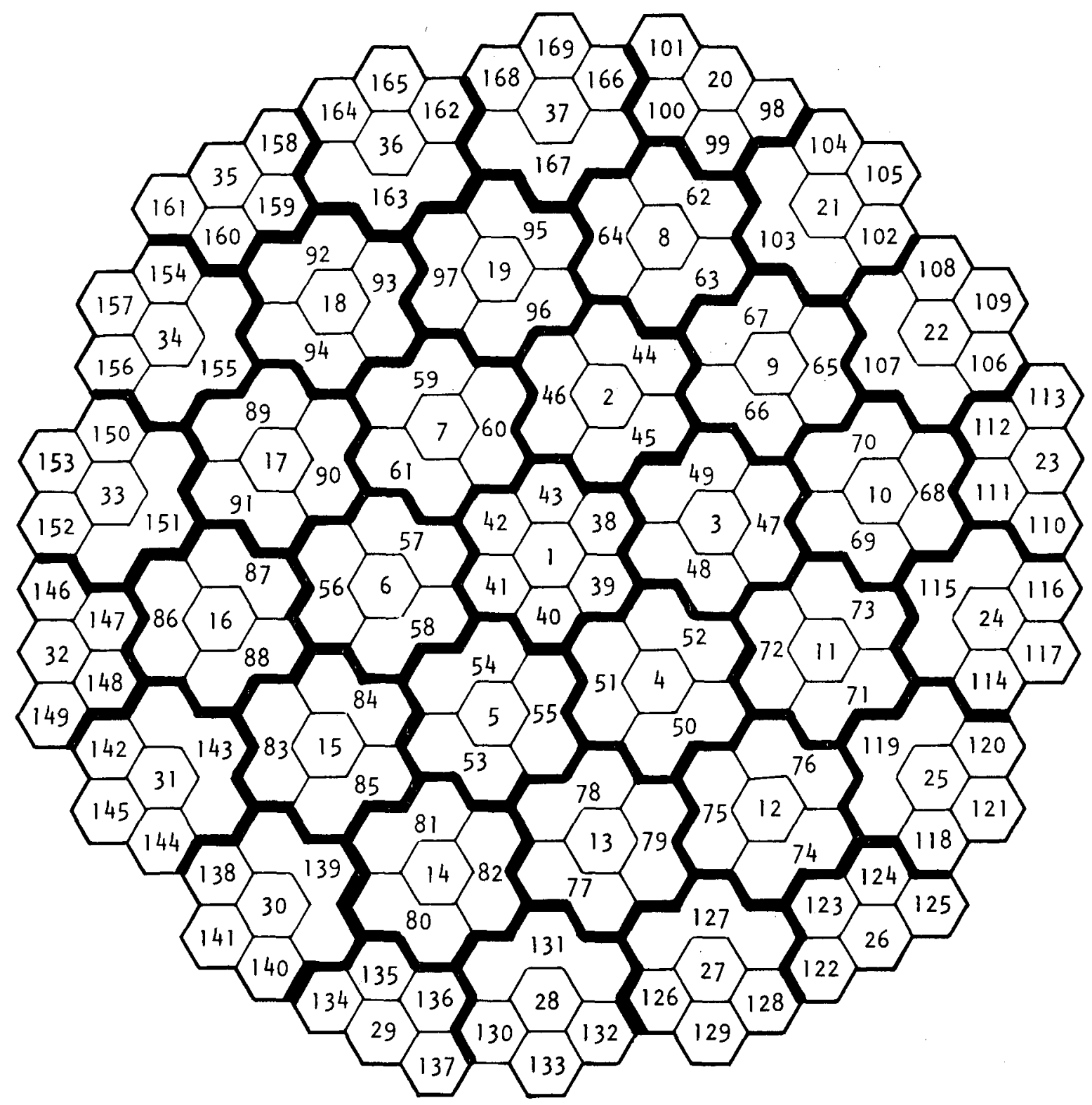

Fig. 5-1. Core burnup region description (GATT-3D) for axial layer 9 


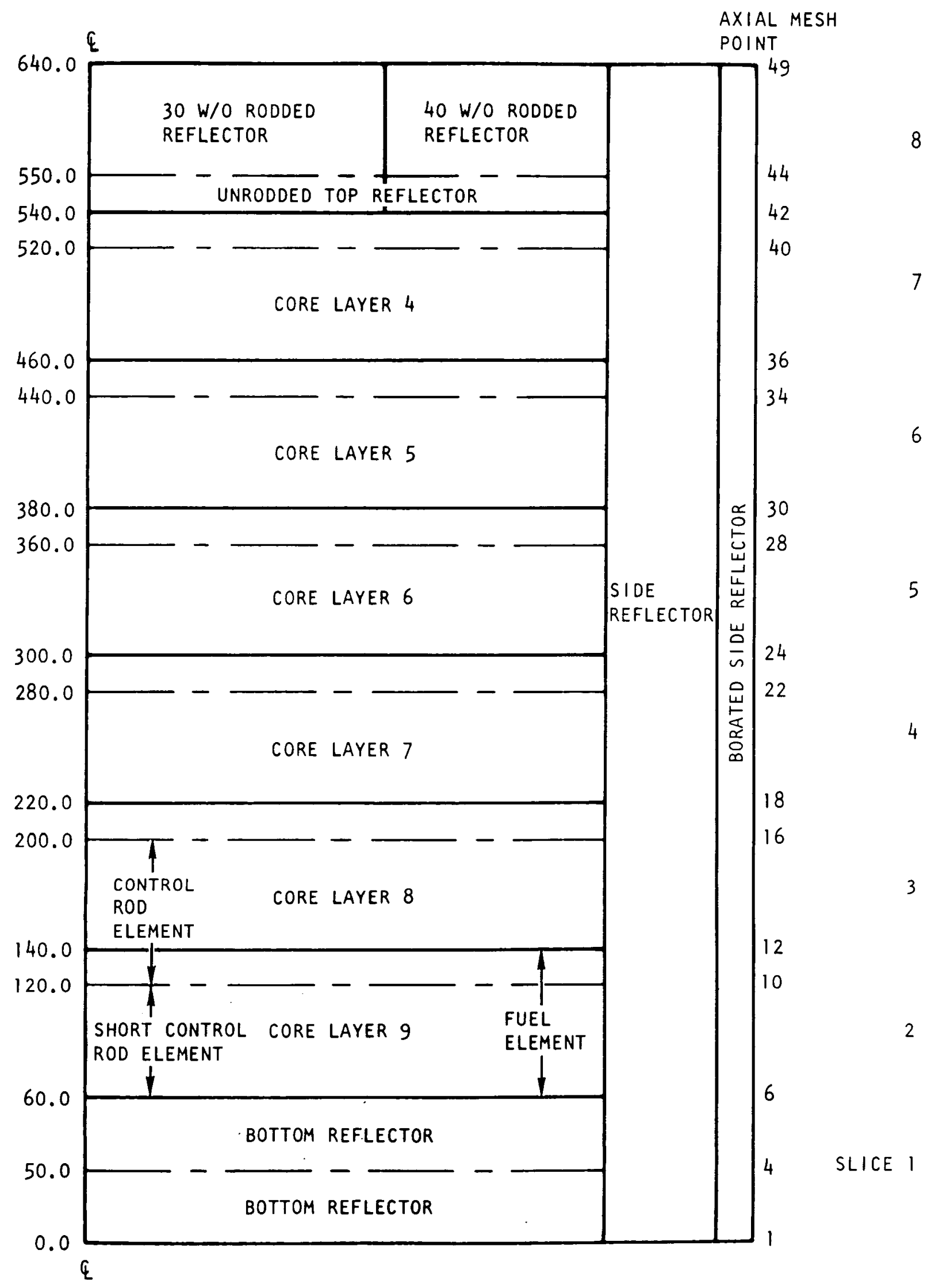

Fig. 5-2. Geometrical description for core assembly GATT Model 3D 
Consequently, each fuel layer was represented by one slice and the top and bottom reflector by a separate and distinct slice. This allowed for explicit representation in the axial direction. Figure 5-2 gives a cross section of the core assembly showing the top to bottom axial description as well as the side reflector. The axial dimensions and mesh point description is also shown.

In each refueling region, the central control rod fuel column is offset axially from the surrounding fuel columns. By having two subslices in each axial fuel layer, it was possible to describe this offset explicitly and include both the short control rod fuel element and control rod fuel elements separately.

As seen by the dimensions in Fig. 5-2, the top reflector is $100 \mathrm{~cm}$ thick while the bottom reflector is only $60 \mathrm{~cm}$ thick. The bottom reflector actually consists of three layers of reflector elements and is about $120 \mathrm{~cm}$ thick, but in the lower half of the second layer some borated rods are loaded to reduce the thermal flux at the core support floor. The amount of boron in that region is sufficient to reduce the incoming thermal current to zero. This can be achieved analytically by forcing the flux to be zero at that boundary. Consequently, both the top and bottom outer boundaries in the GATT analysis were located at the edge of the borated region.

\subsubsection{Macroscopic Cross Sections}

Macroscopic cross sections are required as input to GATT. Macroscopic cross sections were obtained as follows:

1. Atom densities were obtained from the actual "as assembled" fuel loadings for each burnup region. (See Ref. 9.)

2. Four-group basic microscopic cross sections were obtained using the GGC-5 spectrum code (Ref. 3) as described in Ref. 4. These basic cross sections at $300^{\circ} \mathrm{K}$ were obtained as a function of thorium atom density in the fast energy range and as a function 
of the carbon-to-uranium atom ratio in the thermal energy range. Specific cross sections appropriate to the various burnup regions were then obtained by interpolating among the basic cross section sets using the INTERP code (Ref. 5). Cross sections for the lumped burnable poison and the control rods were appropriately self-shielded. The structure of the four energy groups is given in Table 5-1.

TABLE 5-1

ENERGY GROUP STRUCTURE

\begin{tabular}{c|c}
\hline Group & $\begin{array}{c}\text { Lower Energy Boundary } \\
(\mathrm{eV})\end{array}$ \\
\hline 1 & $1.82 \times 10^{5}$ \\
2 & 17.6 \\
3 & 2.38 \\
4 & 0.0 \\
\hline
\end{tabular}

3. Atom densities from 1 and microscopic cross sections from 2 were then inserted into the BUGATT code (Ref. 6) which provided macroscopic cross sections to GATT.

\subsubsection{Control Rod Description}

Some elaboration is required to describe the control rod description in GATT.

In all regions where control rods were located, the effective macroscopic cross sections for that region were obtained by homogenizing selfshielded control rod cross sections with those previously obtained for the region without control rods.

When control rods were inserted in the core assembly, the control rods were homogenized within the central fuel element column of the refueling region. When they were partially withdrawn, they were homogenized within 
the central element column for the first $10 \mathrm{~cm}$ above the core and in that reflector region which extends into the core assembly, because of the axial offset for the control rod column. For the upper part of the top reflector, they were homogenized within all seven reflector element columns of that refueling region. Since there were six axial core layers, control rods could be partially inserted in the core in single layer increments only. That is, they had to be one-sixth, one-third or one-half withdrawn depending on the desired axial position. They could not be partially inserted within an axial core layer. Consequently, the control rod position for group 2B of configuration 1 was $220 \mathrm{~cm}$ rather than the actual position of $201 \mathrm{~cm}$. For control rod group 1 of configuration 2, the assumed control rod position was $300 \mathrm{~cm}$ rather than the actual position of $312 \mathrm{~cm}$.

\subsection{EVALUATION OF CALCULATED DATA}

In order to make a consistent comparison with the measured results, the PROFIL code was used to convert the four energy group fluxes from the GATT calculations into normalized detector responses. PROFIL multiplied the four group fluxes from GATT by the four group boron absorption cross sections appropriate to each fuel element (a11 fuel elements in a column do not have the same loading due to the two axial zones and manufacturing deviations from design, consequently the boron cross section is slightly different from each fuel element in the column). The fluxes at each axial point were radially averaged over the control fuel element. The justification for using the average flux is given in Section 7 of this report.

PROFIL sums the product of the flux and boron cross sections over all four energy groups to obtain boron reaction rates. These reaction rates are then axially integrated over a 12-in. span corresponding to the actual detector position as

$$
R(\bar{z})=\int_{g=1}^{\bar{z}+\frac{L}{2}} \sum_{g}^{4}(z) \sigma_{g}(z) d z,
$$


where $R(\bar{z})=$ a quantity proportional to the detector response at axial position $\overline{\mathbf{z}}$,

$\bar{z}=$ the actual axial location of the center of the detector,

$L=$ the length of the detector,

$\Phi_{g}(z)=$ the control element average neutron flux in energy group $z$ at coordinate $z$,

$\sigma_{g}(z)=$ the boron-10 capture cross section at coordinate $Z$ (boron-10 capture cross section is varied by element according to the $\mathrm{C} / \mathrm{U}$ ratio of the element) in energy group $\mathrm{g}$.

The detector responses are then normalized to an average value of 1.0 over the length of the control element column. By this procedure, the calculated data is made consistent with the measured results using the boron lined detector. PROFIL then plots the measured and calculated normalized response as a function of axial position. 


\section{TEST RESULTS}

The measured axial flux distributions (detector response) are given in Appendix I, Figs. I-1 through I-16. The calculated detector responses are also given in these figures, but they are discussed in Section 7 . The effect of partially inserted rods is clearly visible in these figures. The effect can be observed not only in the regions in which the control rods are partially inserted (region 3, configuration 1) but also in the regions adjacent to the partially inserted rods (e.g., region 1, configuration 1). It is also interesting to compare the flux distribution in regions 6,16 , and 31 from configuration 1 with the distributions in these regions for configuration 2. In all cases, including region 31, the flux is more depressed in the top in configuration 1 than in configuration 2 . This implies that there is some sensitivity to the partially inserted rods, even in regions as far away as the outer ring.

The reproducibility of the measurements can be observed by comparing Figs. I-3, I-4, and I-5 (runs $A, B$, and $C$ ) for region 6 and Figs. $I-8$ and I-9 (runs A and B) for region 23. As can be seen, the reproducibility is quite good. The statistical variations in the measured results are also observed. These variations imply that some caution should be used when trying to interpret the details of the measured detector response. Nonetheless, thermal flux peaking can be observed in the unfueled axial gaps between the fuel blocks. The exact location of these peaks is somewhat indistinct because of the size of the detector (measurement is made over the 12-in. length of the detector), the number of data points used, the width of the peak, and the statistical scatter in the data.

It is possible, however, to discern the approximate location of some of the peaks. In particular, a broad peak near the top of the fourth fuel block occurs at about 120 or 121 in. above the bottom core-reflector 
interface for all unrodded regions except region 31. For region 31 the peak appears at about 114 to 115 in. above the interface for both configurations 1 and 2 . Since the detector is located at a radial distance from the control element center of about two-thirds of the control element equivalent radius, the detector "sees" the flux peak of both the control element and the surrounding standard elements. The standard element is displaced about $8 \mathrm{in}$. higher relative to the control element. Hence, it is reasonable that the peak should occur about midway between the control and standard fuel element gaps, or at about 121 in. For the rodded regions this peak occurs at about 124 in. above the interface except for region 16, where it occurs at about 117 to 118 in. above the interface. Hence, in the rodded regions, the detectors "see" more flux from the surrounding standard fuel elements since the control element flux is depressed due to the presence of the rod.

It should also be observed that the flux dip near the upper corereflector interface occurs at about 175 to $176 \mathrm{in}$. above the bottom interface for a11 regions except for regions 16 and 31, where the dip occurs at about 169 to $170 \mathrm{in.}$ From this discussion, it appears that the measured detector positions for regions 16 and 31 are in error by about 6 in. This point is discussed further in Section 7. 


\section{COMPARISON WITH PREDICTIONS}

\section{1. INITTIAL COMPARISON}

7.1.1. General Shape

The calculated axial flux distributions (detector response) are compared to the measured values in Appendix I, Figs. I-1 through I-16. In general the agreement is very good. The agreement is particularly good for the inner 19 regions with the exception of region 3 in configuration 1 and region 16 in configurations 1 and 2 .

Region 3 contains a partially inserted control rod. The control rod position was assumed to be at $220 \mathrm{~cm}$ (86.6 in.) in the GATT calculation rather than at the actual position of $201 \mathrm{~cm}$ (79.1 in.) above the bottom core-reflector interface. This should cause a slight discrepancy in the flux distribution in the regions that contain partially inserted rods (e.g., region 3). Using a slightly higher than actual rod position in the calculations should have only a very small effect on the regions which do not contain the partially inserted rods; consequently, the rod position effect was ignored for all other regions.

It should be mentioned here that in all of these calculations the calculated fluxes have been radially averaged over the control element rather than using the flux at a single radial point, such as the flux at the radial center of the control element. This is a reasonable procedure since the actual detector position is near the control element radial surface, and the average of the six values at the element surface and the central point should approximate the axial distribution at the detector. Also, it has been observed that the axial flux distribution is practically independent of the radial mesh point (within the control element) that is used, except 
for the partially rodded regions (i.e., region 3). For region 3, the flux is depressed in the radial center in the rodded portion, but not in the unrodded portion. Consequently, the use of the radially averaged flux rather than the central flux point is important for region 3 and unimportant for the other regions.

For the outer 18 regions, the agreement with measurements in the rodded regions is also very good. The agreement is not as good for the unrodded outer regions, particularly for region 31.

It should be noticed that for all regions, except for regions 16 and 31, the flux dip near the upper reflector occurs at the same axial location as the measured value (about 175 to $176 \mathrm{in.}$ ). It is also seen that the calculated flux peak in the upper reflector is generally higher than the measured value. This latter point indicates the possible presence of an additional absorber in the reflector. This latter point will be discussed later in this section.

\subsubsection{Evaluation of Peaks}

Since the GATT calculational model cannot explicitly represent the unfueled gaps, the calculated location of the flux peaks near the gaps can not be determined with this mode1. In order to predict the peak location, a simple RZ cell model was devised. The GAMBLE (Ref. 7) diffusion theory code was used. The model geometry is shown in Fig. 7-1. As can be seen, the control fuel element column is correctly displaced and the unfueled gaps are explicitly shown. Atom densities used in this model correspond to fuel blends 1 and 2 (see Ref. 10 for blend description). Seven group cross sections were used ( 3 fast and 4 thermal) to more correctly treat the thermalization near the unfueled gaps. Vacuum boundary conditions were used at the top and bottom boundaries and reflective boundary conditions were used at the left and right boundaries.

The fluxes calculated by this model were then input to the PROFIL code, and converted to a normalized detector response by the method described in 


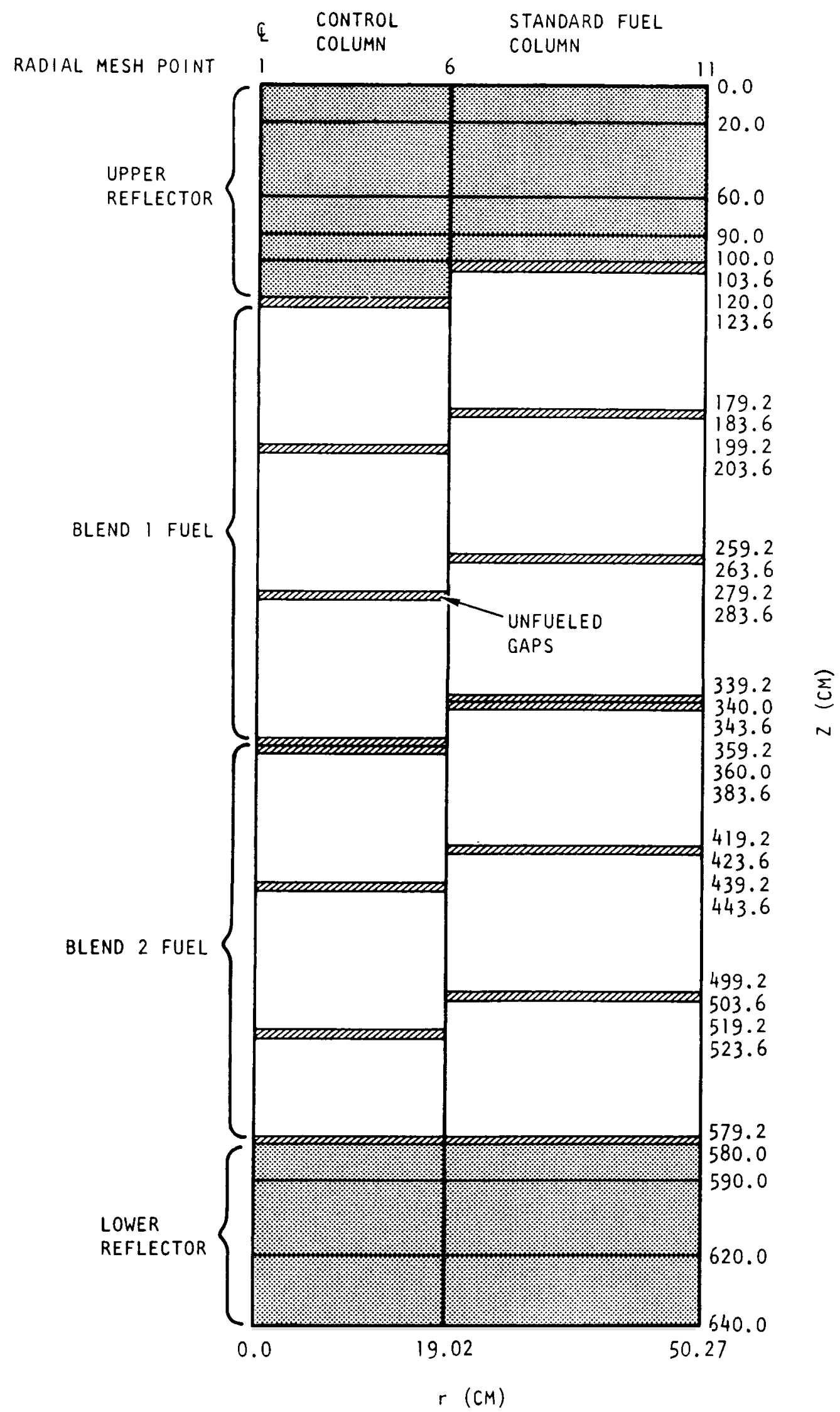

Fig. 7-1. GAMBLE RZ cell model 
Section 5. Figure 7-2 shows the locations of the peaks for the unrodded condition at several radial locations. The radial locations 1,6 , and 11 correspond to the centerline, the radial edge of the control column, and the radial cell boundary, respectively, as shown in Fig. 7-1. For the unrodded case, depending on the radial location, the peak near the top of the fourth element is seen to be located somewhere between the position of the control element gap and the position of the standard element gap. Of the three locations plotted, radial point 6 most nearly represents the radial location of the detector. As can be seen, the fourth peak, for radial point 6 , occurs at about 120 or $121 \mathrm{~cm}$. This is the measured location of the fourth peak for all unrodded regions, except for region 31 , as discussed in Section 6. No calculation was done for the rodded case. It is also seen that this model predicts that the flux dip near the top corereflector interface will occur at about 176 in. above the bottom reflector.

From this discussion and the discussion in Section 6 it can be concluded that the indicated measured detector positions for regions 16 and 31 are too high by about $6 \mathrm{in}$. Subsequent inspections of the detector drives have shown that the position-indicating potentiometer was not firmly clamped on some of the drives and could rotate under some conditions, especially if the drive mechanism were run to either the upper or lower limitstops. This inadvertent shifting of the position indicator would result in an axial position shift of the measured data. Thus, a check of the inherent axial position obtained from the measured data itself is important.

\subsubsection{Response in Lower Block}

The deviation of the calculated relative detector response in the lower fuel block from the measured value was computed. This comparison can be related to the technical specification limit LCO4.1.3. The percent deviation was computed by simply summing up the measured data points and summing up the corresponding calculated data points in the lower element region and computing the percent deviation of the latter from the former. 


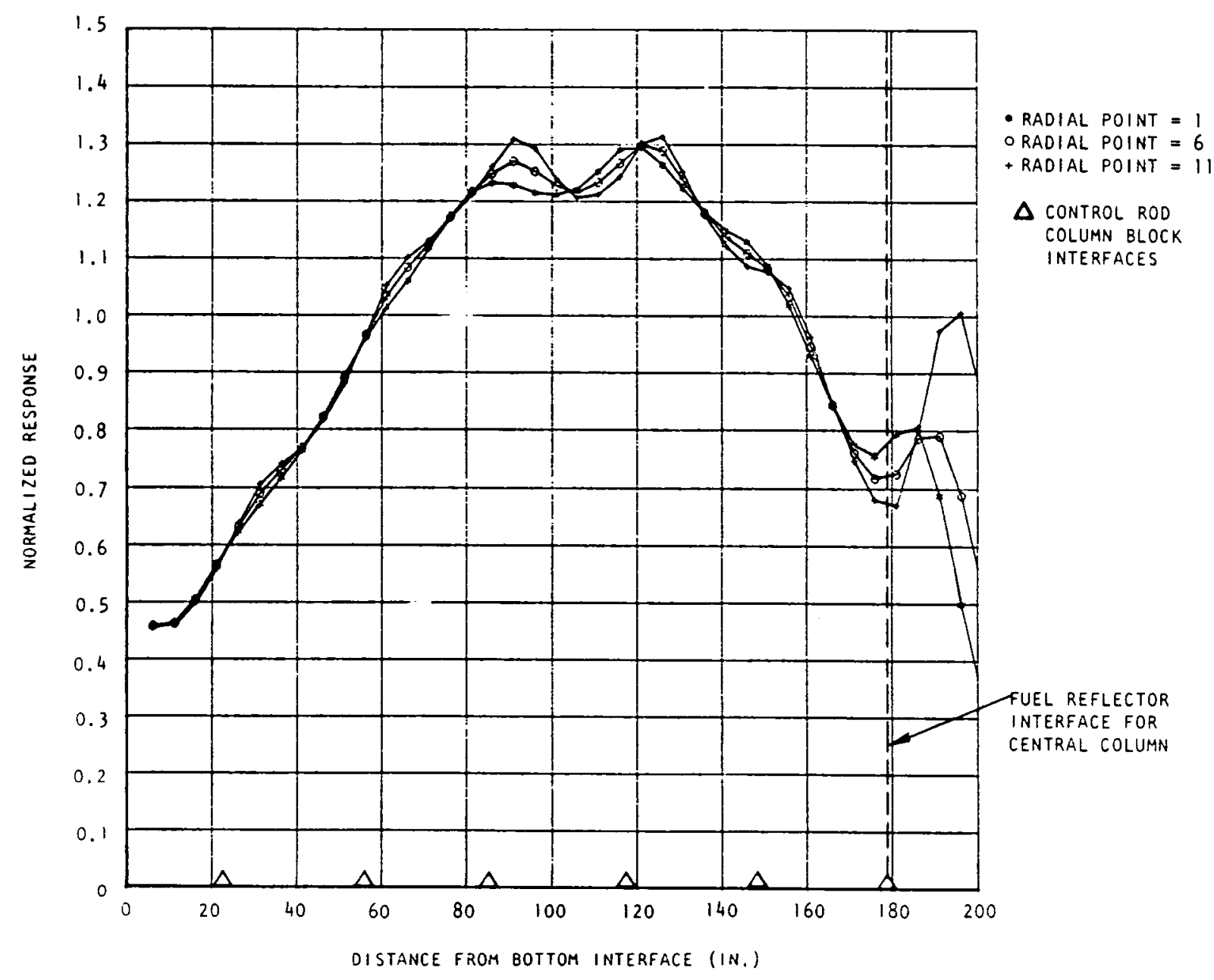

Fig. 7-2. Axial flux distribution (cell model) at several radial locations 
Table 7-1 gives the percent deviation from measurement for the initial comparison. As can be seen, the results in Table 7-1 imply that the calculated response in the lower fuel block is within $10 \%$ of the measured value for all regions except for regions 16,27 , and 31 .

\subsection{CORRECTIONS}

It was pointed out in Section 7.1 that the overprediction of the flux in the upper reflector region indicated the possible presence of an additional absorber in the reflector. This speculation was supported by an evaluation of SUT A-3 (pulsed neutron measurements), in which the calculational agreement with measurements was dramatical1y improved by adding $5 \mathrm{ppm}$ of natural boron to all reflector regions in the calculational model (Ref. 8). Originally, only about $0.5 \mathrm{ppm}$ of boron equivalent was assumed to be in all reflector regions. Consequently, the GATT calculation was repeated for configuration 1 with $5 \mathrm{ppm}$ of natural boron in all reflector regions.

Subsequently, a chemical analysis has shown that the impurity level was about $5 \mathrm{ppm}$ and $2 \mathrm{ppm}$ of natural boron equivalent in the permanent and removable reflector regions, respectively. However, the GATT calculations were not repeated again using the measured reflector impurities since (as will be shown) the additional boron did not significantly affect the flux distribution in the core.

A comparison of the measured and calculated detector response with $5 \mathrm{ppm}$ of natural boron in the reflectors is given in Appendix II, Figs. II-1 through II-11, and Figs. 7-3 and 7-4. As can be seen, the agreement with the measurements, with $5 \mathrm{ppm}$ of boron in the reflectors, is as good as or better than the agreement without the $5 \mathrm{ppm}$ of boron. In general, the calculated flux is shifted more toward the bottom of the core. Also, the agreement of the calculated and measured flux in the upper reflector is much better.

The deviation of the calculated detector response in the bottom element from the measured value, with $5 \mathrm{ppm}$ of boron in the reflector, is given in 
TABLE $7-1$

PERCENT DEVIATION OF CALCULATED RESPONSE IN BOTTOM CONTROL ELEMENT FROM THE MEASURED VALUE

\begin{tabular}{|c|c|c|c|c|c|}
\hline \multicolumn{3}{|c|}{ Condition } & \multicolumn{3}{|c|}{$\begin{array}{l}\% \text { Deviation of Calculated Response in } \\
\text { Bottom Element From Measured Value }\end{array}$} \\
\hline Region & Configuration & $\begin{array}{c}\text { Rod } \\
\text { Condition } \\
\end{array}$ & $\begin{array}{c}\text { Initial } \\
\text { Comparison }\end{array}$ & $\begin{array}{c}5 \mathrm{ppm} \\
\text { Adjustment }\end{array}$ & $\begin{array}{c}\text { All } \\
\text { Corrections } \\
\end{array}$ \\
\hline 1 & 1 & Unrodded & 5 & 3 & 3 \\
\hline 3 & 1 & Partially rodded & 0 & -2 & -2 \\
\hline 6 & 1 , run $A$ & Unrodded & -1 & -1 & -1 \\
\hline 6 & $1, \operatorname{run} B$ & Unrodded & -3 & -1 & -1 \\
\hline 6 & 1 , run $C$ & Unrodded & -4 & -1 & -1 \\
\hline 6 & 2 & Unrodded & -9 & $-7^{(a)}$ & -7 \\
\hline 10 & 1 & Unrodded & -6 & -1 & -1 \\
\hline 16 & 1 & Rodded & -8 & -4 & 3 \\
\hline 16 & 2 & Rodded & -12 & $-10^{(a)}$ & -1 \\
\hline 23 & 1 , run $A$ & Rodded & -3 & -1 & -1 \\
\hline 23 & $1, \operatorname{run} B$ & Rodded & -3 & -2 & -2 \\
\hline 27 & 1 & Unrodded & -13 & -10 & -10 \\
\hline 31 & 1 & Unrodded & -19 & -17 & -7 \\
\hline 31 & 2 & Unrodded & -17 & $-15^{(a)}$ & -5 \\
\hline 32 & 1 & Rodded & -9 & -8 & -8 \\
\hline 37 & 1 & Unrodded & -9 & -6 & -6 \\
\hline
\end{tabular}

(a) A $2 \%$ correction was applied to the configuration 2 results to account for the presence of additional impurities in the reflector. 


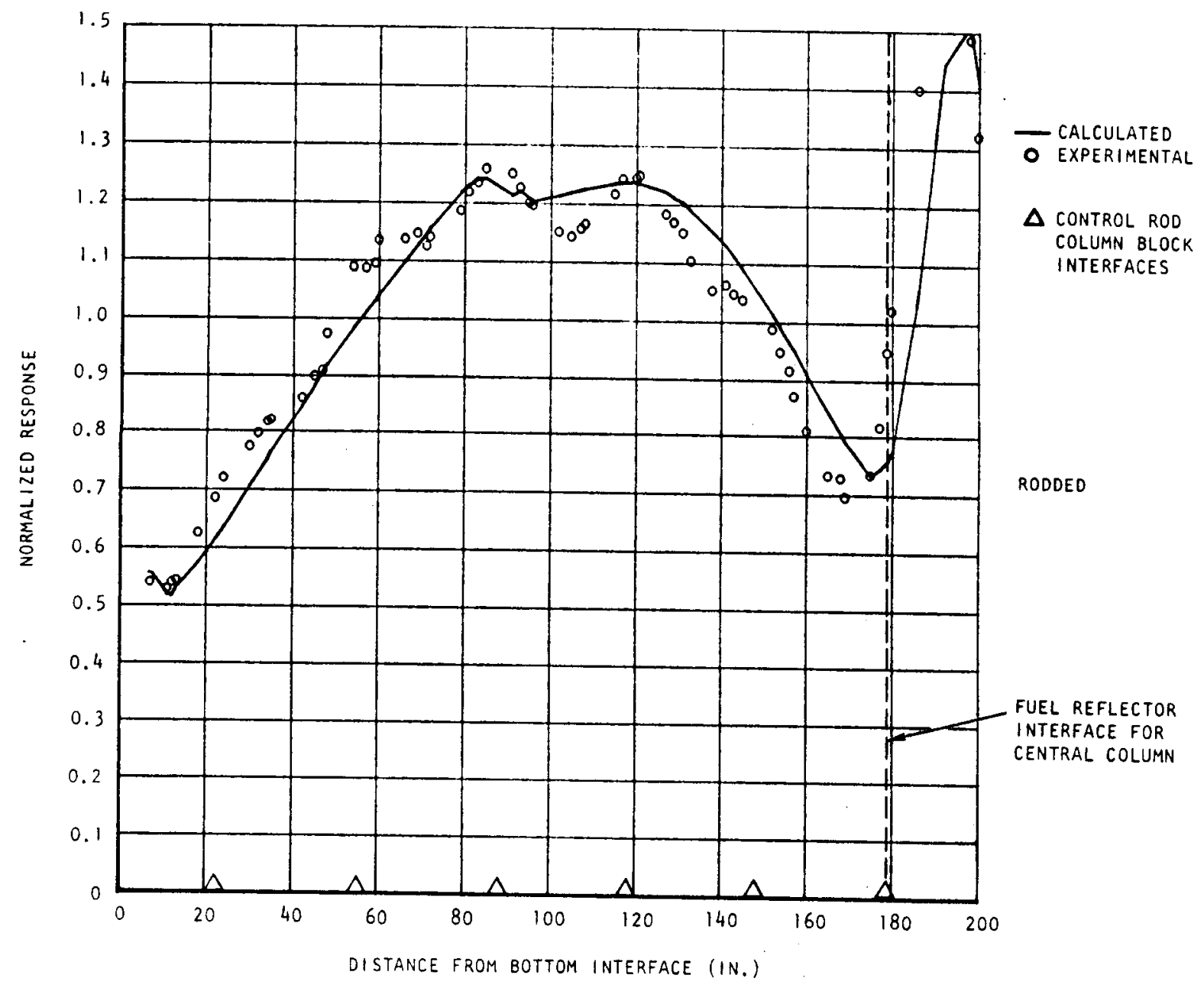

Fig. 7-3. Axial flux distribution (5 ppm in reflector), configuration 1 , region 16 


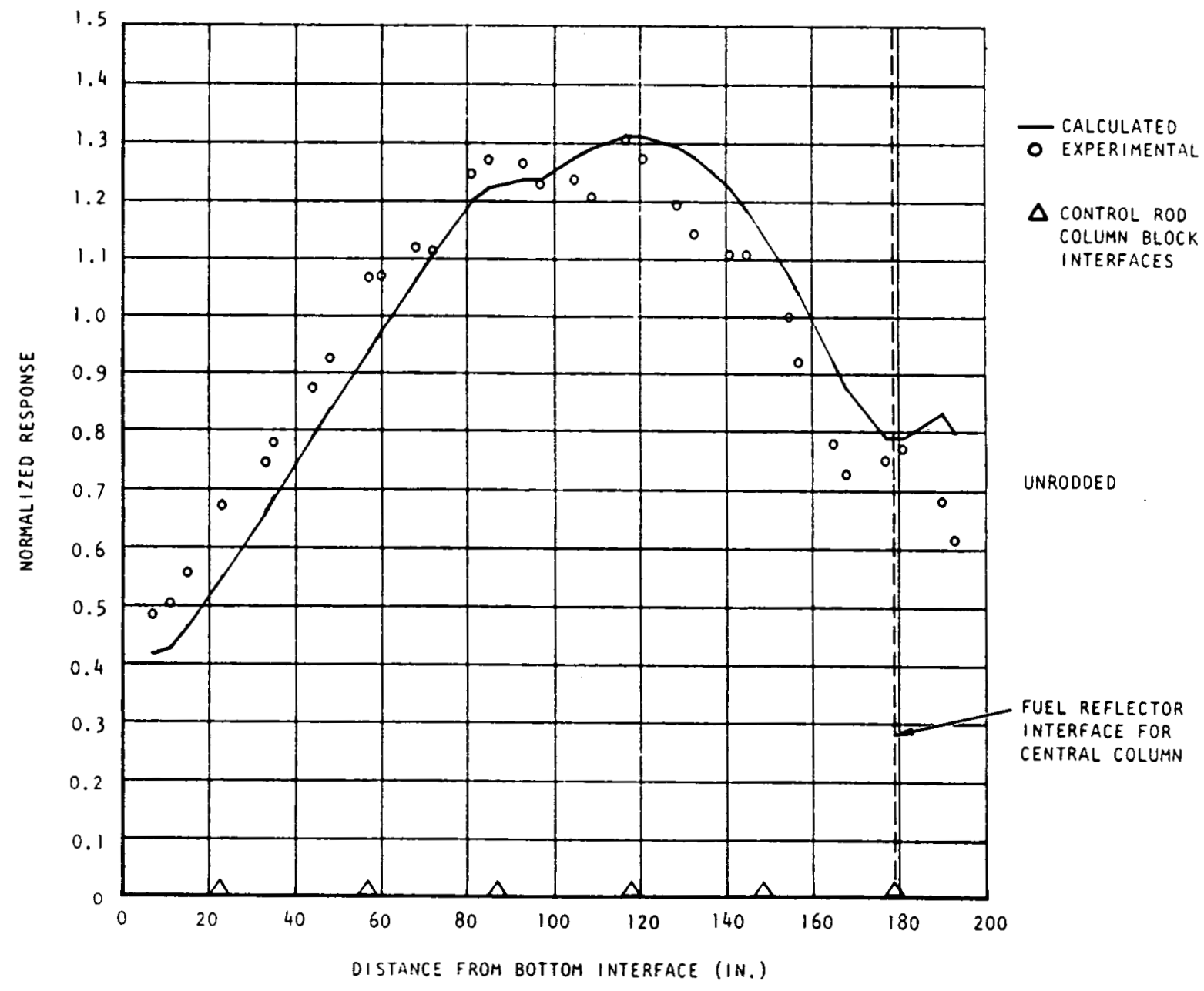

Fig. 7-4. Axial flux distribution (5 ppm in reflector), configuration 1 , region 31 
Table 7-1. As can be seen, there is a general improvement in the agreement when the additional boron is added to the reflector. In the unrodded regions for the outer two rings there is about a $5 \%$ improvement. Since GATT was not re-run for configuration 2, a modest correction (2\%) was made to the results in Table $7-1$.

If we correct regions 16 and 31 for a 6-in. error in detector position, the maximum percent deviation from the measured value in the lower block is $10 \%$ in region 27 (see Table 7-1). A correspondingly adjusted plot of regions 16 and 31 for configuration 1 is shown in Figs. II-12 and II-13. As can be seen, there is excellent agreement between the measured and calculated results, and the measured peaks occur at the expected location. The figures presented in Appendix II are the final comparisons of the calculated and measured axial flux distributions.

\subsection{EVALUATION OF APPROXIMATIONS}

There are a number of approximations in the GATT calculational model which have been evaluated. These approximations are as follows:

1. The control rod positions used in GATT were slightly different from the actual control rod positions.

2. The GATT code uses only a single thermal energy group. This approximation does not account for changes in the thermal spectrum near material boundaries.

3. Since in these calculations all fuel elements are represented as a homogeneous region, the buffer region has been homogenized over the remainder of the fuel element.

4. The GATT model assumes that the unfueled gaps are homogenized in the fuel elements. Also, the atom densities in the axial reflectors were homogenized radially. 
The effect of the control rod position has been discussed in Section 7.1. The effects of thermal group structure and heterogeneities were investigated with two RZ-calculational models. A cell model, which represents a refueling region surrounded by other refueling regions, was used to investigate items 2 and 4 above. A full core model was used to investigate items 2 and 3 . Both of these models examined the unrodded condition.

The cell model used in this investigation is the same model used in Section 7.1 to determine the location of the unfueled gap peaks. This model was used with only four energy groups (one thermal group) and with unfueled gaps, reflector material, and control rod atom densities homogenized in the exact manner used in the GATT calculation. This calculation was then repeated with the heterogeneities correctly described, but without changing the group structure. As can be seen in Fig. 7-5, the effect of including the heterogeneities in the GATT calculational model would be to slightly decrease the flux in the bottom of the core. The calculation was repeated once more with the heterogenieties correctly described and with seven energy groups. As can be seen, the effect of the additional thermal groups is to slightly increase the flux in the bottom core half. Thus, the net effect of including the heterogeneities and using more thermal groups in the GATT model is to cause a very slight reduction in the flux in the bottom core half. It is also interesting to observe that the calculated detector response predicted by this simple model is in good agreement with the measured results for basically all of the fully rodded or unrodded regions that are not adjacent to partially rodded regions.

A very simple full core $R Z$ model was then used to investigate the effect of the group structure and buffer description. The GAMBLE diffusion theory code was used. The model geometry is shown in Fig. 7-6. In this model only three core compositions were used. The top core half was assumed to be all blend 1 fuel and the bottom half was assumed to be all blend 2 fuel. The buffer was shown as a separate region.

A calculation was first made with seven energy groups and the buffer region explicitly represented (thin buffer). Another calculation was made 


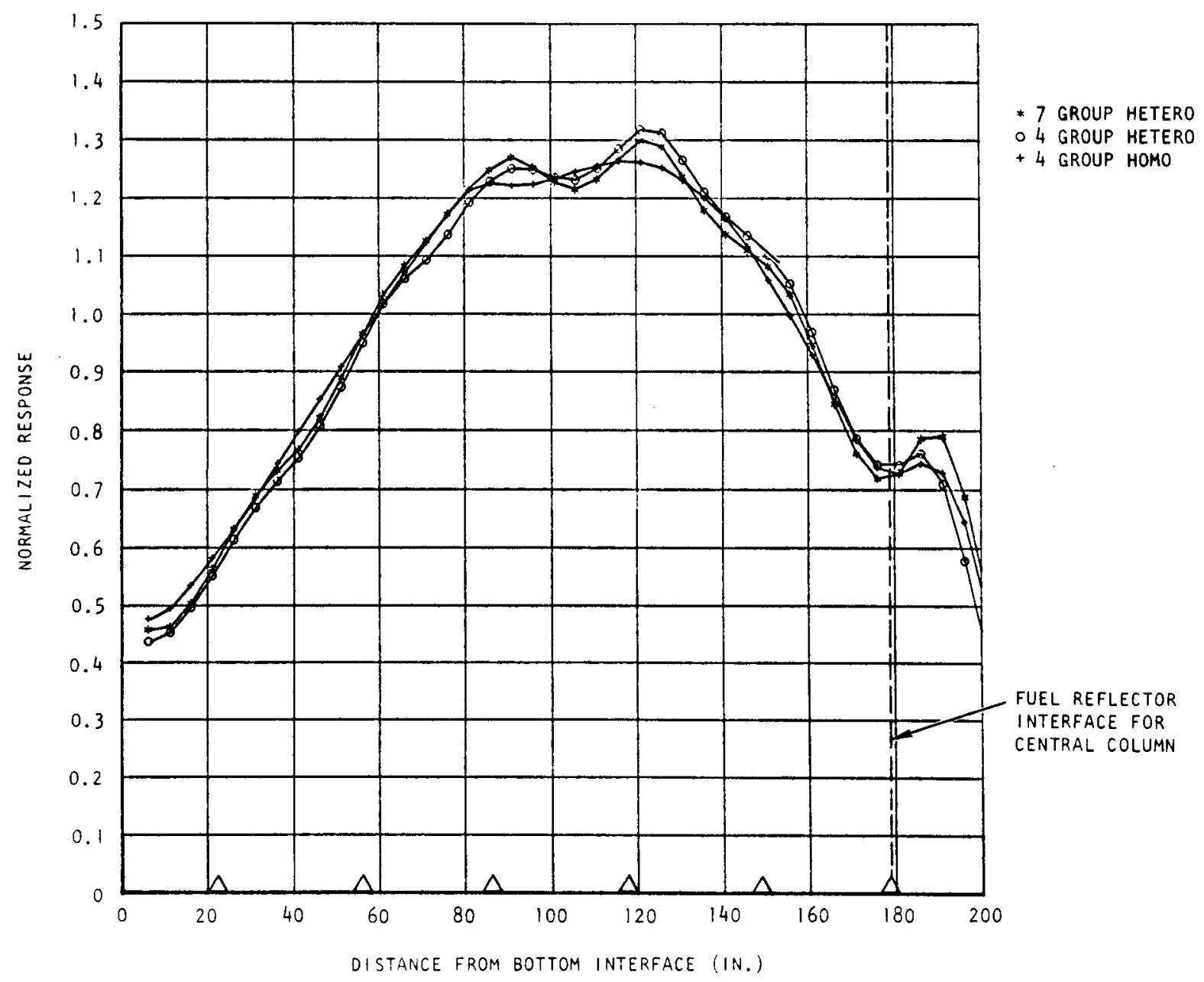

Fig. 7-5. Axial flux distribution at edge of control element (cell model) with 7 groups and heterogeneities described, 4 groups and heterogeneities described, and 4 groups without heterogeneities 


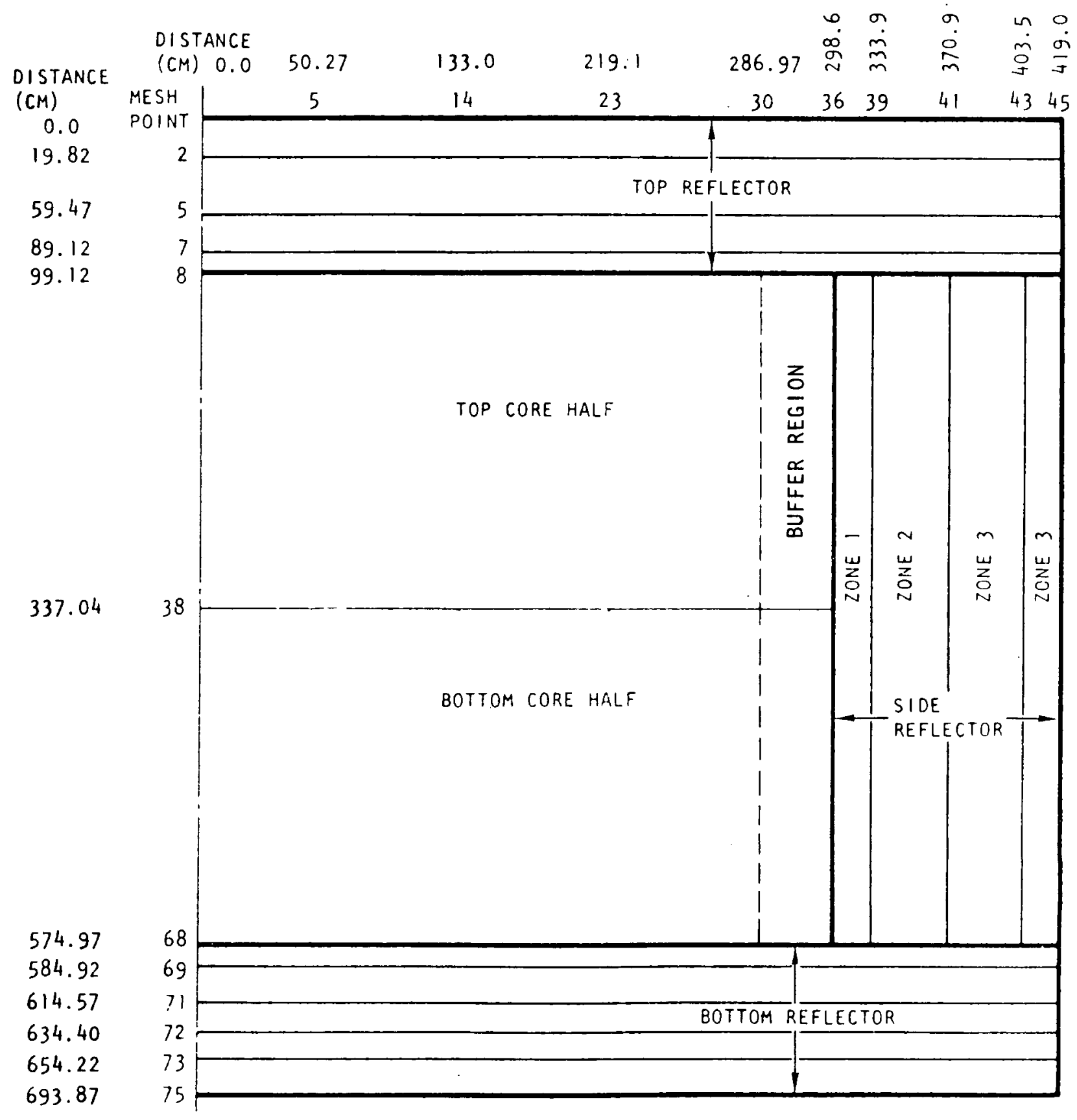

Fig. 7-6. Full core GAMBLE RZ geometry model 
with four energy groups and a GATT representation of the buffer zone (thick buffer). To represent the buffer region as in GATT, the buffer material was homogenized with the non-buffer material over the volume equal to an annulus of the outermost hex blocks. Also, the number of internal mesh points in this outer hex region was reduced from six to one to be consistent with GATT. The results of these calculations are plotted in Figs. 7-7 and 7-8. Figure 7-7 compares the axial detector response using the four group thick buffer model with the results from the seven group thin buffer model. Since the radial position examined is far from the buffer region, the buffer representation will not affect the comparison and only the group structure effect will be observed. As can be seen the results are consistent with the cell model results shown in Fig. 7-5, i.e.; the additional thermal energy groups cause only a very slight increase in the thermal flux in the bottom of the core.

Figure 7-8 compares the responses predicted by the two models at a radial location approximately equal to the detector location in an outer full-patch region (such as region 27, 31, or 37). As can be seen, the buffer description has practically no effect at all on the axial detector response. Hence, both of the cell model and full core model show that the modeling of the heterogeneities and the thermal group structure has practically no effect on the calculated results. 


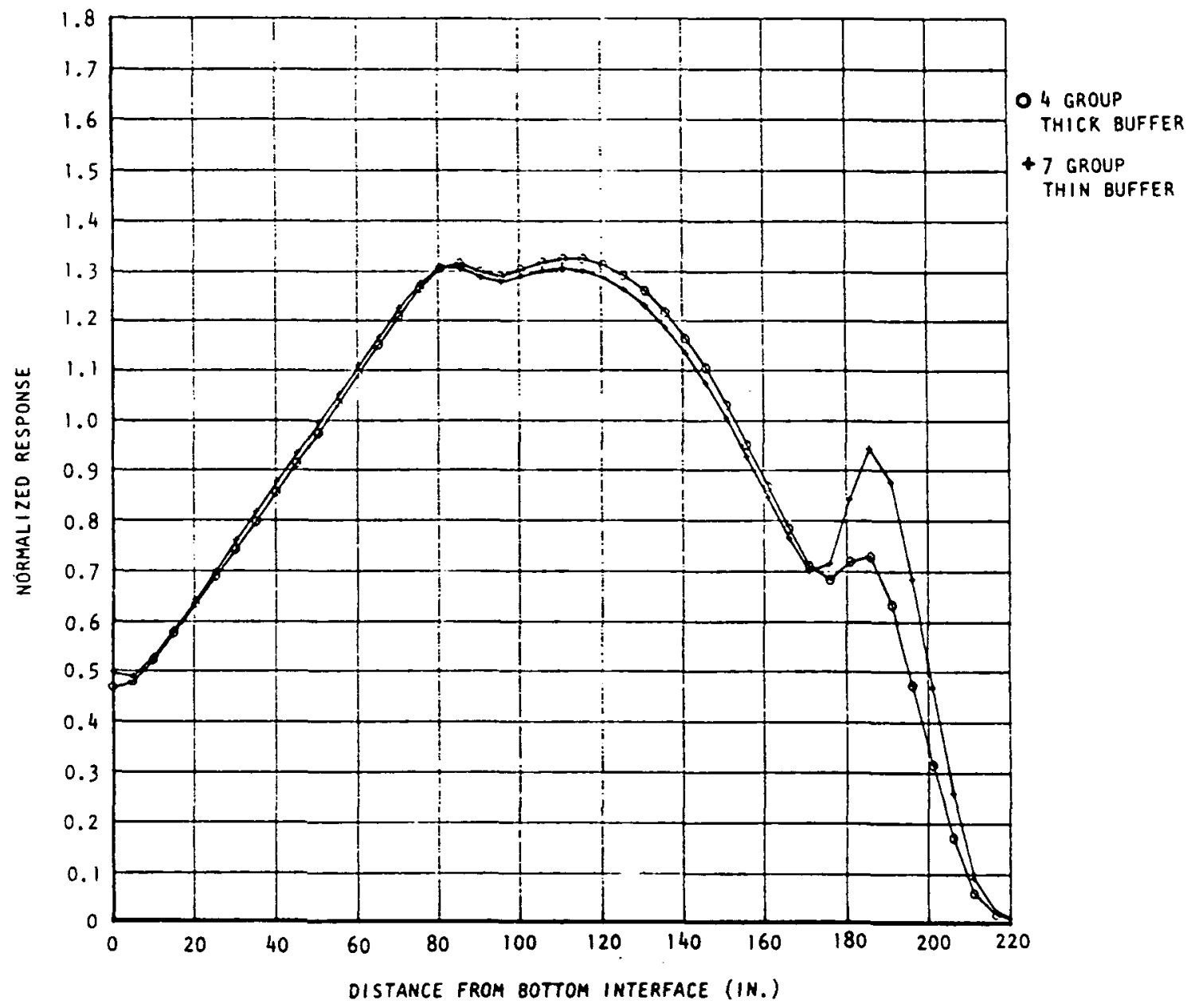

Fig. 7-7. Axial flux distribution, 7 group thin buffer versus 4 group thick buffer at radial center (full core mode1) 


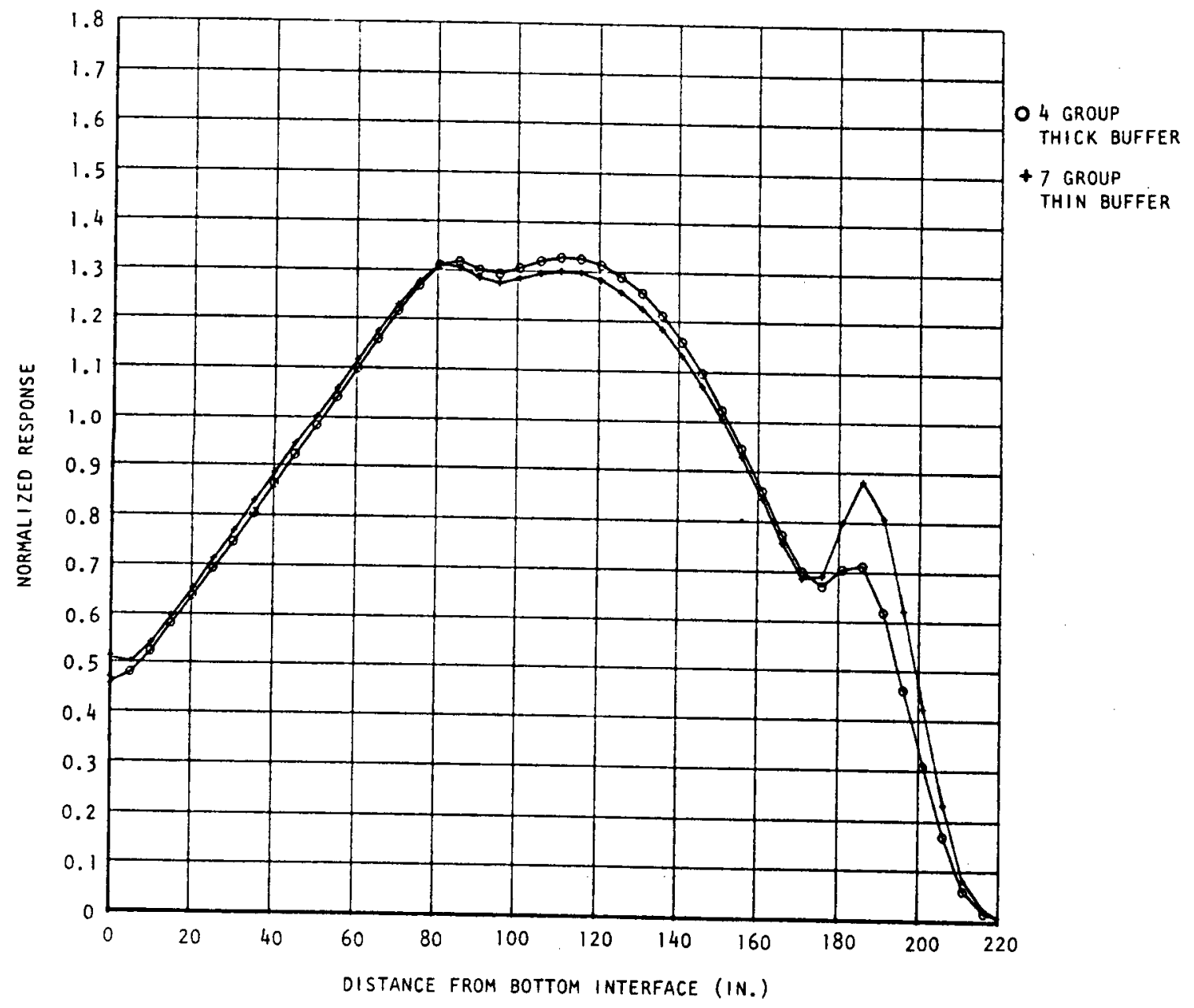

Fig. 7-8. Axial flux distribution, 7 group thin buffer versus 4 group thick buffer near core edge (full core model) 


\section{CONCLUSIONS}

1. When the reflector impurity level and the detector positions in regions 16 and 31 are corrected, the agreement between the calculated and measured flux in the lower fuel element is within $10 \%$ for all of the regions examined. Hence, the measurements show that the calculational accuracy for the prediction of the axial flux distribution is within the technical specification limits and the acceptance criterion has been met.

2. There are very strong indications that the measured detector positions for regions 16 and 31 are in error by about 6 in. too high. This was concluded from an examination of the location of the flux peaks and dips which occur in the vicinity of the unfueled gaps and the upper reflector and from a subsequent inspection of the detector drives which showed that the position indication could have slipped during the measurements.

3. The inclusion of the correct impurity level in the reflector regions results in a small improvement in the agreement between the measured and calculated flux for most of the regions investigated.

4. The approximations used in the GATT calculational model (such as energy group structure, treatment of (heterogenelties, etc.) had only a very slight effect on the calculated flux.

5. A simple $\mathrm{RZ}$ cell model can be used to obtain axial flux or power distributions with reasonable accuracy for fully rodded or unrodded regions that are not adjacent to partially rodded regions. 


\section{REFERENCES}

1. Barre, B., General Atomic, private communication.

2. Kraetsch, H., and M. R. Wagner, "GATT a Three-Dimensional Few-Group Neutron Diffusion Theory Program for a Hexagona1-Z Mesh," USAEC Report GA-8547, Gulf General Atomic, January 1, 1969.

3. Mathews, D. R., et al., "GGC-5, A Computer Program for Calculating Neutron Spectra and Few Group Constants," Gulf General Atomic, unpublished data.

4. Marsha11, A. C., "Cross Sections for the Fort St. Vrain Initial Core," USAEC Report GA-B12406, Gulf General Atomic, November 1, 1972.

5. Zane, G., "INTERP - A Program for Interpolation of Group Cross Sections," General Atomic, to be published.

6. Davison, W., General Atomic private communication.

7. Dorsey, J. P., and R. Froelich, "GAMBLE-5, A Program for the Solution of the Multigroup Neutron-Diffusion Equations in Two Dimensions with Arbitrary Group Scattering, for the UNIVAC-1108 Computer," USAEC Report GA-8188, Gulf General Atomic, December 4, 1967.

8. Pfeiffer, W., J. R. Brown, and A. C. Marshall, "Fort St. Vrain Startup Test A-3: Pulsed Neutron Experiments," USAEC Report GA-A13079, General Atomic, July 1974.

9. Marsha11, A. C., and J. R. Brown, "Loading of Fuel and Reflector Elements in the Fort St. Vrain Initial Core," (Results of Start-up Test A-1), USAEC Report GA-A13101, General Atomic, November 1, 1974.

10. Kapernick, R. J., and R. J. Nirschl, "Fuel Fabrication Acceptance Report FSV-Initial Core," USAEC Report GA-B12697, Gulf General Atomic, December 1, 1973. 


\section{ACKNOWLEDGMENTS}

In addition to the second author, the following General Atomic personnel directly participated in the experiments at the Fort St. Vrain site: K. Asmussen, R. Hackney, V. Malakhof, and R. Nirschl. K. Hofmann of HRB (Germany) also participated in the experiments. The experiments were actually performed by the reactor operating staff of the Public Service Company of Colorado. Calculational support in San Diego was provided by the Core Physics Branch, with special efforts by G. Zane (GA), H. Arai (EPDC-Japan), and B. Barré (CEA-France). 
APPENDIX I

PRELIMINARY COMPARISON OF CALCULATED AND MEASURED AXIAL FLUX DISTRIBUTION 


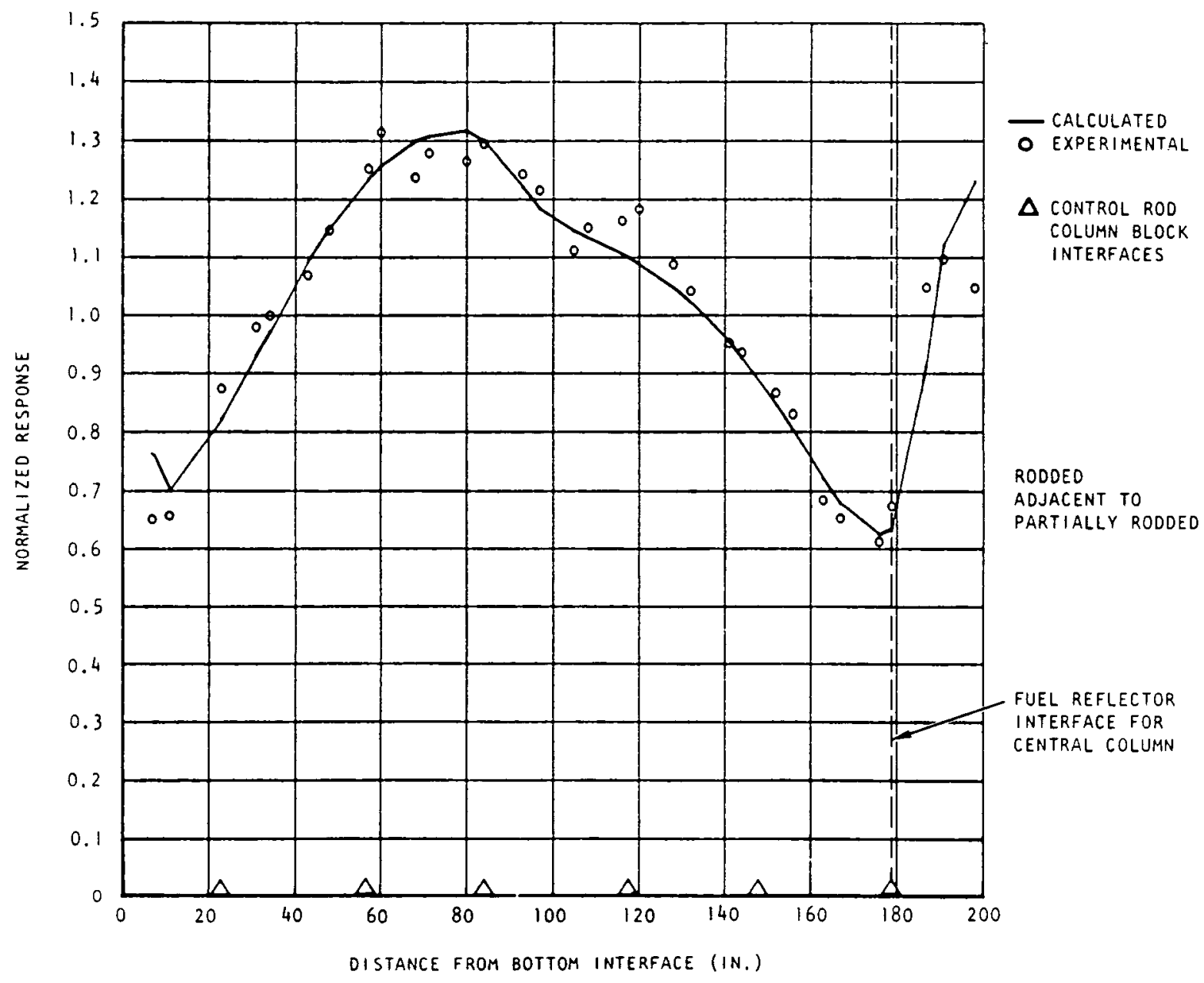

Fig. I-1. Axial flux distribution, configuration 1, region 1 


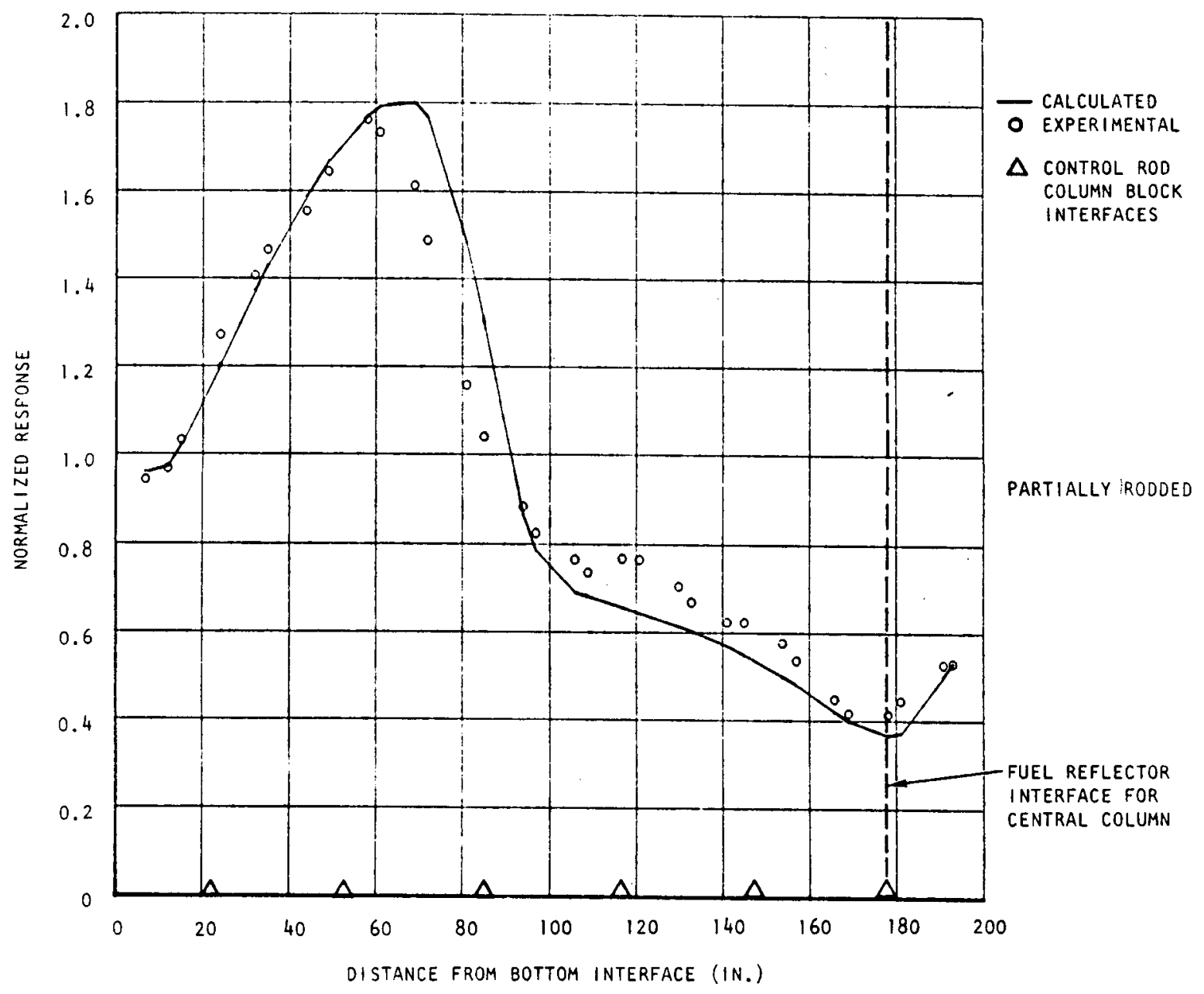

Fig. I-2. Axial flux distribution, configuration 1, region 3 


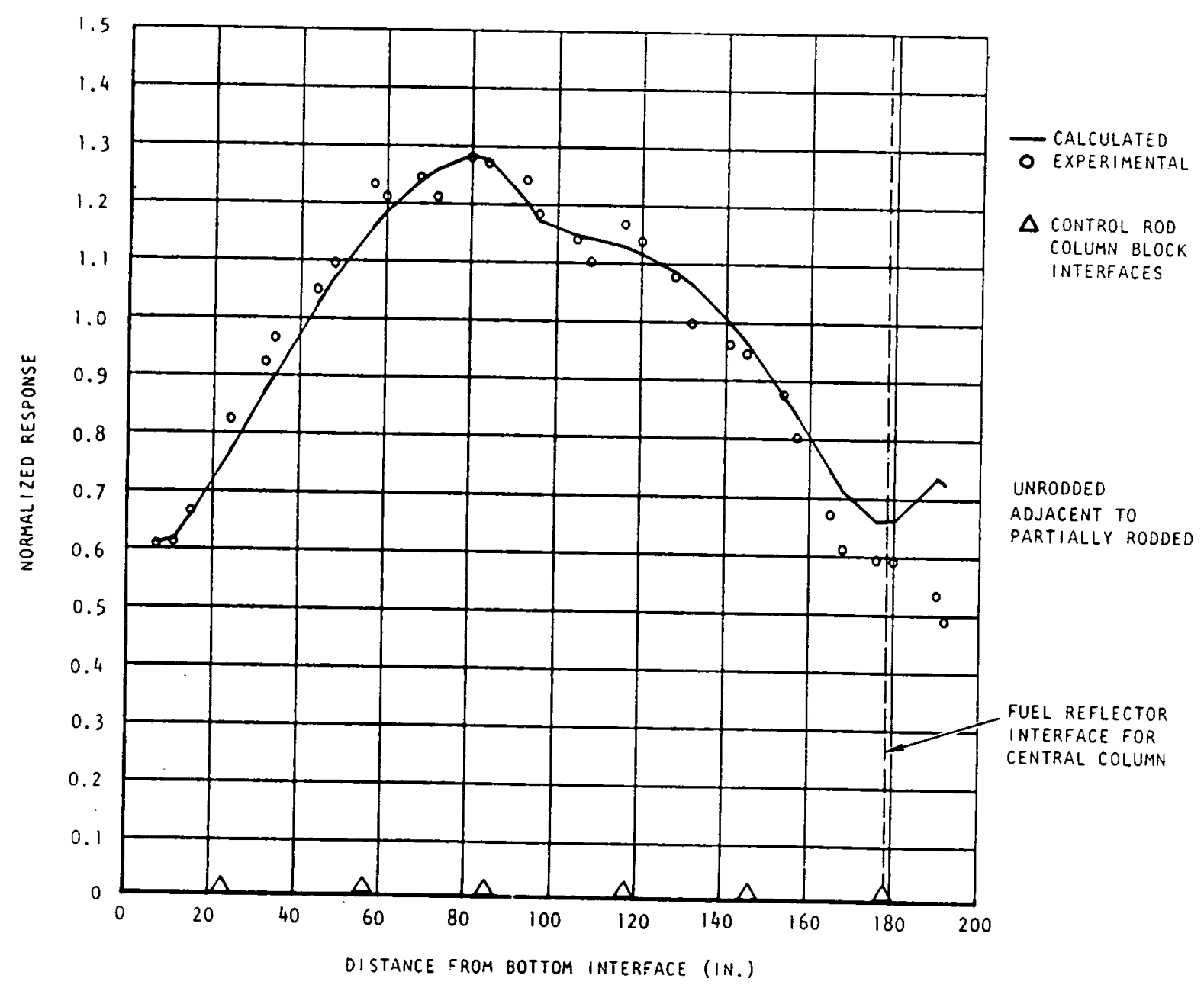

Fig. I-3. Axial flux distribution, configuration 1, region 6 , run A 


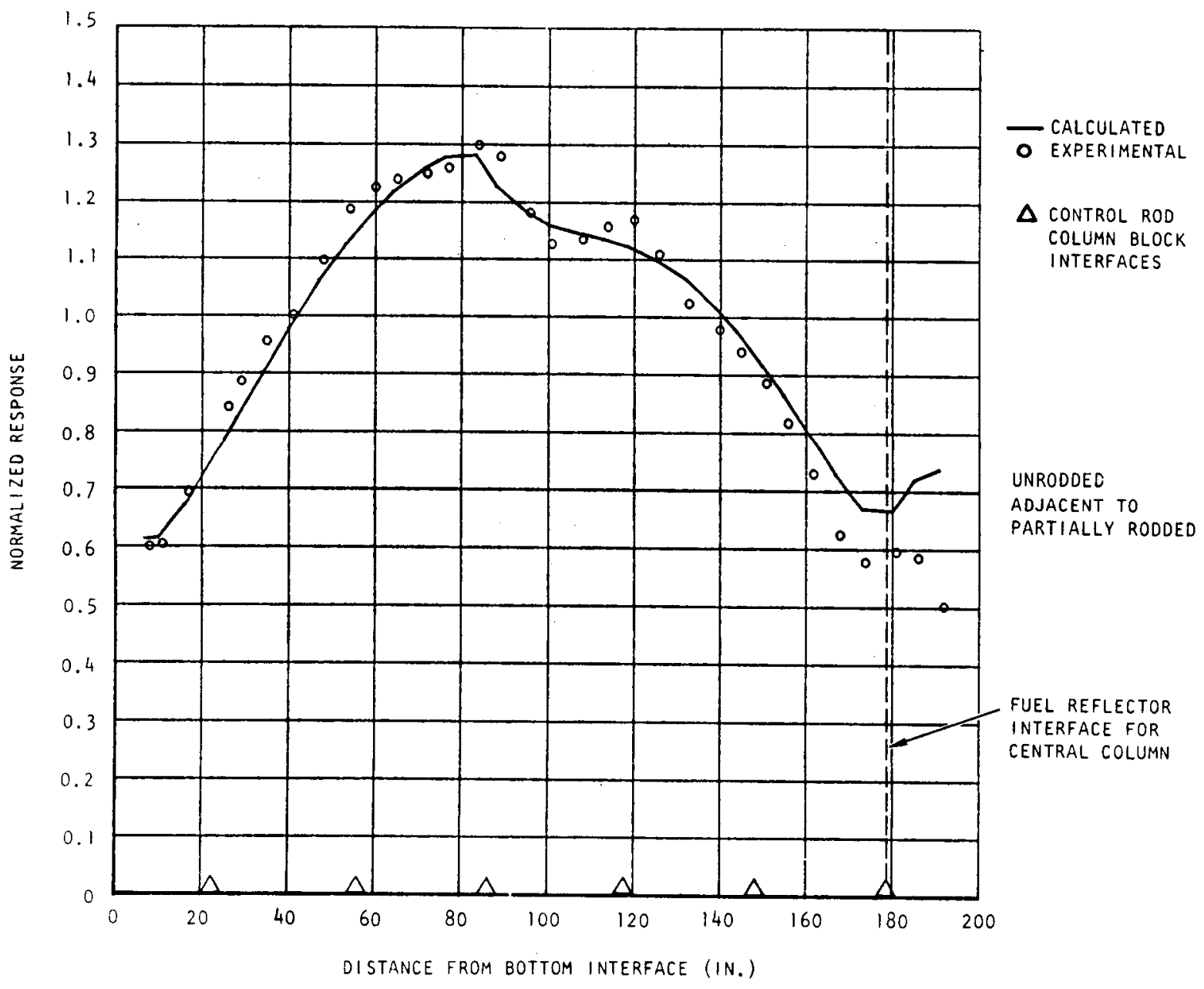

Fig. I-4. Axial flux distribution, configuration 1, region 6 , run $B$ 


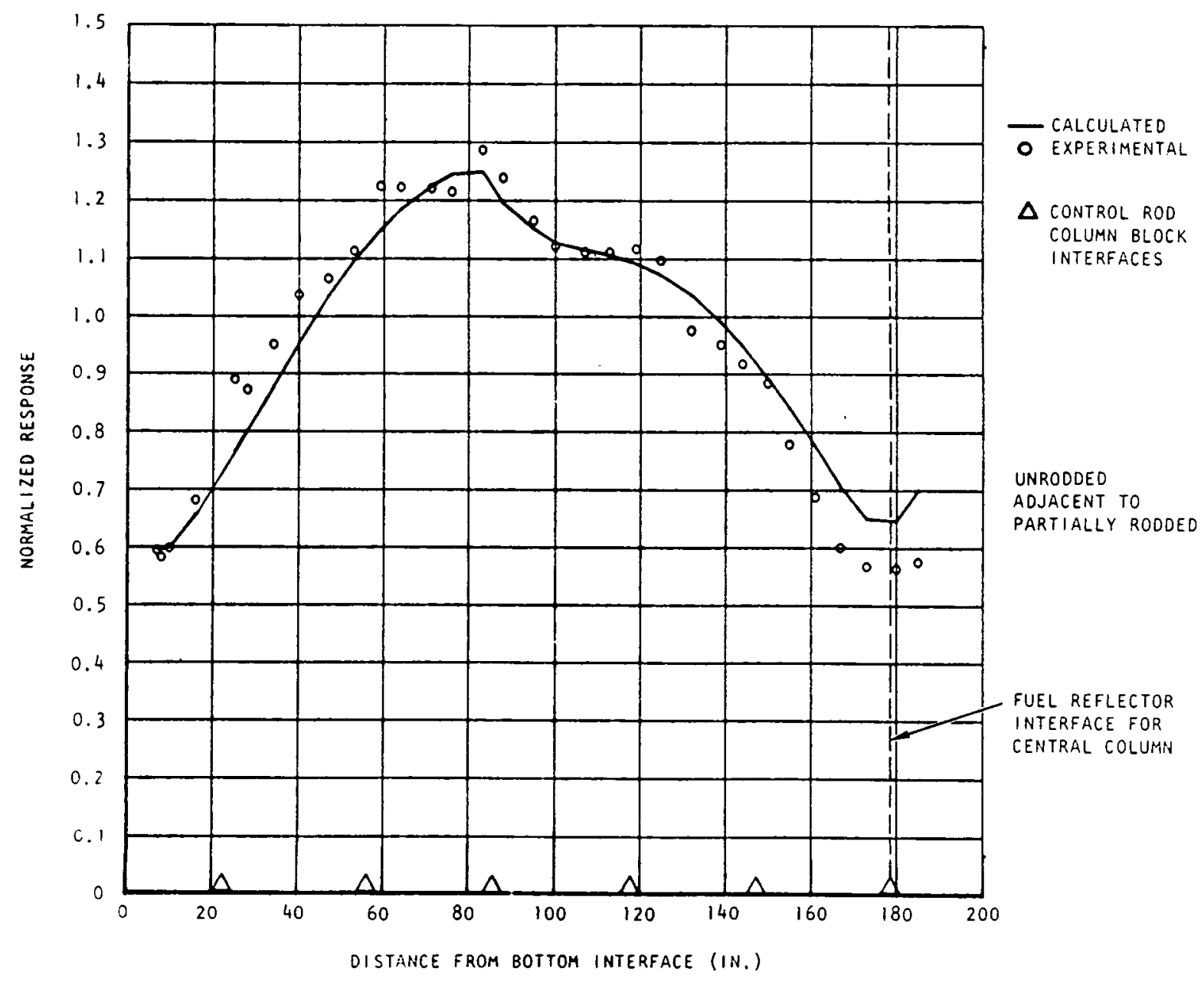

Fig. I-5. Axial flux distribution, configuration 1, region 6 , run $C$ 


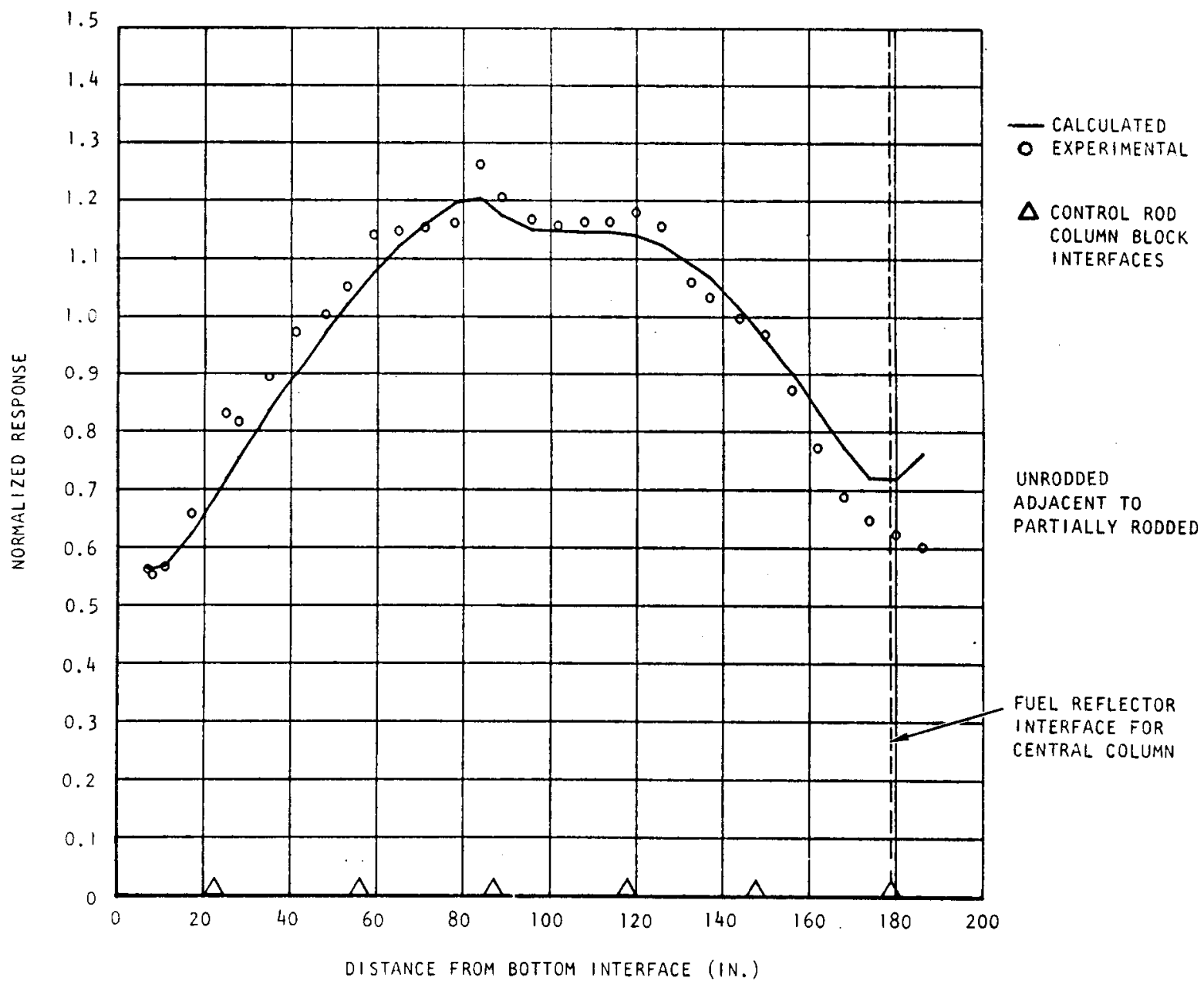

Fig. I-6. Axial flux distribution, configuration 1, region 10 


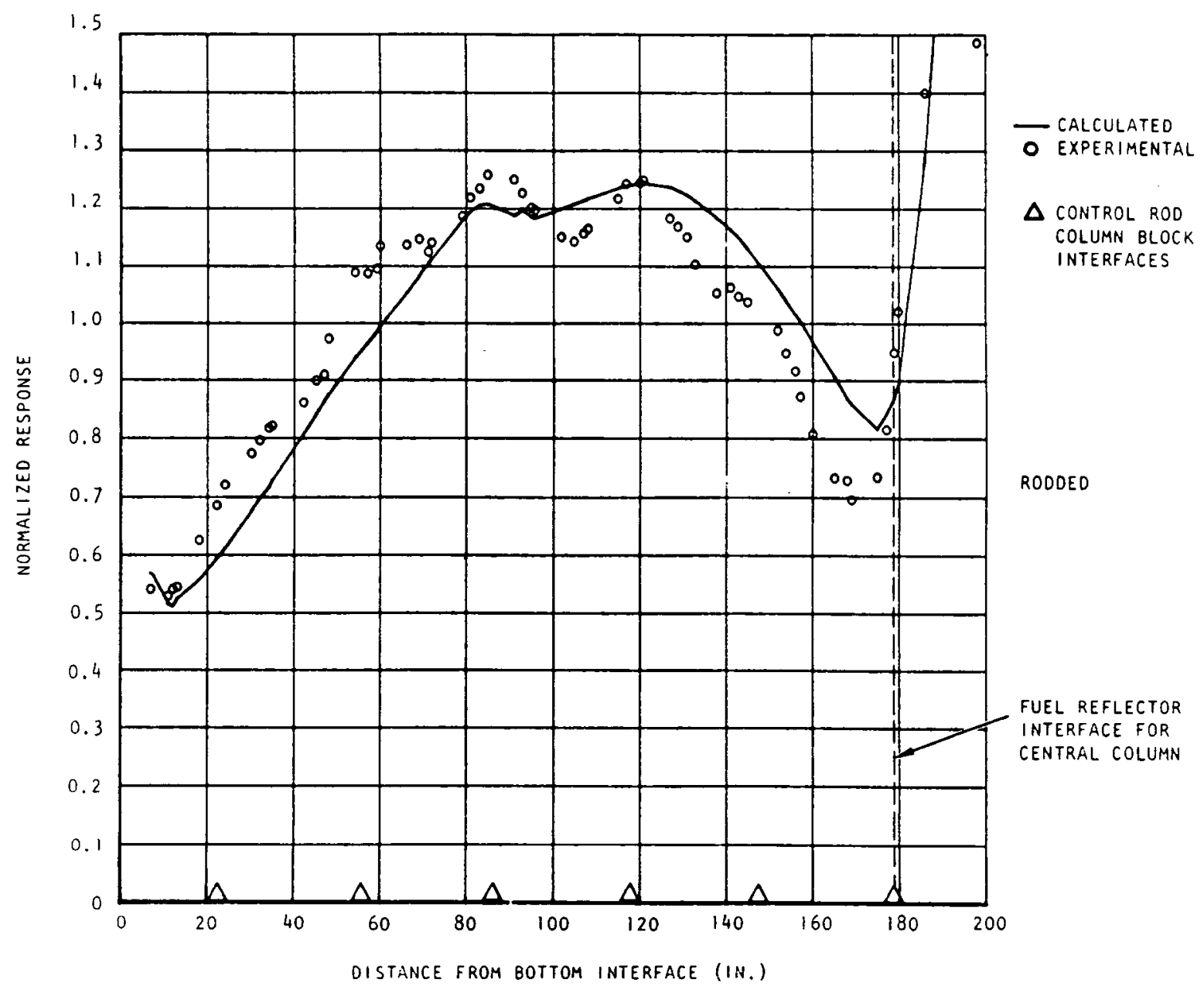

Fig. I-7. Axial flux distribution, configuration 1, region 16 


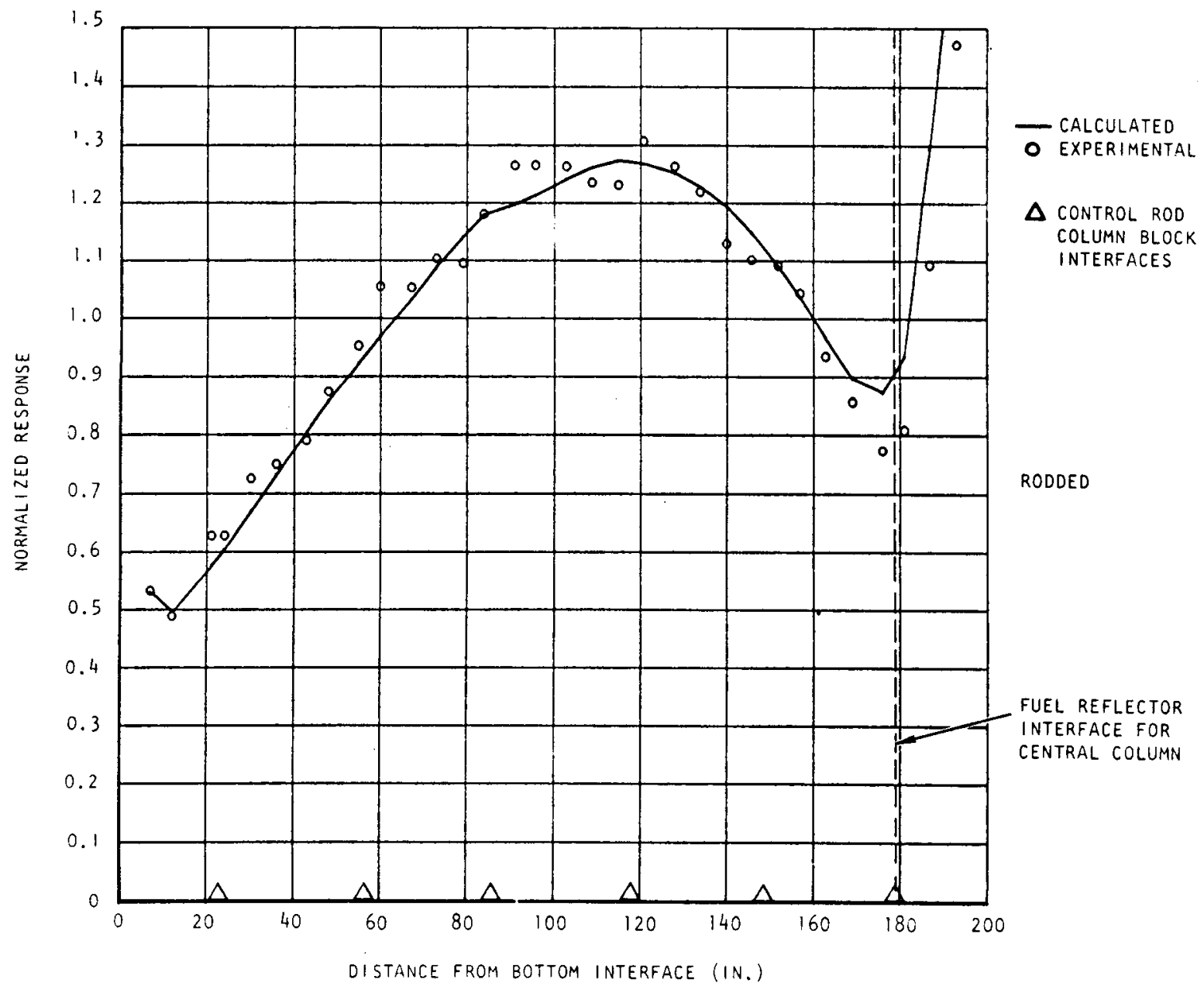

Fig. I-8. Axial flux distribution, configuration 1, region 23, run A 


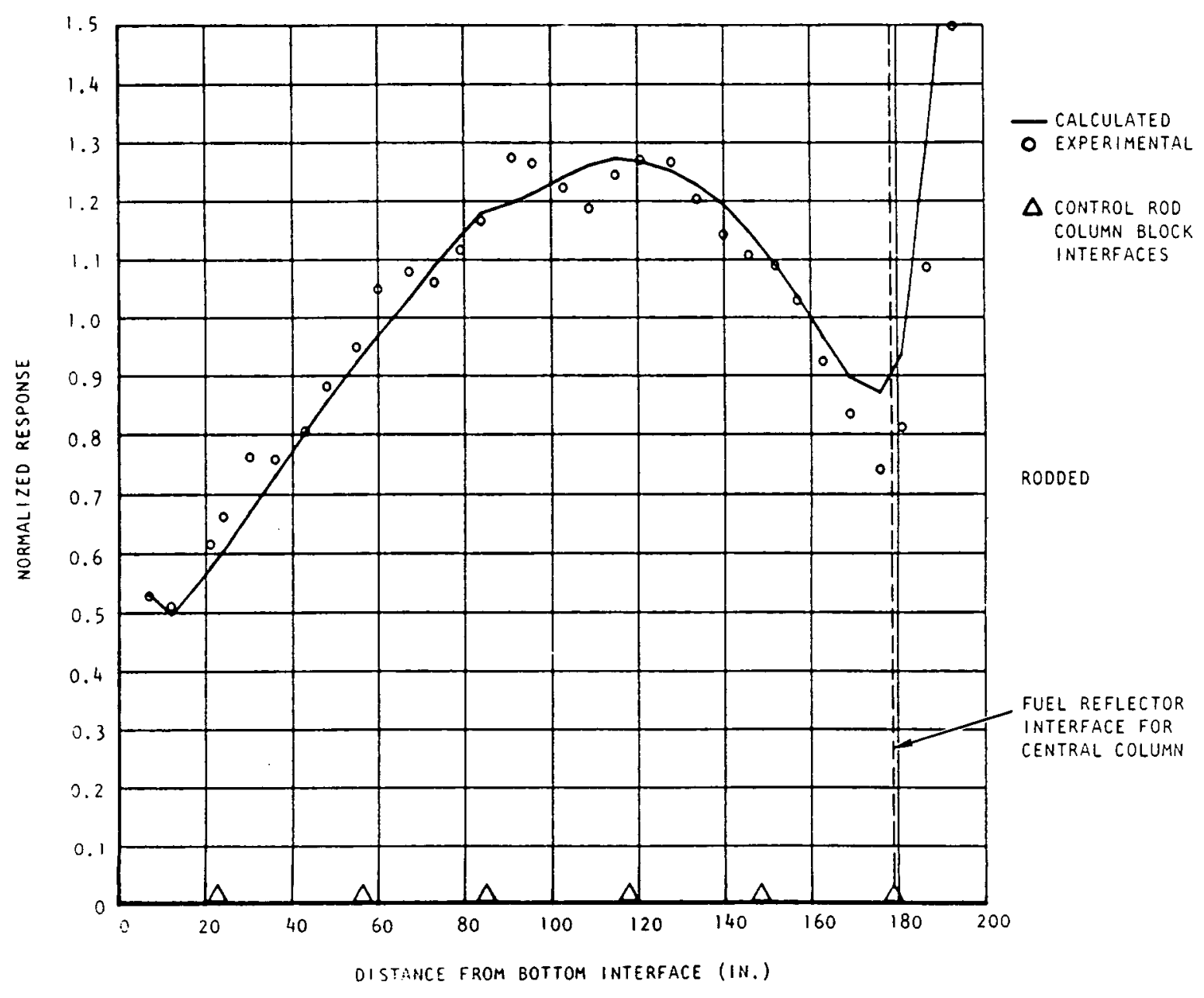

Fig. I-9. Axial flux distribution, configuration 1, region 23, run $B$ 


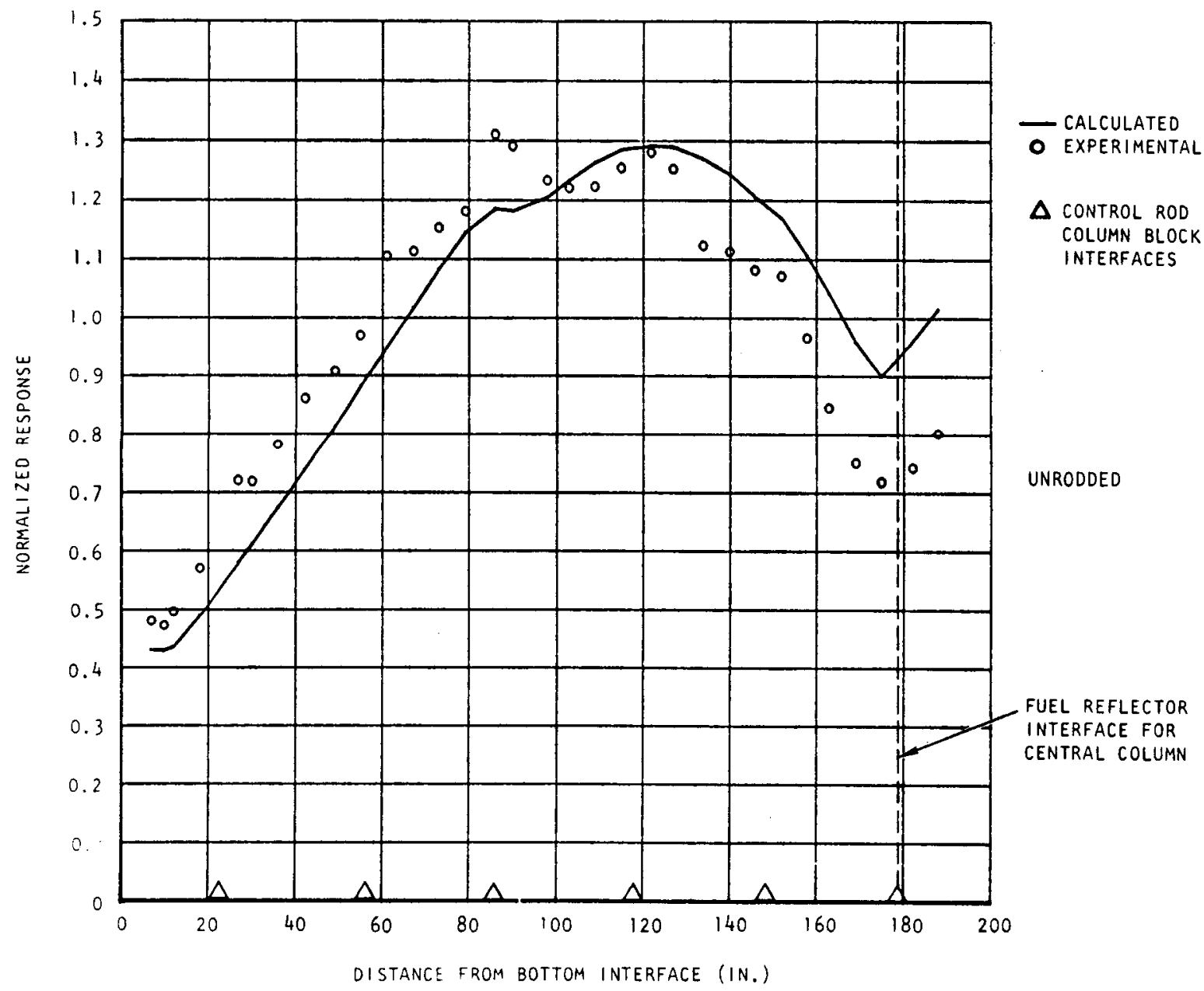

Fig. I-10. Axial flux distribution, configuration 1, region 27 


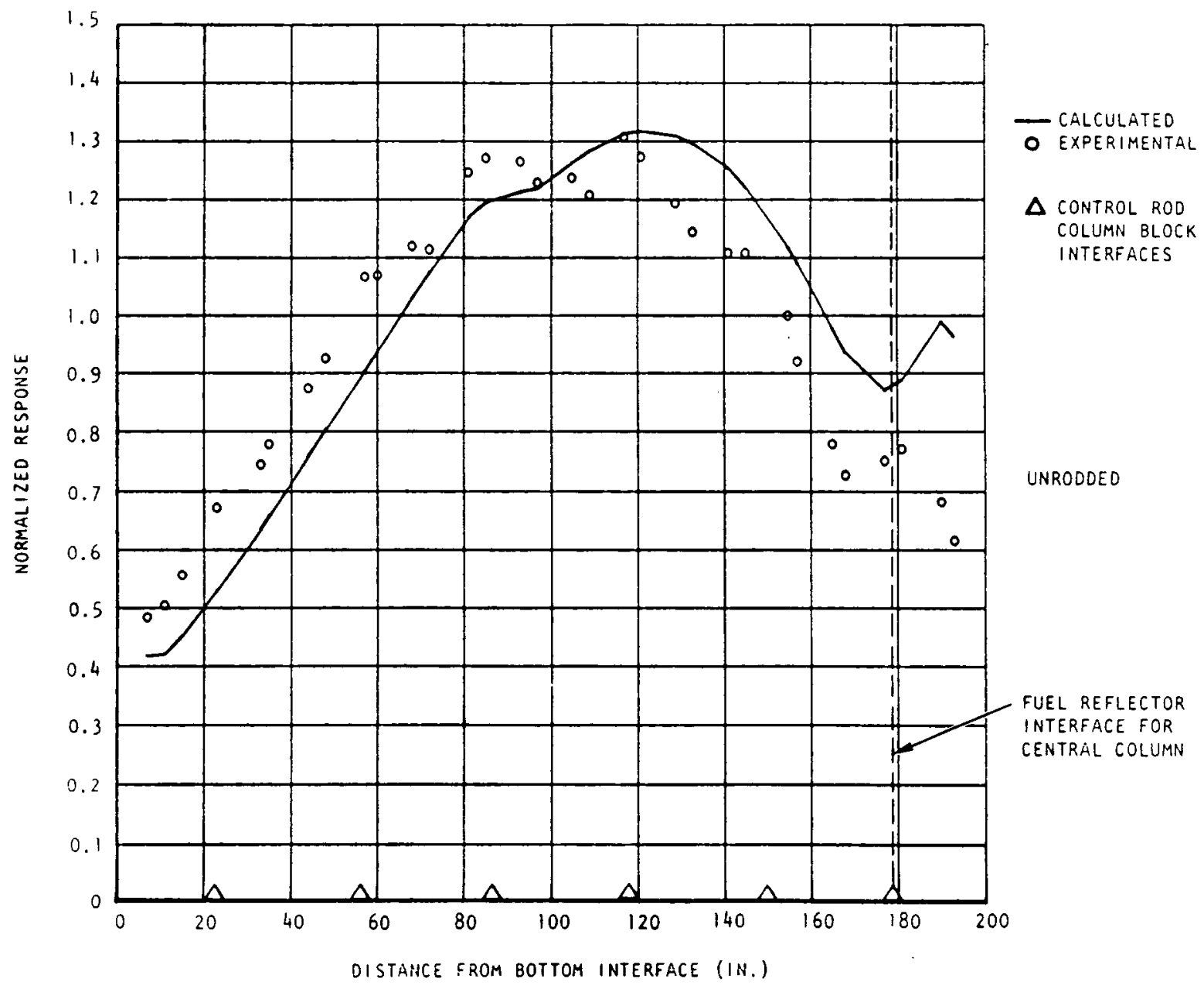

Fig. I-11. Axial flux distribution, configuration 1, region 31 


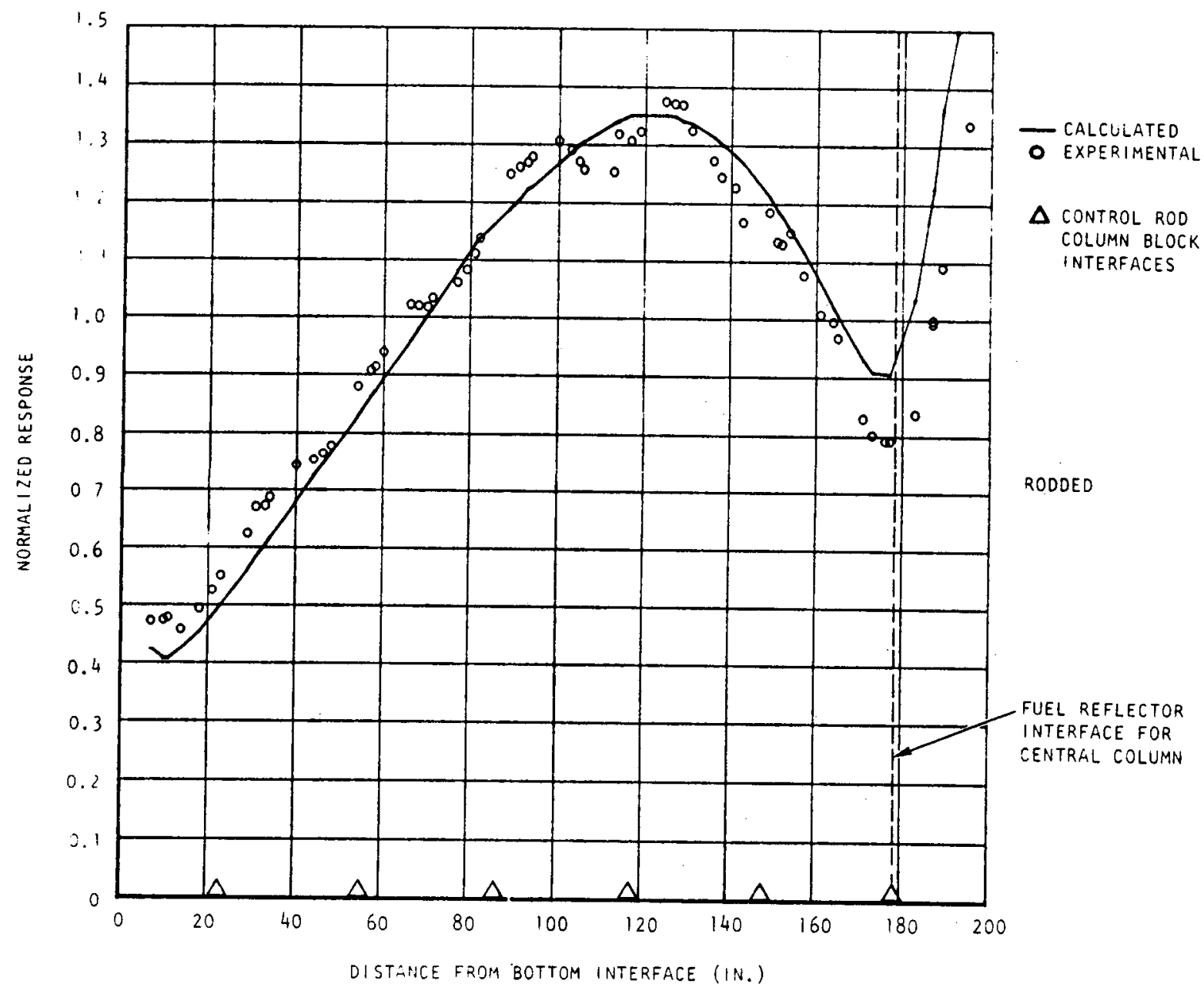

Fig. I-12. Axial flux distribution, configuration 1, region 32 


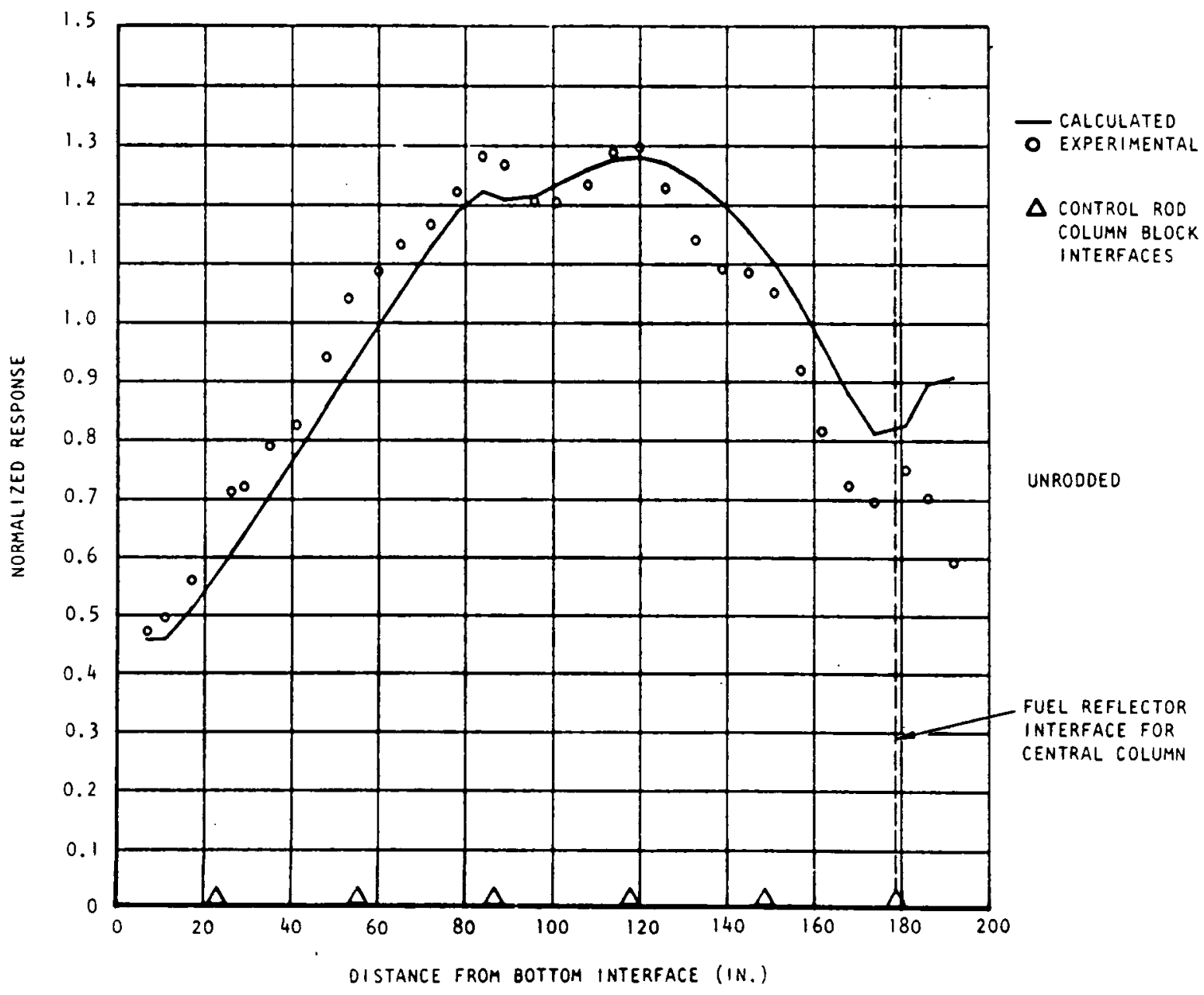

Fig. I-13. Axial flux distribution, configuration 1, region 37 


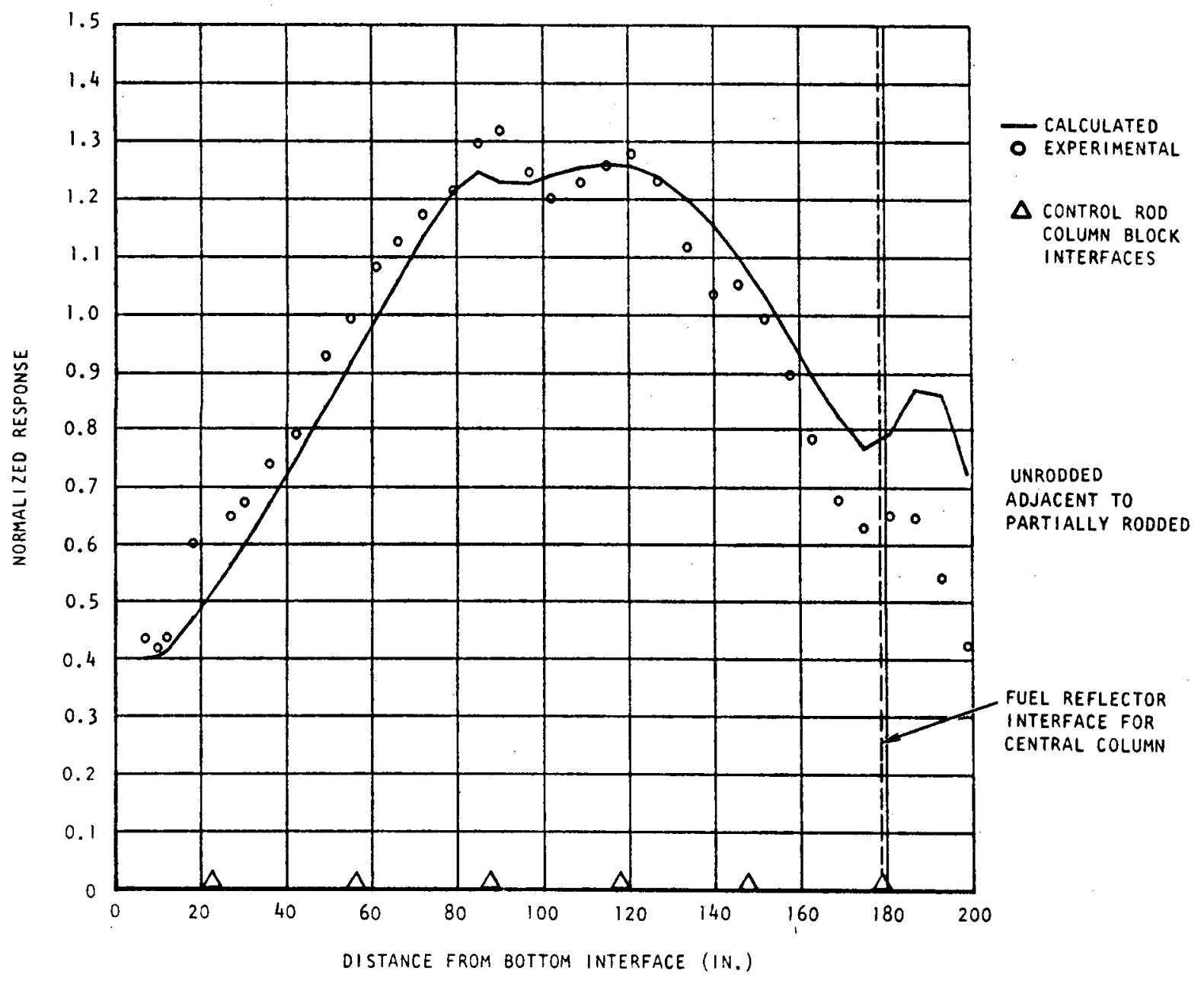

Fig. I-14. Axial flux distribution, configuration 2, region 6 


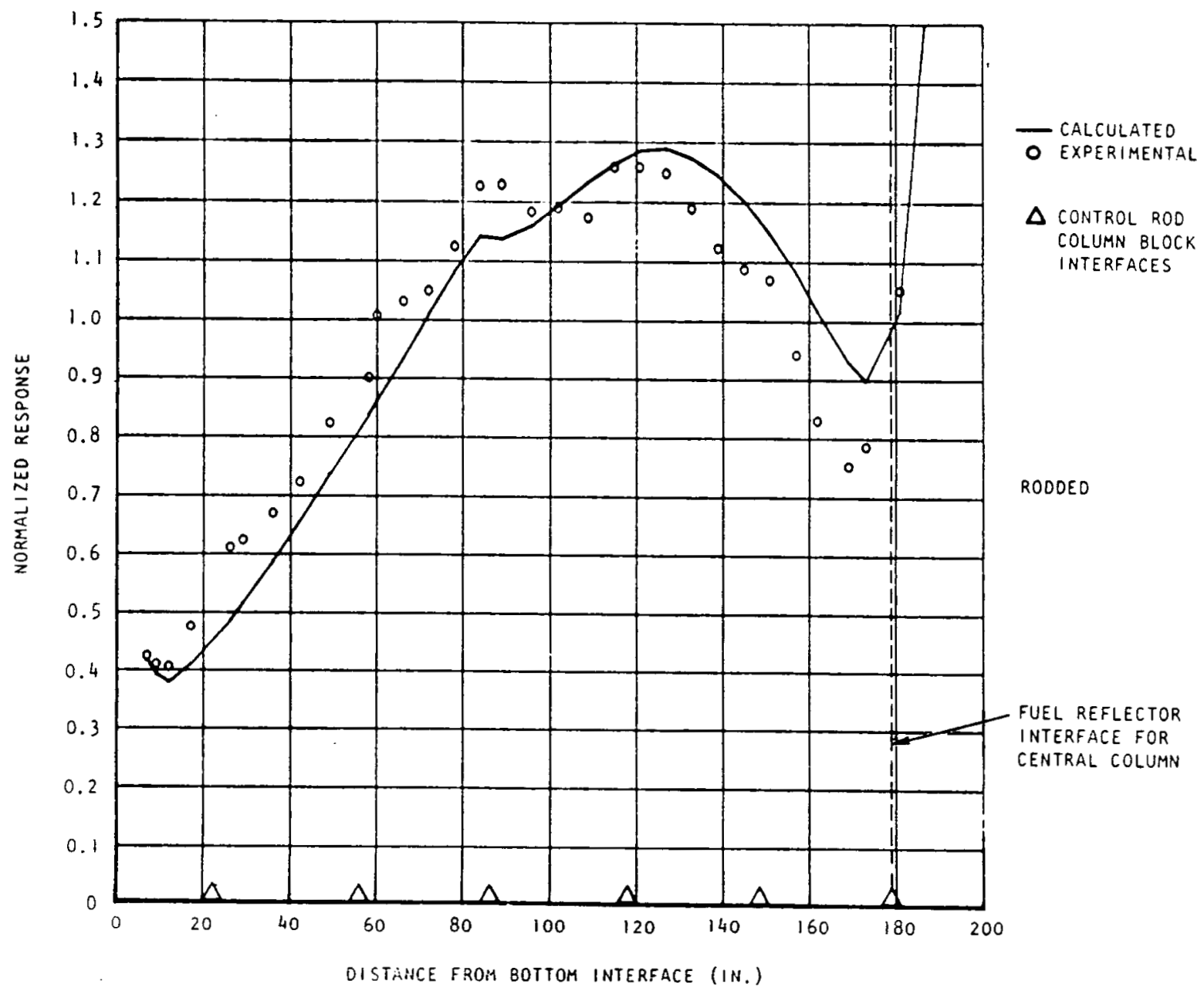

Fig. I-15. Axial flux distribution, configuration 2, region 16 


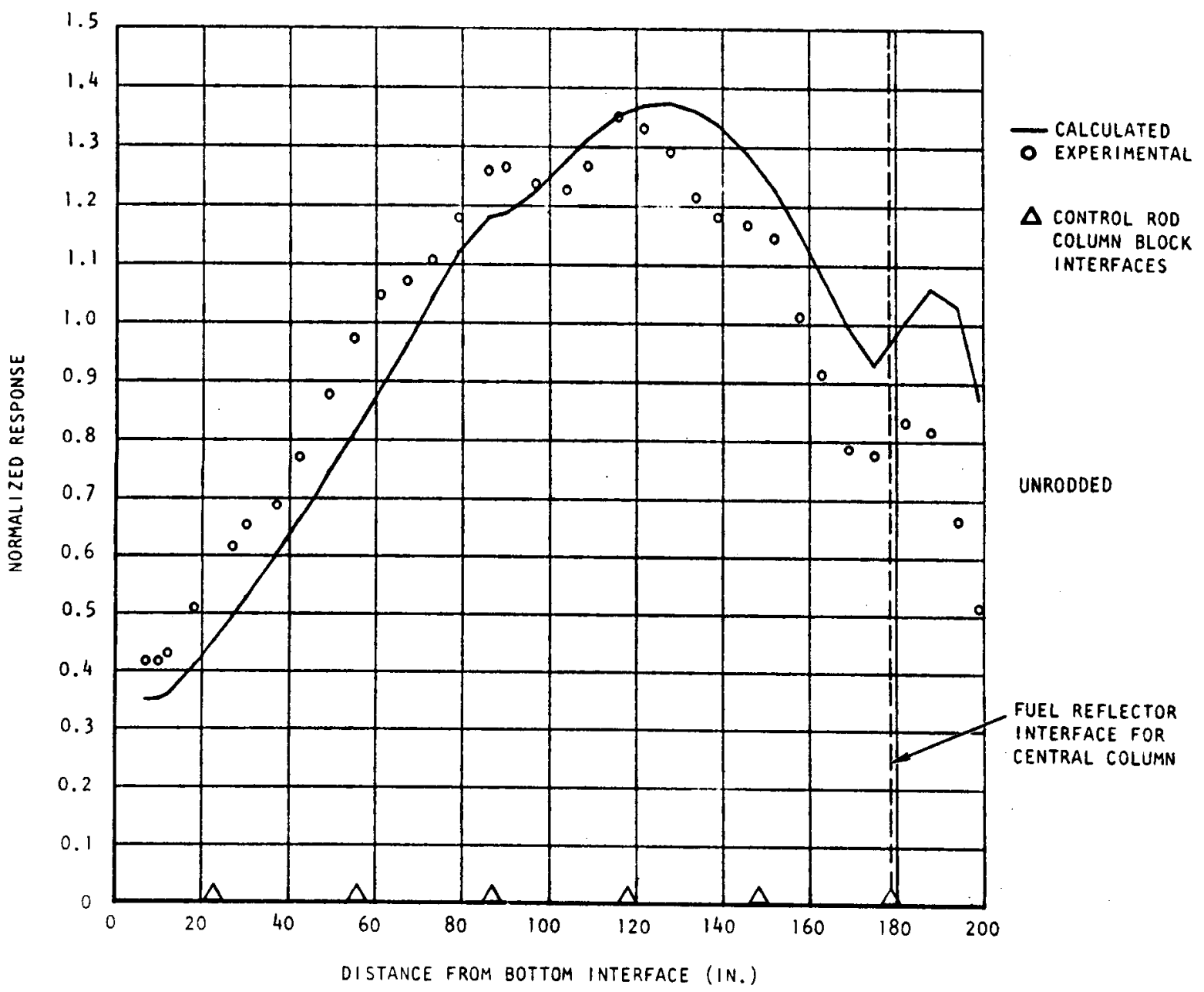

Fig. I-16. Axial flux distribution, configuration 2, region 31 
APPENDIX II

FINAL COMPARISON OF CALCULATED AND MEASURED AXIAL FLUX DISTRIBUTION 


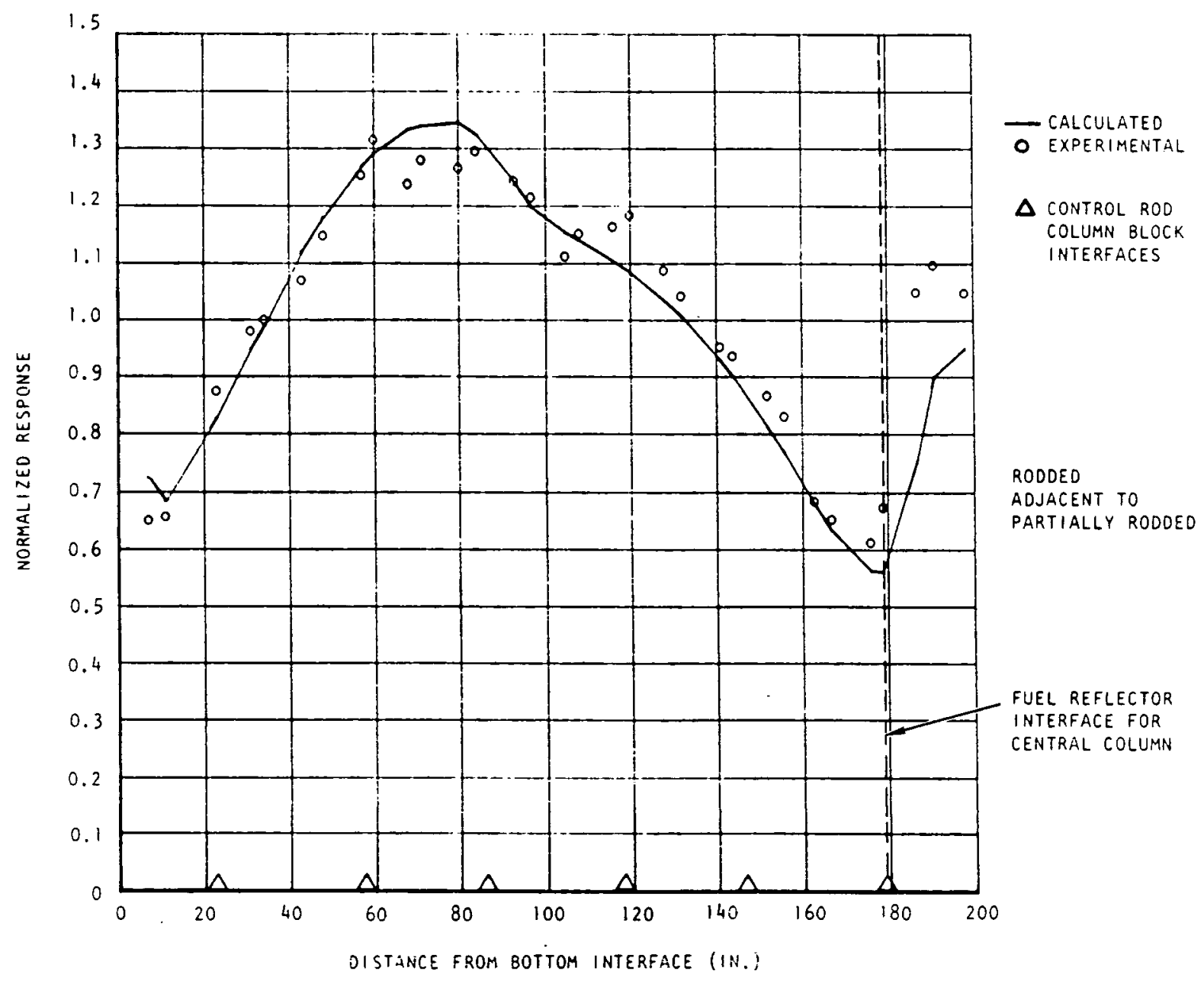

Fig. II-1. Axial flux distribution (5 ppm in reflector), configuration 1 region 1 


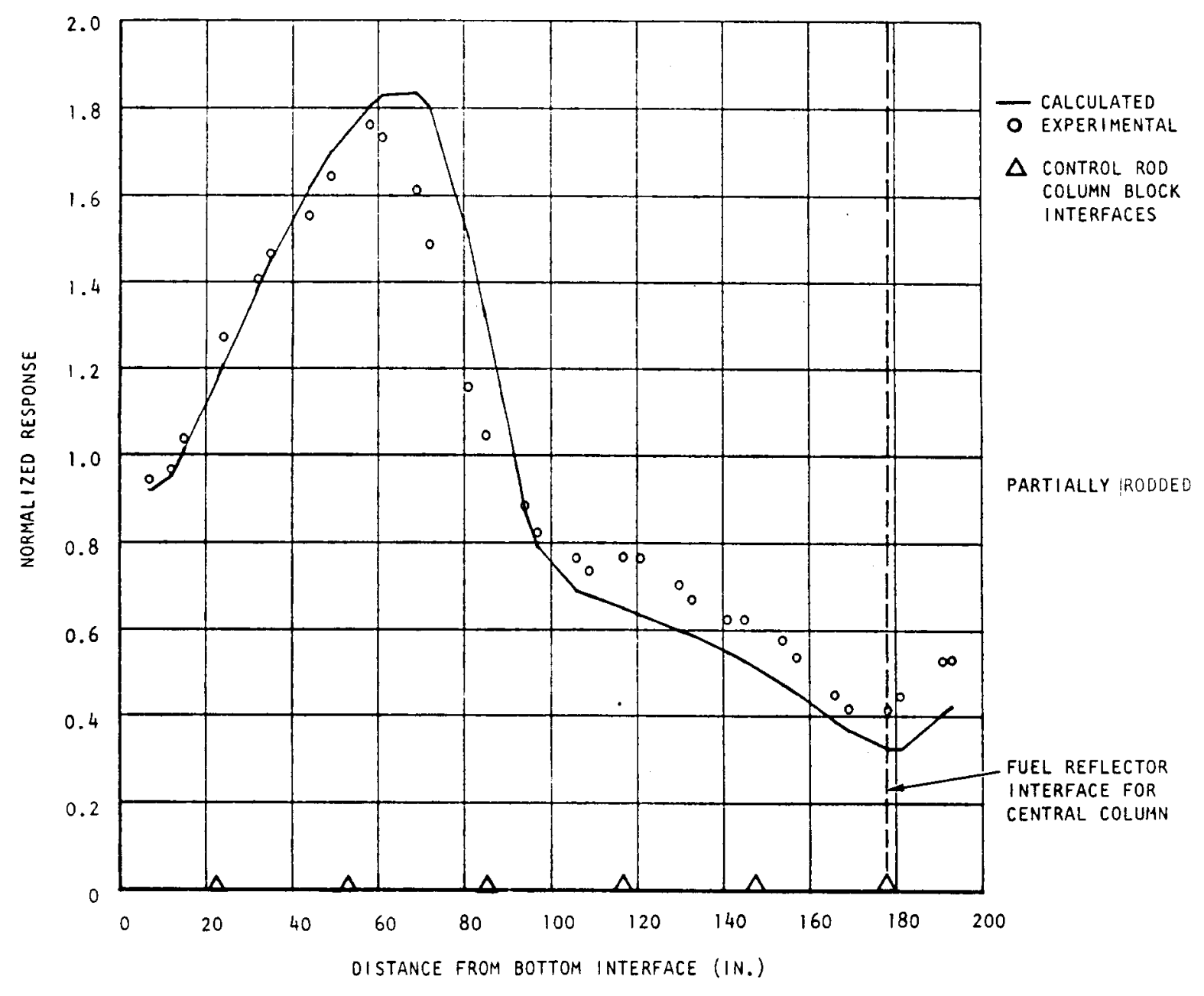

Fig. II-2. Axial flux distribution ( $5 \mathrm{ppm}$ in reflector), configuration 1 , region 3 


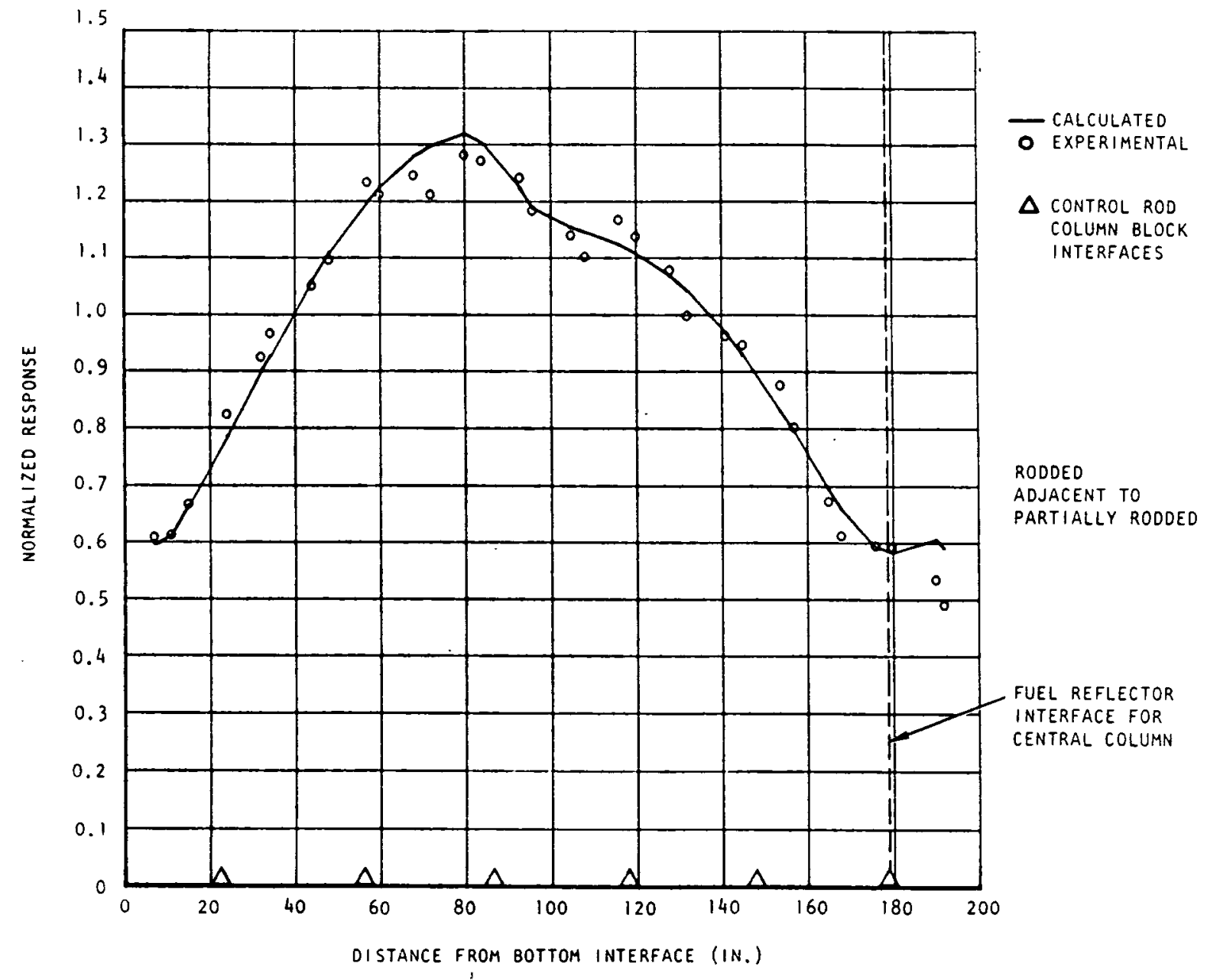

Fig. II-3. Axial flux distribution (5 ppm in reflector), configuration 1, region 6 , run $A$ 


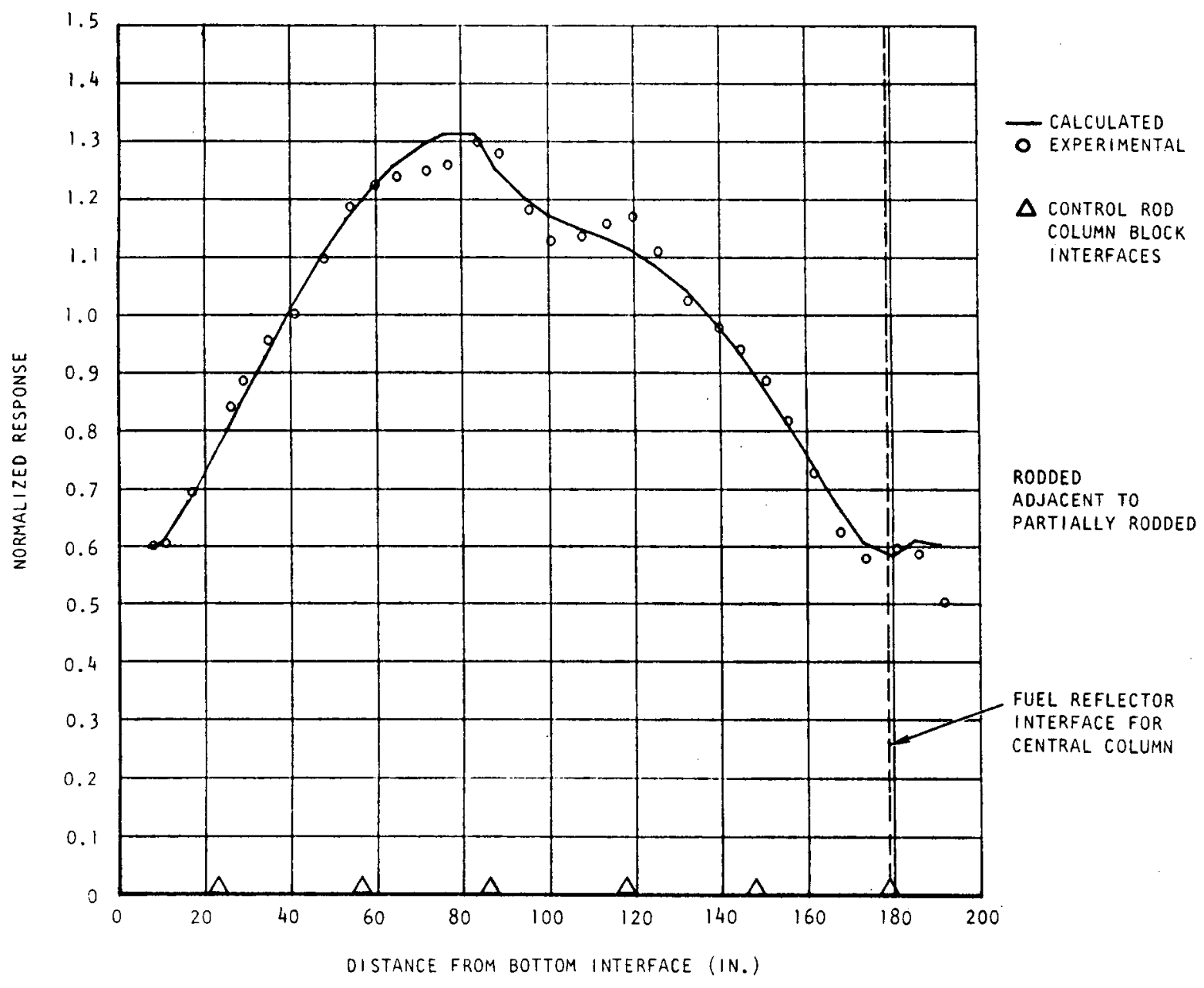

Fig. II-4. Axial flux distribution (5 ppm in reflector), configuration 1, region 6 , run $B$ 


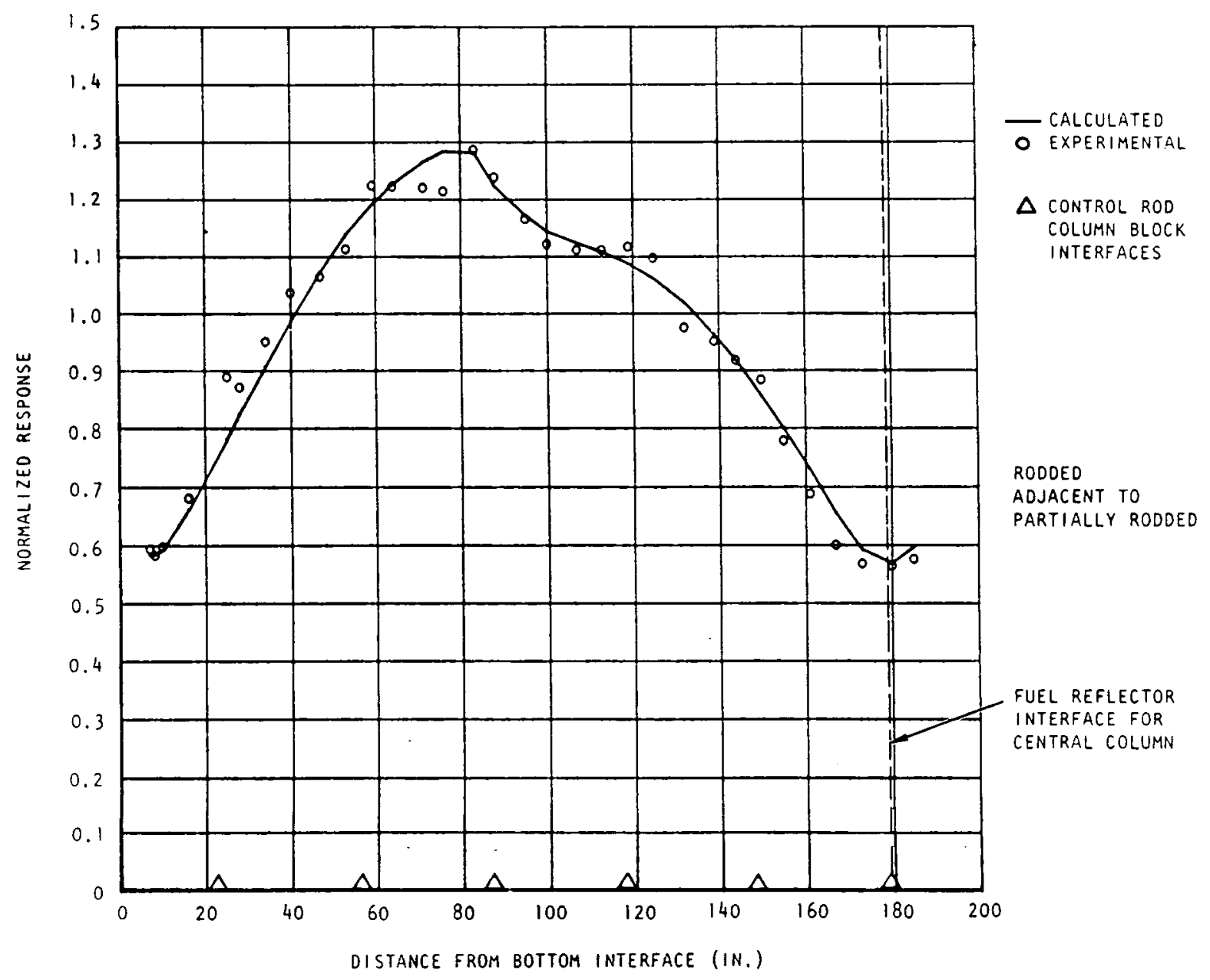

Fig. II-5. Axial flux distribution (5 ppm in reflector), configuration 1 , region 6 , run $C$ 


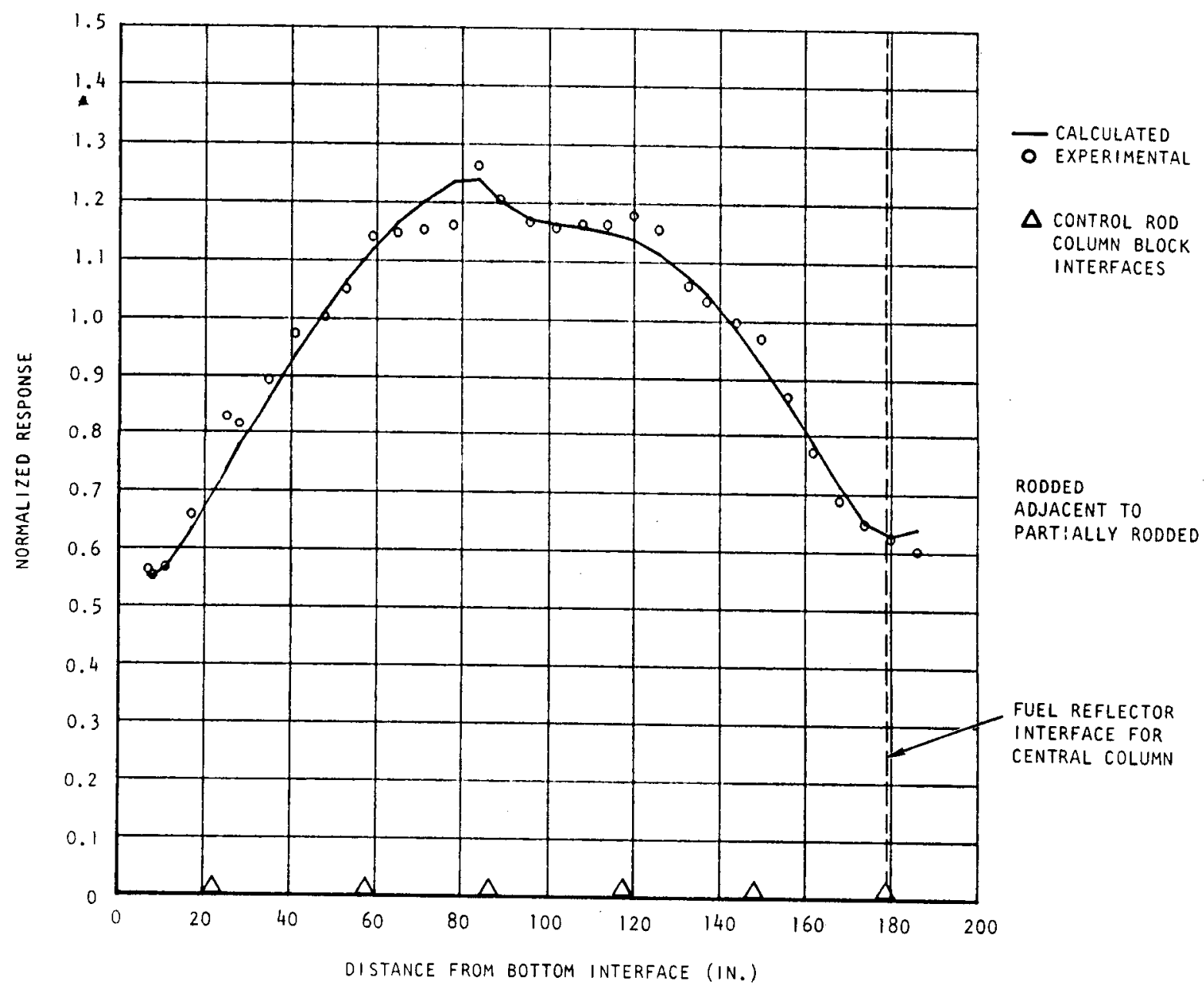

Fig. II-6. Axial flux distribution (5 ppm in reflector), configuration 1, region 10 


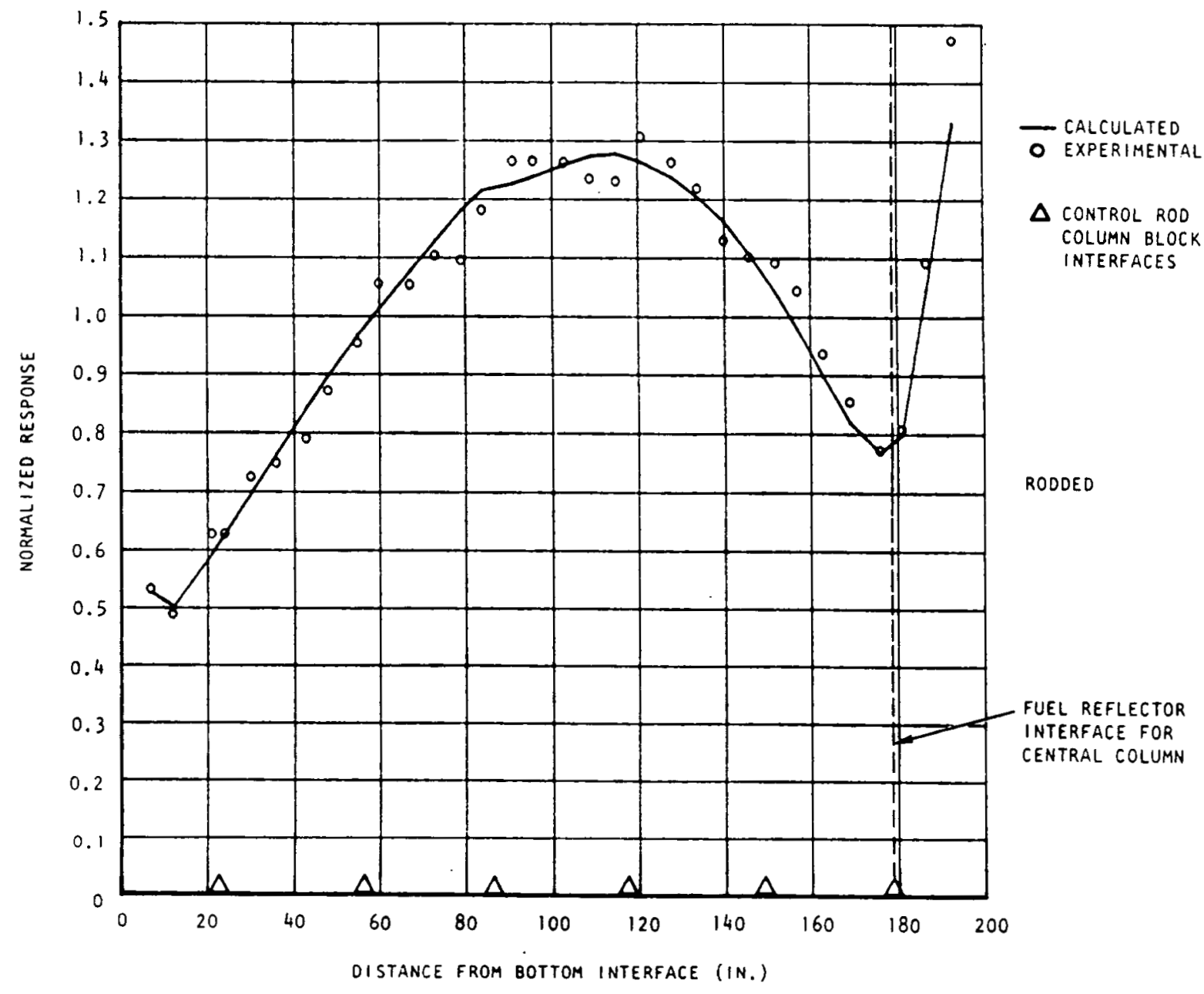

Fig. II-7. Axial flux distribution (5 ppm in reflector), configuration 1, region 23, run $A$ 


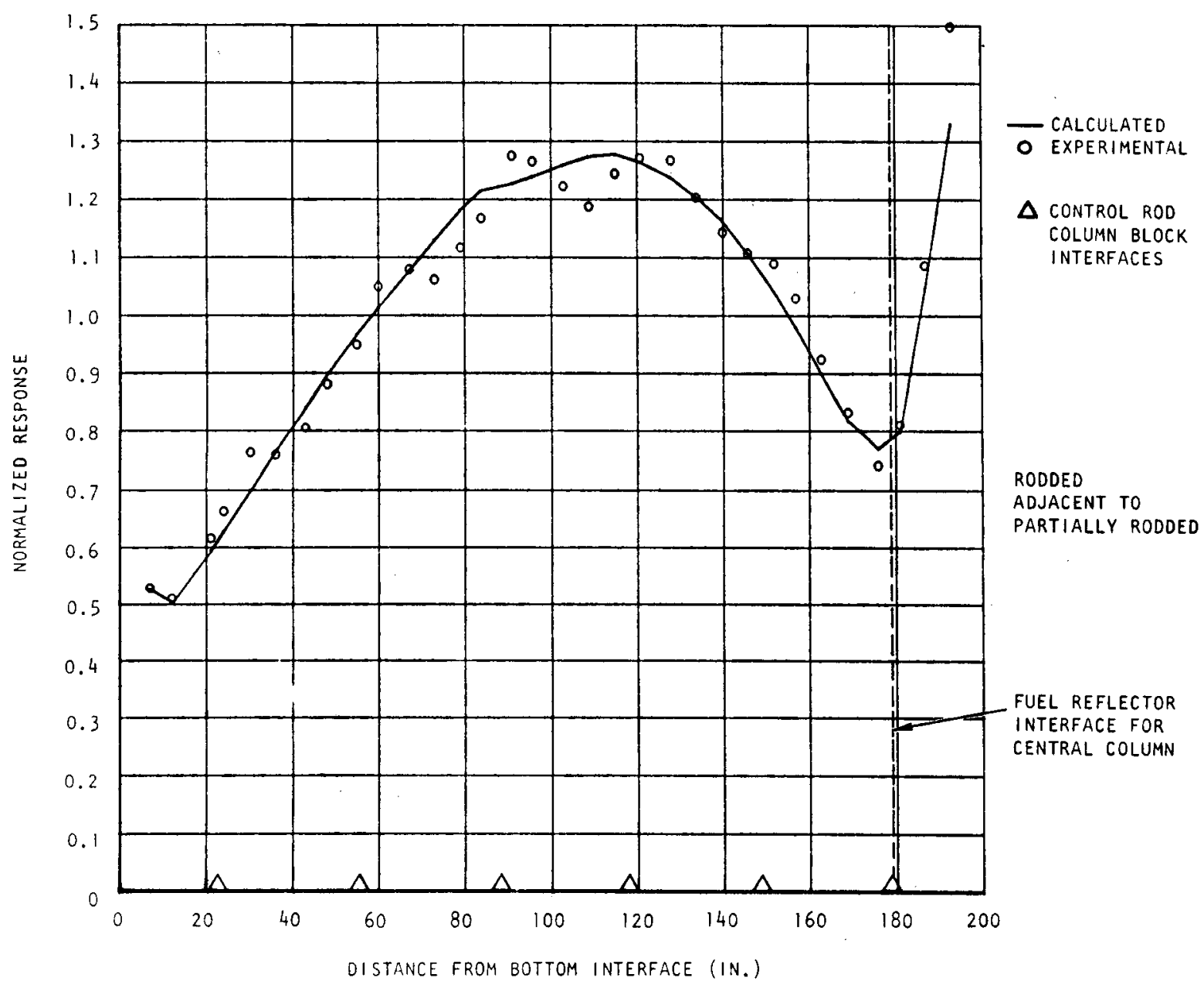

Fig. II-8. Axial flux distribution (5 ppm in reflector), configuration 1, region 23 , run $B$ 


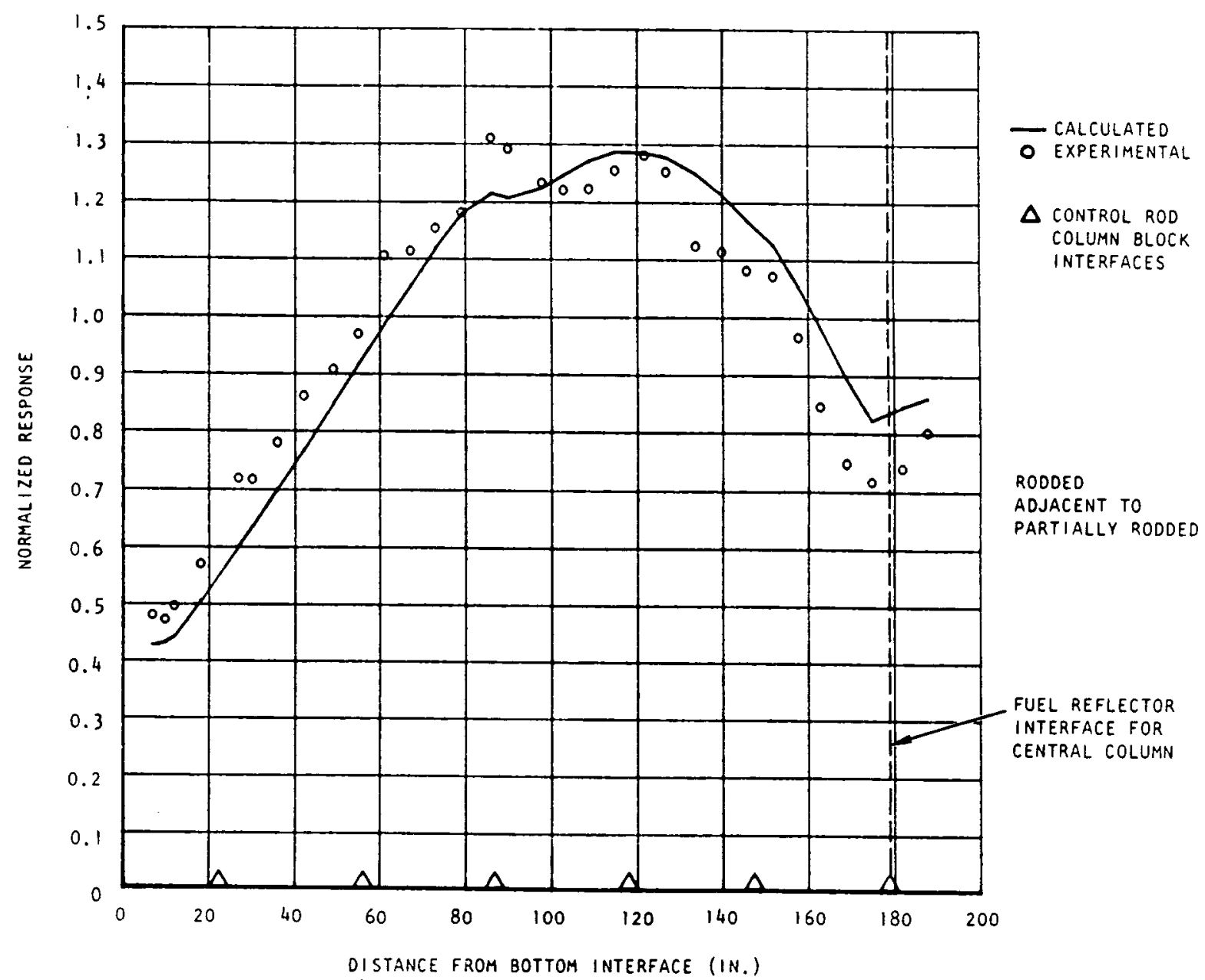

Fig. II-9. Axial flux distribution (5 ppm in reflector), configuration 1, region 27 


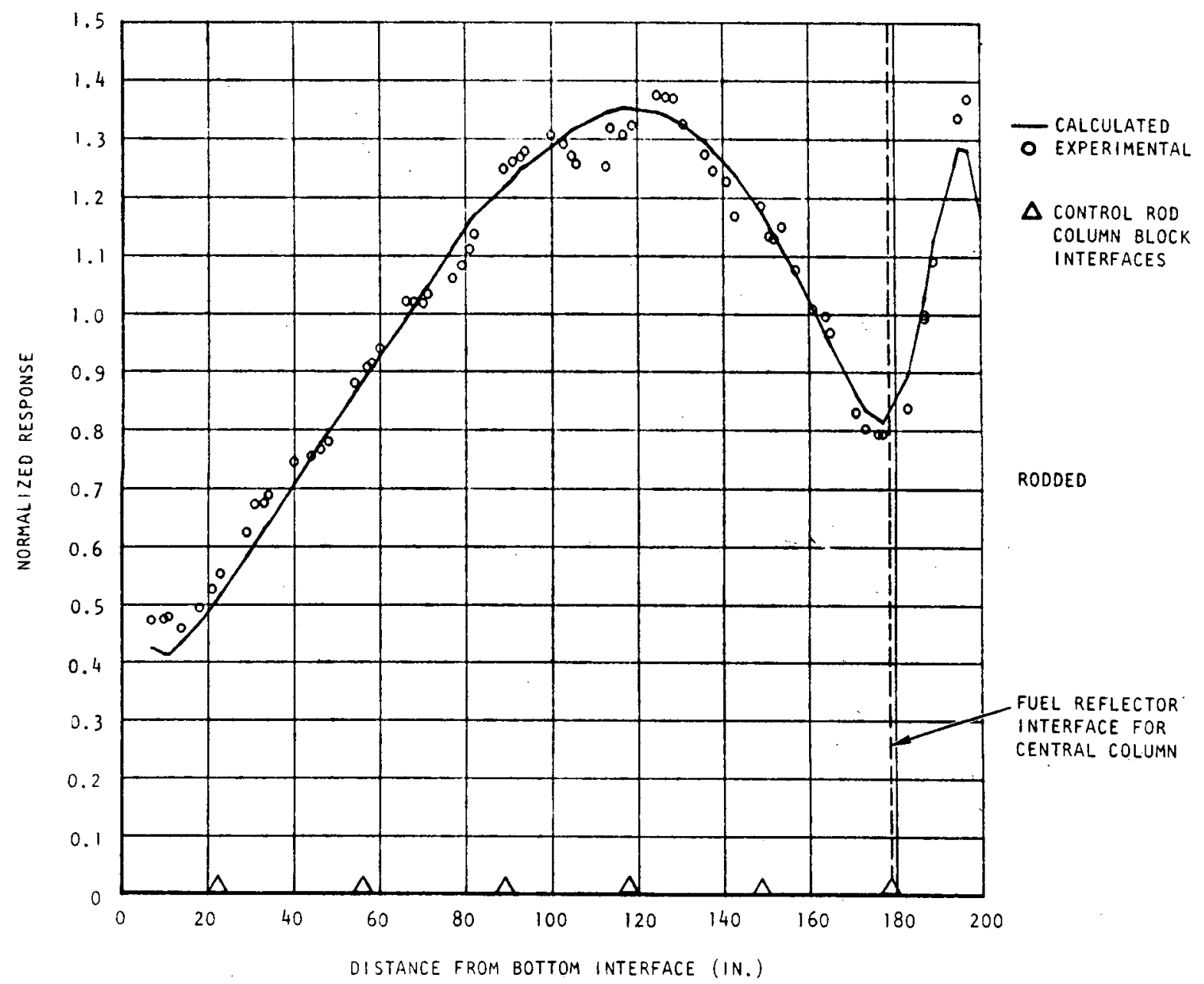

Fig. II-10. Axtal flux distribution (5 ppm in reflector), configuration 1, region 32 


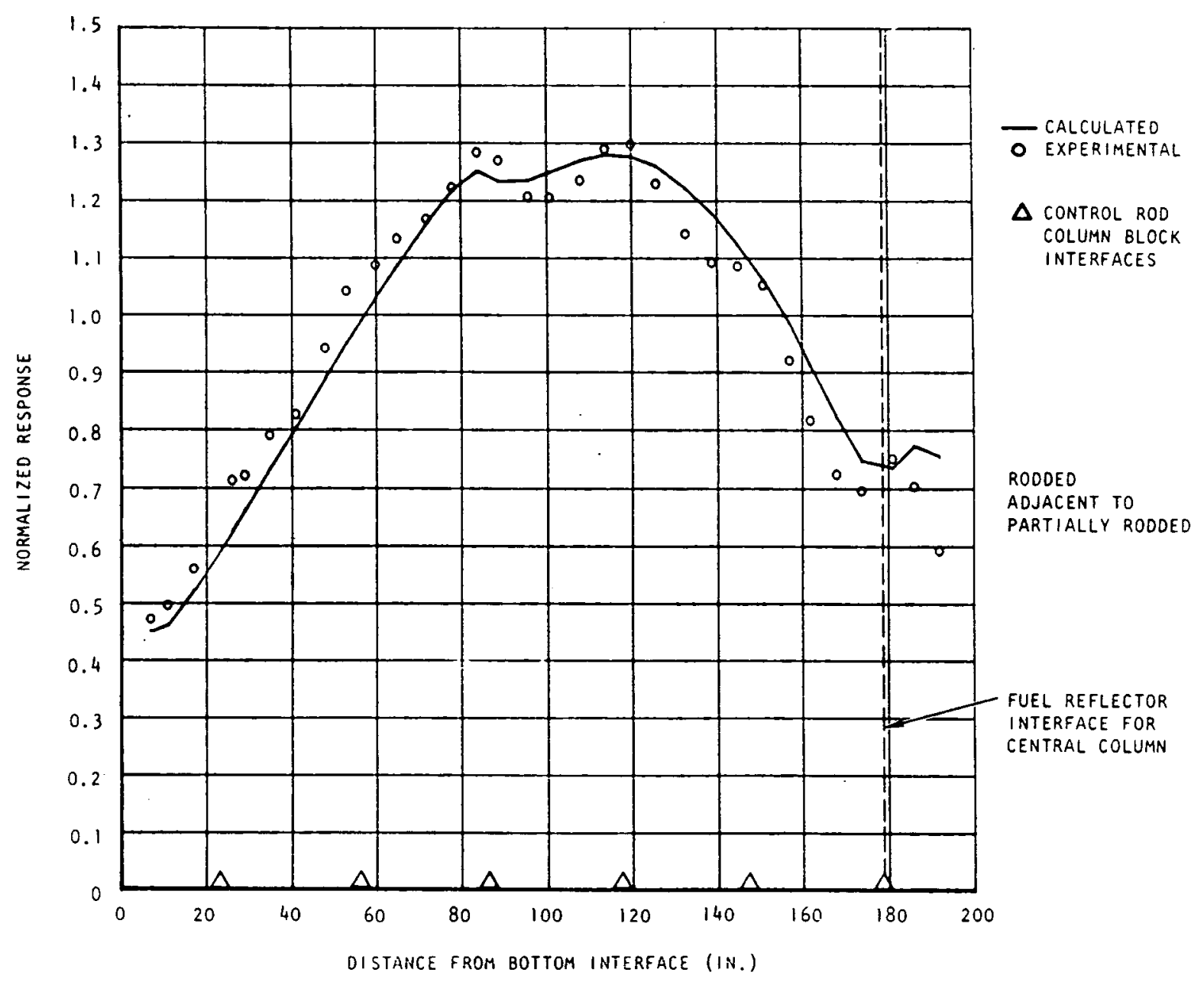

Fig. II-11. Axial flux distribution (5 ppm in reflector), configuration 1 region 37 


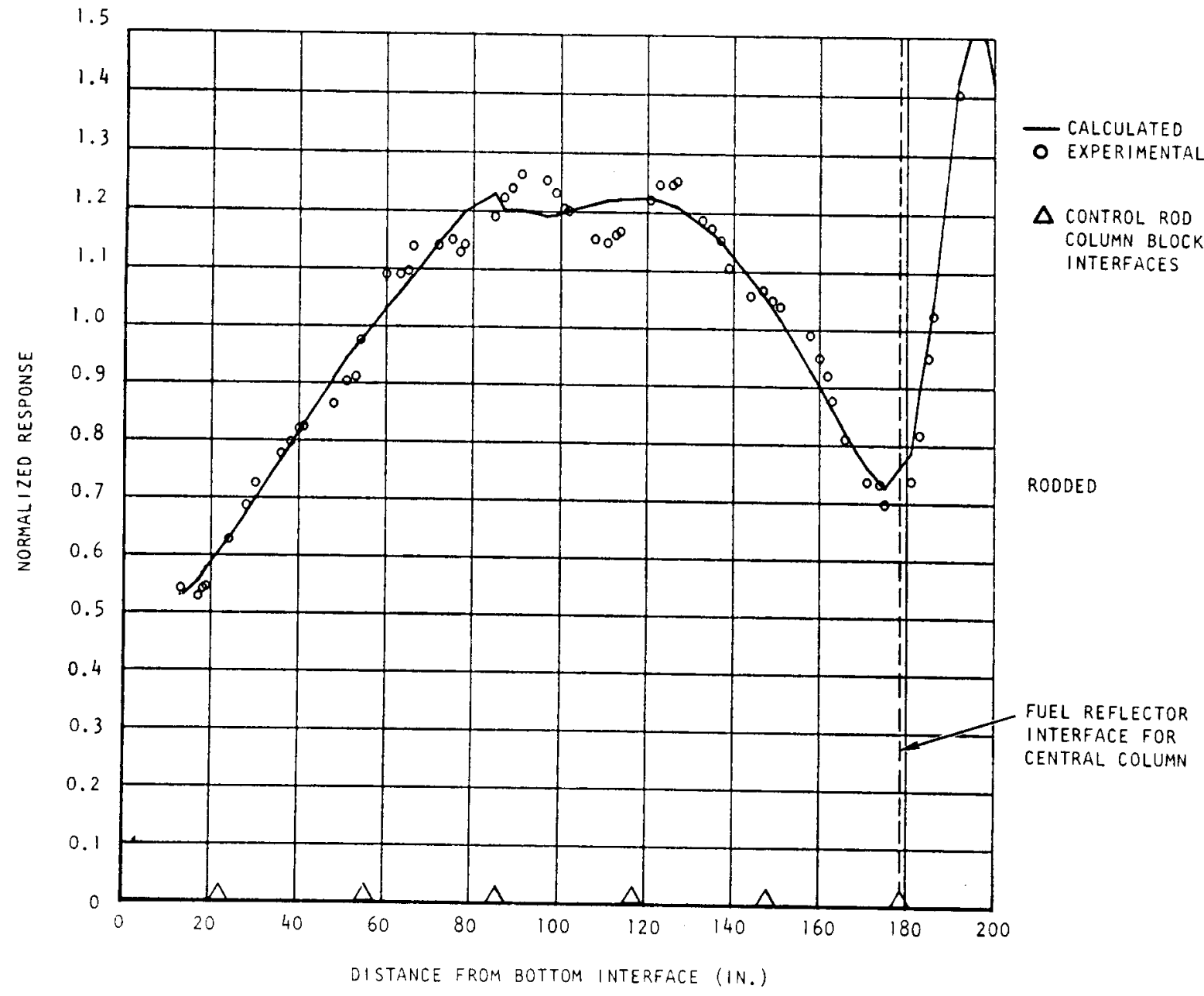

Fig. II-12. Axial flux distribution (5 ppm in reflector), configuration 1, region 16 with $6-i n$. shift 


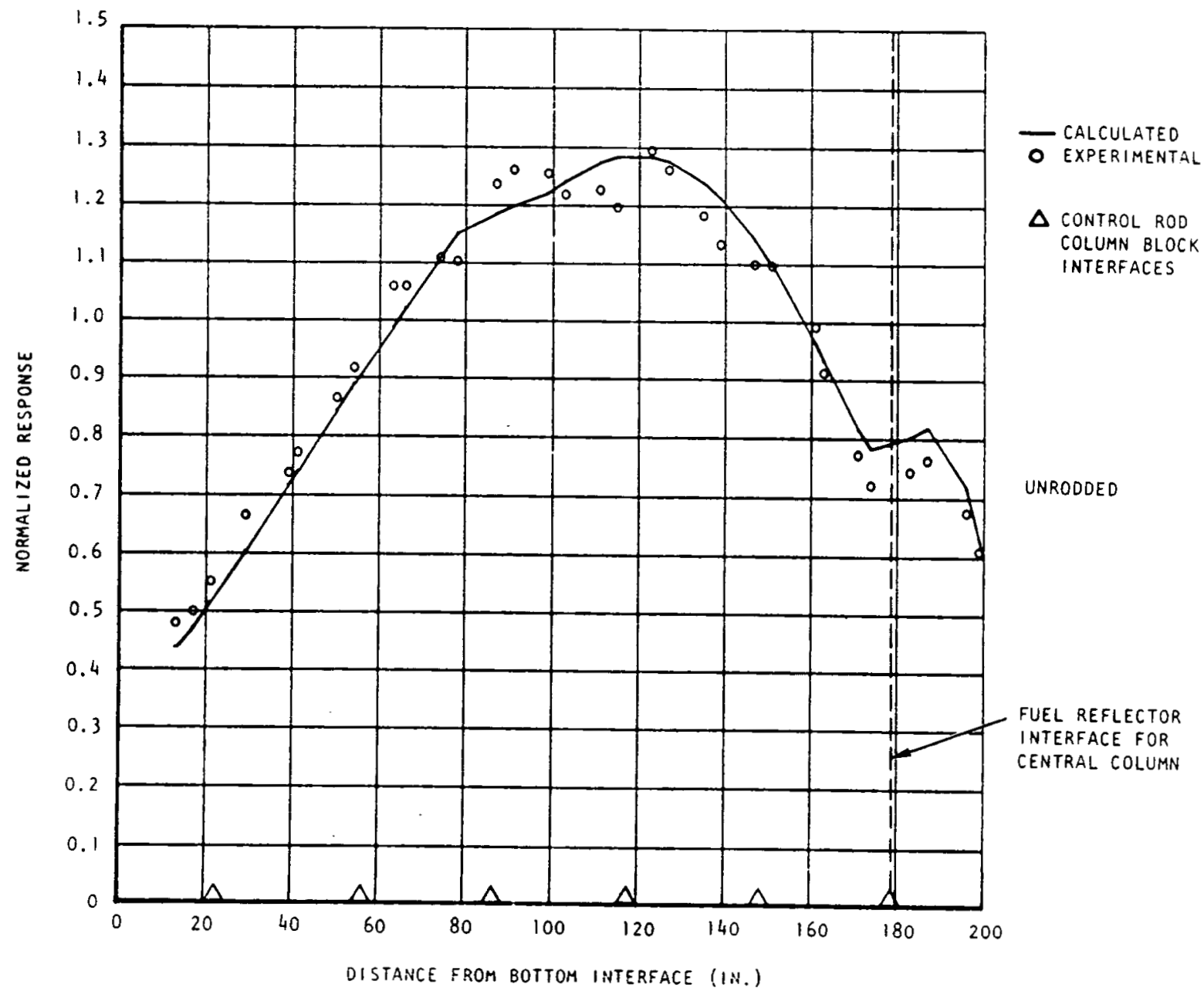

Fig. II-13. Axial flux distribution (5 ppm in reflector), configuration 1, region 31 with 6 -in. shift 
APPENDIX III

SUMMARY OF STORED DATA FOR SUT A-7 ANALYSIS 


\section{SECTIONS 5, 6, AND 7}

\begin{tabular}{|c|c|}
\hline Description & Stored \\
\hline \multicolumn{2}{|l|}{ Output } \\
\hline \multicolumn{2}{|l|}{ FSV/Output/ASASS, BOC, $300 \mathrm{~K}$} \\
\hline GATT非 1 rods $3,5,7$ through layer 7 (SUT A-7) & CIC $-74-4440$ \\
\hline GATT非 1 restart & CIC $-74-4440$ \\
\hline GATT非 2 rods $3,5,7$ through layer 6 (SUT A-7) & CIC $-74-4440$ \\
\hline \multicolumn{2}{|l|}{ FSV/Output/ASASS, 300K, BOC } \\
\hline 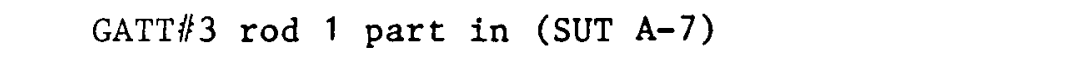 & CIC-74-4441 \\
\hline 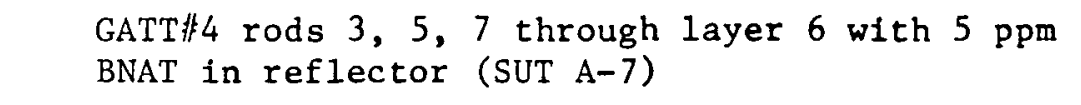 & CIC-74-4441 \\
\hline \multicolumn{2}{|l|}{ FSV/Output/ASASS, 300K, BOC } \\
\hline BUGATT for GATT非 $1,2,3$ (SUT A-7) & CIC-74-4442 \\
\hline BUGATT and AXPROF for GATT" 4 (SUT A-7) & CIC-74-4442 \\
\hline AXPROF for GATT非 1,2 , and 3 (SUT A-7) & CIC $-74-4442$ \\
\hline \multicolumn{2}{|l|}{ FSV/Output/SUT A-7 } \\
\hline $\begin{array}{l}\text { PROFIL final (without } 5 \mathrm{ppm} \text { BNAT) at } 140 \text { and } \\
220 \mathrm{~cm} \text { plus measured (no plot) }\end{array}$ & CIC-74-4450 \\
\hline $\begin{array}{l}\text { PROFIL final (with and without } 5 \text { ppm BNAT) } \\
\text { (with plot) }\end{array}$ & CIC-74-4450 \\
\hline GAMBLE 1 patch and full core PROFIL & CIC $-74-4450$ \\
\hline \multicolumn{2}{|l|}{ Cards } \\
\hline $\begin{array}{l}\text { SUT A-7 raw data on cards and GATT results for } \\
\text { PROFIL }\end{array}$ & $\begin{array}{l}\text { Physics office, } \\
\text { To-362 }\end{array}$ \\
\hline SUT A-7 GAMBLE models & $\begin{array}{l}\text { Physics office, } \\
\text { T0-362 }\end{array}$ \\
\hline PROFIL using GAMBLE data & $\begin{array}{l}\text { Physics office, } \\
\text { To-362 }\end{array}$ \\
\hline \multicolumn{2}{|l|}{ Notes } \\
\hline Raw data, plots, and notes for SUT A-7 & $\begin{array}{l}\text { Physics Office, } \\
\text { TO-362, SUT A-7 } \\
\text { Notebook }\end{array}$ \\
\hline
\end{tabular}




\begin{tabular}{|c|c|}
\hline Description & Stored \\
\hline Tapes & Tape No. \\
\hline FSV ASASS MICROS for BUGATT & 1020 \\
\hline FSV ASASS MACRO $1-23$ in 7 & 1664 \\
\hline FSV ASASS GATT 1 AXPROF & 1412 \\
\hline FSV ASASS BOC DEN & 1813 \\
\hline FSV ASASS GATT 1 POWER & 2562 \\
\hline FSV ASASS GATT 1 RESTART & 3667 \\
\hline FSV ASASS GATT 2 RESTART & 1361 \\
\hline FSV ASASS GATT 2 AXPROF & 2844 \\
\hline FSV ASASS GATT 4 POWER & 9318 \\
\hline FSV ASASS GATT 3 AXPROF & 9219 \\
\hline FSV ASASS GATT 3 RESTART & 9275 \\
\hline FSV ASASS GATT 3 POWER & 9256 \\
\hline FSV ASASS MACROS for GATT 3 & 9342 \\
\hline FSV ASASS BUGATT for GATT 4 & 7640 \\
\hline FSV ASASS GATT 4 (5 ppm) POWER & 6636 \\
\hline FSV ASASS GATT $4(5 \mathrm{ppm})$ FLUX & 6532 \\
\hline FSV ASASS GATT 4 (5 ppm) AXPROF & 7997 \\
\hline
\end{tabular}

